\title{
Evaluation of New Options for Reducing Mercury Release at the Y-12 National Security Complex
}

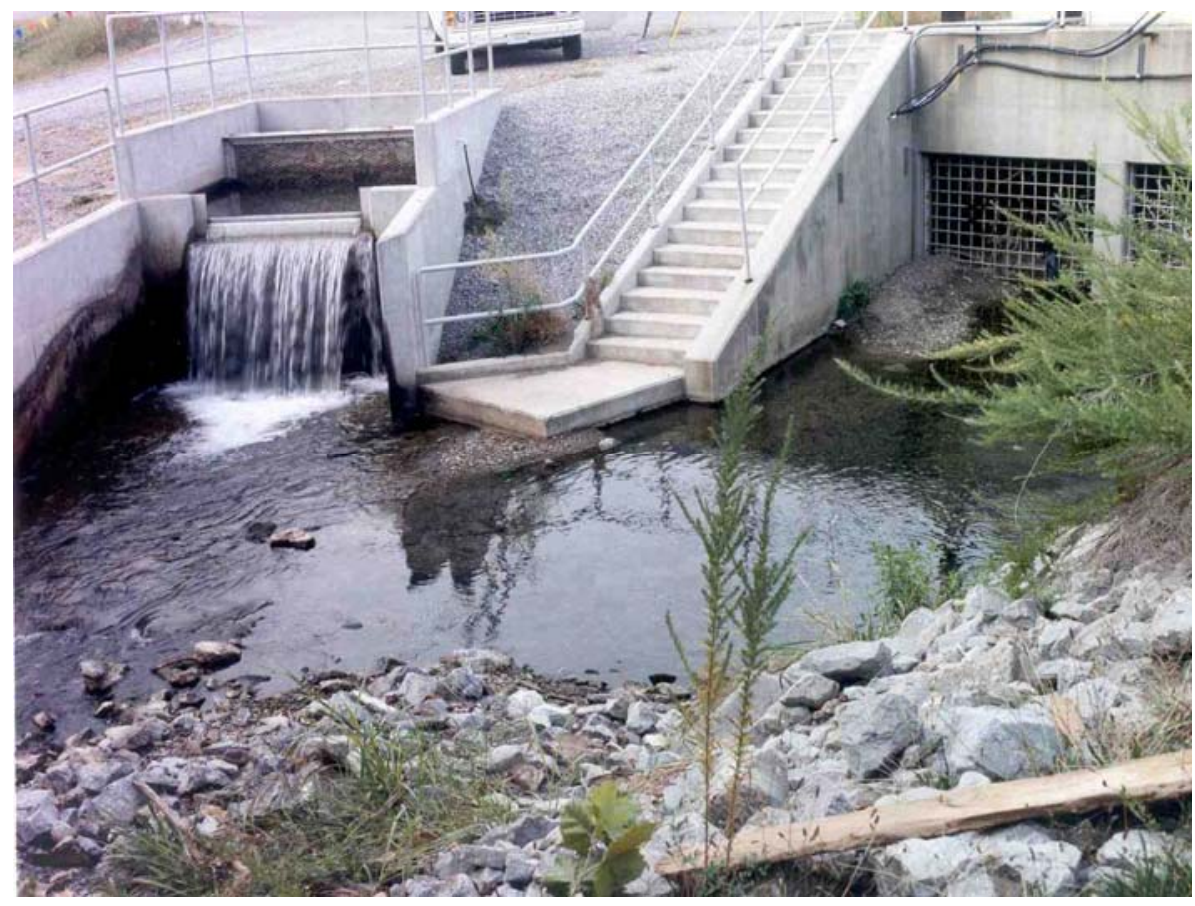

George Southworth Mary Anna Bogle Scott Brooks Liyuan Liang Mark Peterson Brian Spalding David Watson Fan Zhang T. J. Abraham 


\title{
DOCUMENT AVAILABILITY
}

Reports produced after January 1, 1996, are generally available free via the U.S. Department of Energy (DOE) Information Bridge.

Web site http://www.osti.gov/bridge

Reports produced before January 1, 1996, may be purchased by members of the public from the following source.

\author{
National Technical Information Service \\ 5285 Port Royal Road \\ Springfield, VA 22161 \\ Telephone 703-605-6000 (1-800-553-6847) \\ TDD 703-487-4639 \\ Fax 703-605-6900 \\ E-mail info@ntis.fedworld.gov \\ Web site http://www.ntis.gov/support/ordernowabout.htm
}

Reports are available to DOE employees, DOE contractors, Energy Technology Data Exchange (ETDE) representatives, and International Nuclear Information System (INIS) representatives from the following source.

Office of Scientific and Technical Information

P.O. Box 62

Oak Ridge, TN 37831

Telephone 865-576-8401

Fax 865-576-5728

E-mail reports@adonis.osti.gov

Web site http://www.osti.gov/contact.html

This report was prepared as an account of work sponsored by an agency of the United States Government. Neither the United States Government nor any agency thereof, nor any of their employees, makes any warranty, express or implied, or assumes any legal liability or responsibility for the accuracy, completeness, or usefulness of any information, apparatus, product, or process disclosed, or represents that its use would not infringe privately owned rights. Reference herein to any specific commercial product, process, or service by trade name, trademark, manufacturer, or otherwise, does not necessarily constitute or imply its endorsement, recommendation, or favoring by the United States Government or any agency thereof. The views and opinions of authors expressed herein do not necessarily state or reflect those of the United States Government or any agency thereof. 
ORNL/TM-2010/33

\title{
EVALUATION OF NEW OPTIONS FOR REDUCING MERCURY RELEASE AT THE Y-12 NATIONAL SECURITY COMPLEX
}

\author{
George R. Southworth ${ }^{1}$ \\ Mary Anna Bogle ${ }^{2}$ \\ Scott Brooks ${ }^{1}$ \\ Liyuan Liang ${ }^{1}$ \\ Mark Peterson ${ }^{1}$ \\ Brian Spalding ${ }^{1}$ \\ David Watson ${ }^{1}$ \\ Fan Zhang ${ }^{1}$ \\ T. J. Abraham ${ }^{3}$ \\ ${ }^{1}$ Environmental Sciences Division \\ Oak Ridge National Laboratory \\ ${ }^{2}$ Oak Ridge Associated Universities \\ ${ }^{3} \mathrm{MSE}$, Inc.
}

April 2010

\author{
Prepared for \\ EM-22 Groundwater and Soil Remediation Program \\ U.S. Department of Energy \\ Washington, DC
}

Prepared by

OAK RIDGE NATIONAL LABORATORY

Oak Ridge, Tennessee 37831

managed by

UT-BATTELLE, LLC

for the

U.S. DEPARTMENT OF ENERGY

under contract DE-AC05-00OR22725 



\section{CONTENTS}

$\begin{array}{rll}\text { Page } & \end{array}$

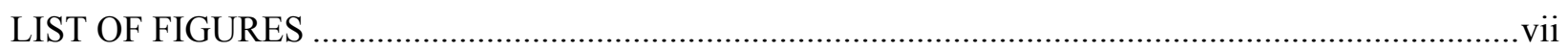

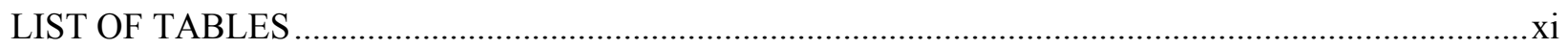

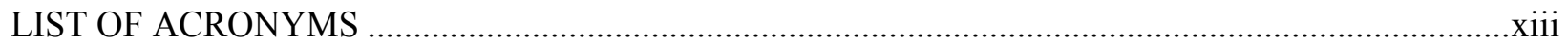

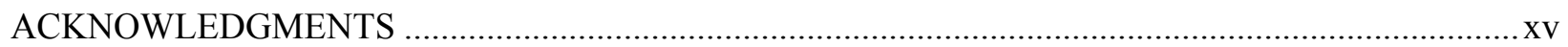

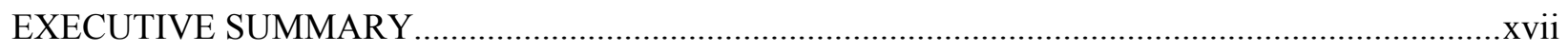

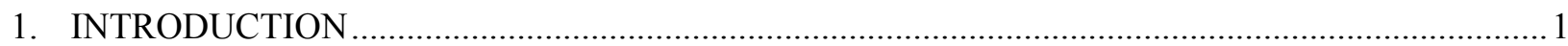

2. EFFECTS OF FLOW MANAGEMENT DIVERSION ON WATERBORNE MERCURY FLUX IN UPPER EAST FORK POPLAR CREEK …....................................................................... 5

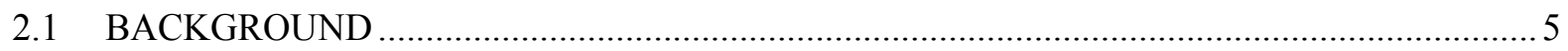

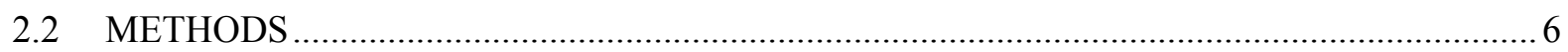

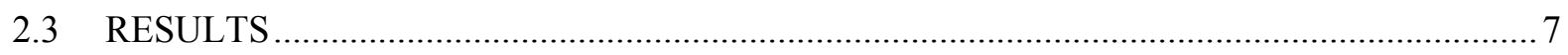

2.3.1 Results of Modeling Flow Management Alternatives................................................ 11

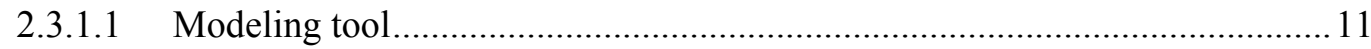

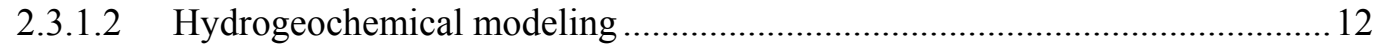

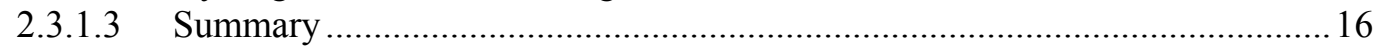

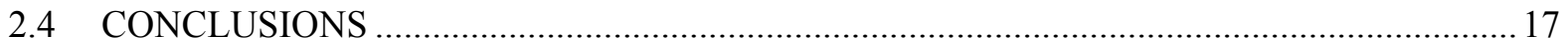

3. CHEMICAL REDUCTION TO REMOVE MERCURY FROM STORM DRAIN DISCHARGES

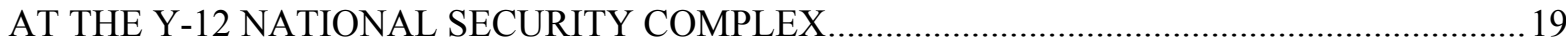

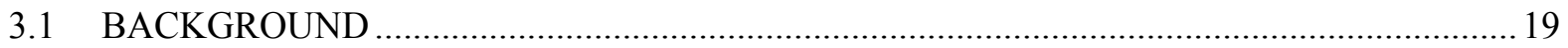

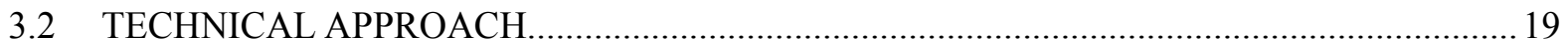

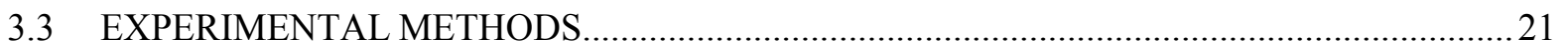

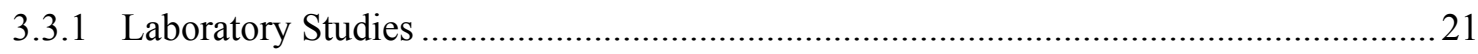

3.3.1.1 Alternate reducing agents for total residual chlorine .................................21

3.3.1.2 Effects of reducing agents on dissolved oxygen and $\mathrm{pH}$ of stream water ......22

3.3.1.3 Reduction of $\mathrm{Hg}(\mathrm{II})$ by sodium borohydride $\left(\mathrm{NaBH}_{4}\right)$..............................22

3.3.1.4 Mercury(II) reduction testing of drainage waters at locations upstream of

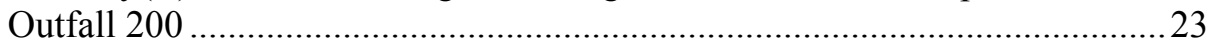

3.3.1.5 Toxicity testing for sodium borohydride and ascorbic acid............................23 


\section{CONTENTS (cont'd)}

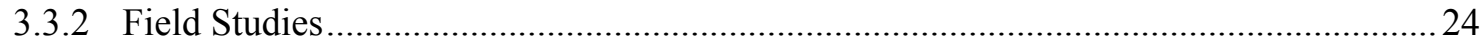

3.3.3 Potential $\mathrm{Hg}(0)$ Evasion from Stream Following $\mathrm{SnCl}_{2}$ Addition ................................25

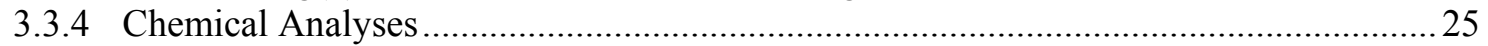

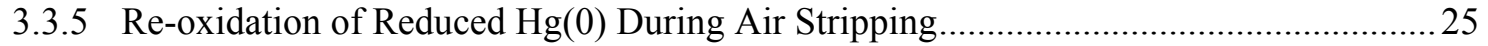

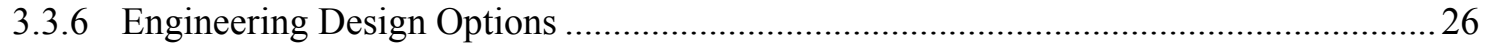

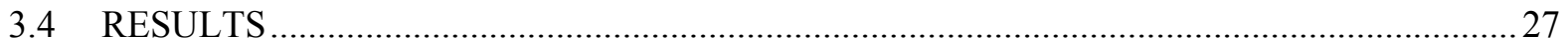

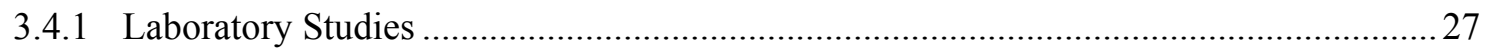

3.4.1.1 Alternate reducing agents for total residual chlorine ..................................27

3.4.1.2 Effects of reducing agents on dissolved oxygen and $\mathrm{pH}$ of stream water ......28

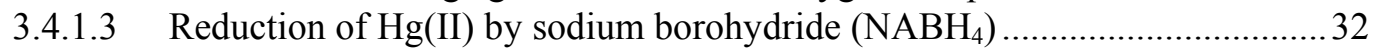

3.4.1.4 Mercury(II) reduction testing of drainage waters at locations upstream of

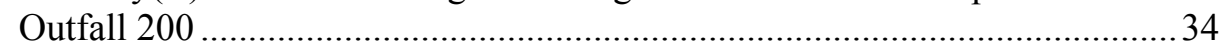

3.4.1.5 Toxicity testing for sodium borohydride and ascorbic acid............................. 35

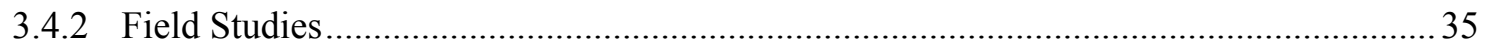

3.4.2.1 Conversion of total mercury to dissolved gaseous $\mathrm{Hg}$...................................35

3.4.2.2 Downstream profile of dissolved gaseous $\mathrm{Hg}$ and potential loss of $\mathrm{Hg}$ by

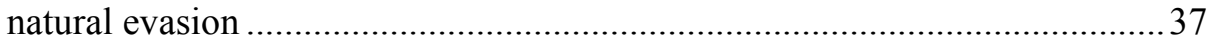

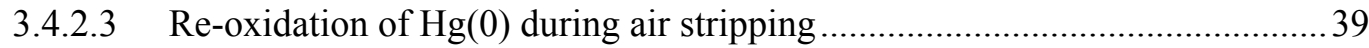

3.4.3 Engineering Evaluation of Air Stripping at Outfall 200 and within the Storm Drain

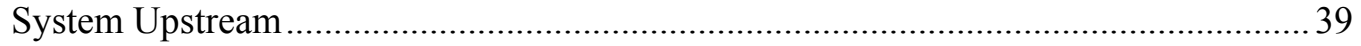

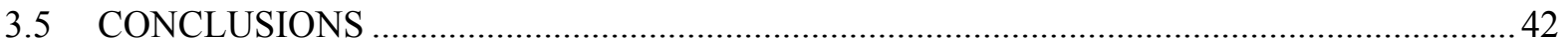

4. CONCEPTUAL MODELING EFFORTS AND OTHER PROJECT ACTIVITIES ..........................45

4.1 CONCEPTUAL MODELING AND DEVELOPMENT OF A SYSTEMS-BASED

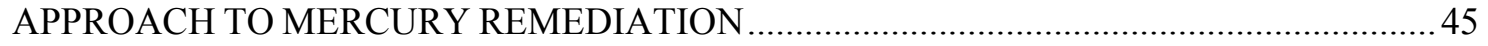

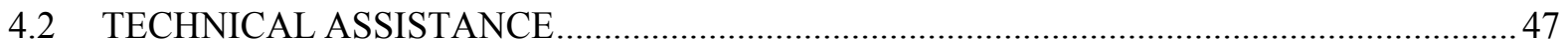

4.3 STUDIES LEVERAGING WITH THE MERCURY SCIENCE FOCUS AREA ..................... 47

4.4 WEST END MERCURY AREA (WEMA) SOURCE INVESTIGATION .............................. 49

4.5 RELEVANCE OF EM 32 STUDIES TO MERCURY REMEDIATION AT Y-12 NSC ...........51

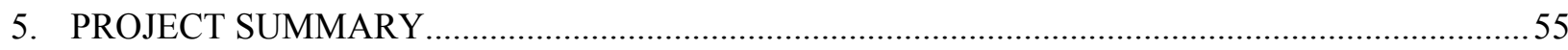

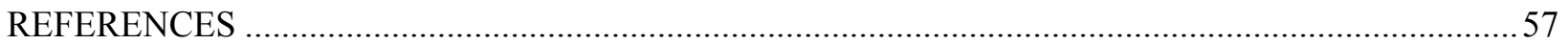




\section{CONTENTS (cont'd)}

Page

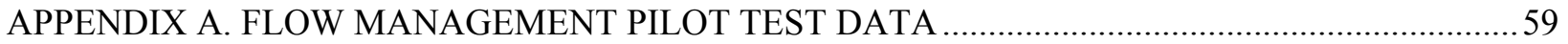

APPENDIX B. DESIGN ALTERNATIVES FOR AIR STRIPPING NEAR OUTFALL 200 _................61

APPENDIX C. DISSOLVED OXYGEN AND pH RESPONSES TO STANNOUS CHLORIDE, ASCORBIC ACID, AND SODIUM BOROHYDRIDE …………...................................69

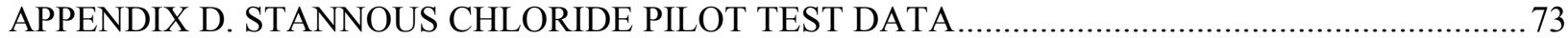





\section{LIST OF FIGURES}

Fig. 1. Key surface water sampling locations for flow management diversion and chemical reduction (using reduced tin) tests conducted in year 2008 at Y-12 National Security Complex.

Fig. 2. Mean concentration of total $\mathrm{Hg} \pm \mathrm{SE}$ at sites in upper East Fork Poplar Creek in January 2009 monitoring (flow management on) and April 2009 (flow management off).

Fig. 3. Mean downstream flux of total $\mathrm{Hg} \pm \mathrm{SE}$ at sites in upper East Fork Poplar Creek in January 2009 monitoring (flow management on) and April 2009 (flow management off)...8

Fig. 4. Mean concentrations ( \pm SE) of total suspended solids in EFPC in January 2009 monitoring (flow management on) and April 2009 (flow management off).

Fig. 5. Gradients in concentrations of dissolved gaseous $\mathrm{Hg}(\mathrm{Hg}(0)$, dissolved total $\mathrm{Hg}$ (degassed, $<0.45 \mu \mathrm{m}$ filtered, and total $\mathrm{Hg}$ (contains particulates) with depth in a transect of EFPC with the streambed $\mathrm{Hg}$ source reach).

Fig. 6. Rate of dissolution of $\mathrm{Hg}$ from the surface of metallic $\mathrm{Hg}$ into deionized water................11

Fig. 7. Sediments and chemicals simulated in surface water systems. .................................... 12

Fig. 8. Elevation profile of the UEFPC channel: the distances (x) are measured upstream and downstream from the center of Second Street Culvert Bridge at Lake Reality

Fig. 9. Baseflow water depth simulation of the UEFPC channel. 14

Fig. 10. Simulation of flow velocity under different scenarios for the UEFPC channel.................. 15

Fig. 11. Simulated suspended sediment concentration for the UEFPC channel..............................15

Fig. 12. Simulated dissolved and total Hg concentrations for the UEFPC channel. ....................... 16

Fig. 13. Simulated total load of suspended sediment and $\mathrm{Hg}$ for the UEFPC channel.................... 17

Fig. 14. Schematic plan view of the upper East Fork Poplar Creek (UEFPC) showing the storm drain system (in gray) at its juncture with the open creek (in blue).. .26

Fig. 15. Dissolved oxygen in Northwest Tributary stream water following additions of increasing concentrations of stannous chloride (see Appendix $\mathrm{C}$ for responses at greater amendment concentrations)

Fig. 16. Northwest Tributary stream water $\mathrm{pH}$ following additions of increasing concentrations of stannous chloride (see Appendix $\mathrm{C}$ for responses at greater amendment concentrations). 


\section{LIST OF FIGURES (cont'd)}

Fig. 17. Dissolved oxygen in Northwest Tributary stream water with increasing concentrations of ascorbic acid (see Appendix $\mathrm{C}$ for responses at greater amendment concentrations)......30

Fig. 18. Northwest Tributary stream water $\mathrm{pH}$ following additions of increasing concentrations of ascorbic acid (see Appendix $\mathrm{C}$ for responses at greater amendment concentrations).......30

Fig. 19. Effect of sodium borohydride additions to Northwest Tributary stream water on dissolved oxygen (see Appendix $\mathrm{C}$ for responses at greater amendment concentrations)...31

Fig. 20. The effect of sodium borohydride amendments on the $\mathrm{pH}$ of Northwest Tributary stream water (see Appendix C for responses at greater amendment concentrations).

Fig. 21. Reduction of 25 pmoles of $\mathrm{Hg}$ (II) spiked into distilled water, creek (NWT) water, and tap water (containing 318 nmoles $\mathrm{Cl}_{2}$ ) by sodium borohydride.

Fig. 22. Incremental additions of $\mathrm{NaBH}_{4}$ or $\mathrm{SnCl}_{2}$ standard solutions, stabilized with ascorbic acid (AA), to de-ionized (DI) water and three drainage waters flowing into UEFPC.

Fig. 23. Concentrations of total $\mathrm{Hg}$, dissolved gaseous $\mathrm{Hg}$ and post-purge $\mathrm{Hg}$ in Outfall 200 water versus time during the September 2009 in-stream Hg reduction experiment in East Fork Poplar Creek

Fig. 24. Concentrations of tin in East Fork Poplar Creek at Outfall 200 and monitoring Station

$\mathrm{C} 11$ during the in-stream $\mathrm{Hg}$ reduction experiment.

Fig. 25. Concentrations of total $\mathrm{Hg}$ and dissolved gaseous along a downstream profile of sites in upper EFPC during the period when $\mathrm{Hg}$ at Outfall 200 was reduced by $\mathrm{SnCl}_{2}$ 38

Fig. 26. Concentrations of total $\mathrm{Hg}$ along a downstream profile of sites in upper EFPC before and after reduction of $\mathrm{Hg}(\mathrm{II})$ at Outfall 200 to $\mathrm{Hg}(0)$.

Fig. 27. Concentrations of total $\mathrm{Hg}$ and dissolved gaseous $\mathrm{Hg}$ in a $3.2 \mathrm{~L}$ sample of Outfall 200 water purged with air at $100 \mathrm{ml} /$ minute.

Fig. 28. Overlay of all potential transport pathways considered in evaluation................................46

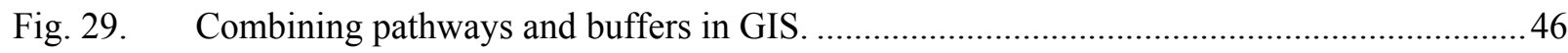

Fig. 30. Result of assigning risk values and joining preferred transport layers.............................46

Fig. 31. Overlay of $\mathrm{Y}-12 \mathrm{Hg}$ soil sampling data converted to Thiessen polygons and $\mathrm{Hg}$ use buildings with high risk transport pathways.

Fig 32. Map of the storm drain network with the West End Mercury Area show highest priority (red) and lower priority (blue) sections of the system that contribute most waterborne mercury to the Outfall 200 discharge. 


\section{LIST OF FIGURES (cont'd)}

Fig. 33. Hypothetical relationship between total wateraborne HG in upper EFPC and $\mathrm{Hg}$ (methylmercury) in fish. 52

Fig. 34 Hypothetical response of $\mathrm{Hg}$ in fish to decreased total $\mathrm{Hg}$ in water in EFPC....................52

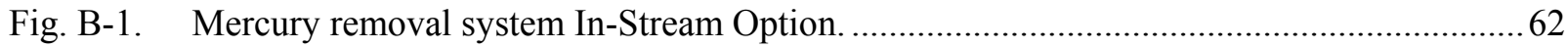

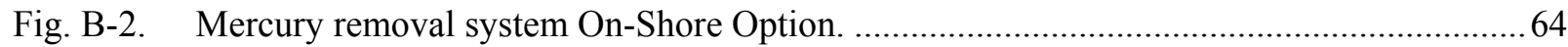

Fig. B-3. Mercury removal system North/South Pipe Option. .........................................................66

Fig. C-1. Dissolved oxygen in Northwest Tributary stream water following additions of increasing concentrations of stannous chloride.

Fig. C-2. Northwest Tributary stream water $\mathrm{pH}$ following of increasing concentrations of stannous chloride.

Fig. C-3. Dissolved oxygen in Northwest Tributary stream water following additions of increasing concentrations of ascorbic acid.

Fig. C-4. Northwest Tributary stream water $\mathrm{pH}$ following additions of increasing concentrations of ascorbic acid.

Fig. C-5. Dissolved oxygen in Northwest Tributary stream water following additions of increasing concentrations of sodium borohydride

Fig. C-6. Northwest Tributary stream water $\mathrm{pH}$ following additions of increasing concentrations of sodium borohydride. 



\section{LIST OF TABLES}

Page

Table 1. Flux of $\mathrm{Hg}$ in EFPC under varied addition of water from the flow management system .......9

Table 2. Cross section characters of the four main segments of UEFPC ....................................... 12

Table 3. Average baseflow at NPDES outfalls along UEFPC ….............................................. 13

Table 4. Chemical characteristics of drainage water samples from accessible locations upstream of Outfall 200 in UEFPC sampled on July 14, 2009 ......................................................24

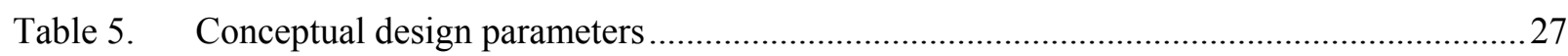

Table 6. Iodometric titration of water containing a standard addition of total residual chlorine (TRC) with standard solutions of various potential reducing agents ................................28

Table 7. Summary of sodium borohydride and ascorbic acid 48-hour acute toxicity tests conducted June 16-19, 2009 (testing by ORNL Environmental Toxicology Laboratory

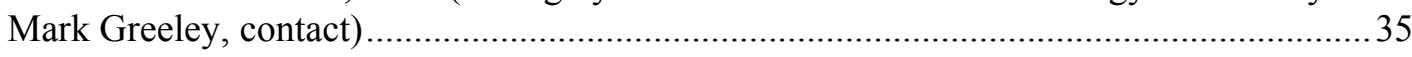

Table 8. Results from the September 2009 in-steam Hg reduction experiment in East Fork Poplar

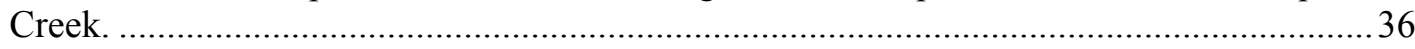

Table 9. Summary comparison of the three mercury removal options...........................................40

Table 10. Summary of ORNL technical assistance activities in calendar year 2010 .......................48

Table A-1. Total mercury concentration (HgT), flow rate, mercury loading and total suspended (TSS) at monitoring locations before the flow diversion period.

Table A-2. Total mercury concentration (HgT), flow rate, mercury loading and total suspended solids (TSS) at UEFPC monitoring locations during the flow diversion

Table D-1. Results of tin (Sn) analysis by ICP-MS for samples collected during the September 2009 $\mathrm{SnCl}_{2}$ addition test.

Table D-2. Dissolved gaseous mercury (DGM), total mercury (HgT) and non-purgable Hg measured during the September $2009 \mathrm{SnCl} 2$ addition test.

Table D-3. Downstream profile of total mercury (HgT) and dissolved gaseous mercury (DGM) before and during treatment with ascorbic acid and $\mathrm{SnCl}_{2}$ (September 2009 test) ..... .75

Table D-4. Concentrations of total mercury (HgT) and dissolved gaseous mercury (DGM) in a $3.2 \mathrm{~L}$ sample of ascorbic acid $/ \mathrm{SnCl}_{2}$ treated Outfall 200 water purged for 2 hours with air at $100 \mathrm{ml} /$ minute. 



\section{LIST OF ACRONYMS}

\begin{tabular}{|c|c|}
\hline ASCEM & Advanced Simulation Capability for Environmental Management \\
\hline $\mathrm{BJC}$ & Bechtel Jacobs Co. LLC \\
\hline BMAP & Biological Monitoring and Abatement Program \\
\hline DGM & Dissolved gaseous mercury \\
\hline DOE & Department of Energy \\
\hline EM & Environmental Management \\
\hline EFPC & East Fork Poplar Creek \\
\hline GPD & Gallons per day \\
\hline $\operatorname{Hg}(0)$ & elemental mercury \\
\hline $\operatorname{Hg}(\mathrm{II})$ & mercury in oxidation state II \\
\hline NPDES & National Pollutant Discharge Elimination System \\
\hline $\mathrm{OF}$ & Outfall \\
\hline ORNL & Oak Ridge National Laboratory \\
\hline SFA & Science Focus Area \\
\hline RMPE & Reduction of Mercury in Plant Effluent \\
\hline SRS & Savannah River Site \\
\hline TDEC & Tennessee Department of Environment and Conservation \\
\hline TMDL & Total Maximum Daily Load \\
\hline TRC & Total residual chlorine \\
\hline UEFPC & Upper East Fork Poplar Creek \\
\hline WRRP & Water Resources Restoration Program \\
\hline Y-12 NSC & Y-12 National Security Complex \\
\hline
\end{tabular}





\section{ACKNOWLEDGMENTS}

The research presented herein was funded by the U.S. Department of Energy's (DOE) Office of Technology Innovations \& Development (EM-30) Groundwater \& Soil Remediation Program (EM-32). Appreciation is extended to the people from many organizations who provided technical input, advice, and work approvals for the pilot testing, including staff from the Y-12 National Security Complex's (NSC) Environmental Compliance and Utilities, DOE Oak Ridge Operations (DOE-ORO), the Tennessee Department of Environment and Conservation (TDEC), and the Environmental Protection Agency (EPA). Guidance regarding programmatic direction was generously given by Karen Skubal and Skip Chamberlain in the DOE's EM-32 office, and Elizabeth Phillips at the DOE-ORO office. MSE Technology Applications, Inc. staff (supporting TJ Abraham) evaluated the operation design alternatives for the chemical reduction by stannous chloride. Sincere thanks are given to many Environmental Sciences Division staff members who provided support for various aspects of the 2009 studies, including Mark Greeley Jr., Mary McCracken, Carrie Miller, Gail Morris, and Xiangping Yin. 



\section{EXECUTIVE SUMMARY}

This report summarizes research conducted in calendar year 2009 by Oak Ridge National Laboratory for the U.S. Department of Energy (DOE) Office of Technology Innovations \& Development (EM-30) Groundwater \& Soil Remediation Program (EM-32). This end-of-year report satisfies a key deliverable listed in the Mercury Remediation Technology Development Project (Project number OR081301). Broad objectives of the multi-year project are: 1) evaluation of remediation technologies for waterborne mercury, 2) source identification, characterization, and transport modeling to understand where and how mercury enters EFPC, and 3) development of treatment methods for soil mercury.

Inorganic mercury $(\mathrm{Hg})$ is a common environmental contaminant within the DOE complex, including the Y-12 National Security Complex (Y-12 NSC), Oak Ridge National Laboratory (ORNL), and East Tennessee Technology Park (ETTP) in Oak Ridge, the Savannah River site (SRS), Hanford, and other sites. At Y-12 NSC, the mercury contamination exists as both diffused and point sources. The distribution of $\mathrm{Hg}$ in building rubbles and subsurface soils is yet to be characterized. In 2008 and 2009, we focused on developing technologies to treat the headwaters of East Fork Poplar Creek (EFPC) for mercury that originates primarily from a discharge point (Outfall 200) draining historic $\mathrm{Hg}$ use areas and from contaminated streambed sediments in EFPC within Y-12 NSC.

In the 2008 study, we found that a 50\% reduction in flow augmentation to upper EFPC resulted in decreasing $\mathrm{Hg}$ inputs from the streambed source by $\sim 50 \%$ over a two-week period (Southworth et al. 2009). Preliminary laboratory experiments showed that $\sim 90 \%$ mercury was chemically reduced to $\operatorname{Hg}(0)$ by low levels of tin, $\mathrm{Sn}(\mathrm{II})$. Reductive conversion of $\mathrm{Hg}(\mathrm{II})$ to $\mathrm{Hg}(0)$ was also demonstrated in the field, where $\sim 30 \%$ of baseline $\mathrm{Hg}$ (II) was converted by in-situ addition of $\mathrm{Sn}$ (II) in the headwaters. Based on these results, we focused our experimental efforts on the following in 2009:

- Evaluate the persistence and magnitude of the decrease in $\mathrm{Hg}$ input from contaminated stream sediments when flow is reduced by $50 \%$ on a long-term basis.

- Further field and laboratory testing of stannous chloride $\left(\mathrm{SnCl}_{2}\right)$ reduction of $\mathrm{Hg}(\mathrm{II})$ to $\mathrm{Hg}(0)$, coupled with an evaluation of enhanced volatilization of $\mathrm{Hg}(0)$.

Additionally, we began working on site conceptual models that address the sources and distribution of $\mathrm{Hg}$ in subsurface environments.

For the first experimental effort, delays at Y-12 NSC in implementing changes to control flow augmentation prevented the long-term study. Short-term study showed that under full flow augmentation, the streambed source continued to add $\mathrm{Hg}$ to the surface flow at a rate of $\sim 2 \mathrm{~g} / \mathrm{d}$, somewhat higher than was observed in summer 2008. During a short-term shut-down of flow augmentation we did not observe a decreased $\mathrm{Hg}$ input from the sediment source as expected, but the shut-down period was too short to allow definitive conclusions. In the interstitial water of the streambed, we found high concentrations of both dissolved elemental $\mathrm{Hg}(0)$ and oxidized $\mathrm{Hg}(\mathrm{II})$. Laboratory studies using beads of mercury metal suggest that metallic $\mathrm{Hg}$ was oxidized and dissolved in water at a rate high enough to sustain the observed $\mathrm{Hg}$ input to EFPC. Preliminary model (which did not include site-specific sediment information, storm events, current outfall flows) and empirical observations indicate that the streambed acts as both a source and sink for waterborne $\mathrm{Hg}$, with greater export under conditions of higher volumetric discharge at the headwaters. Elimination of the suspended solid load added by flow augmentation was counterbalanced by net re-suspension of streambed particulates in both the field studies and the model. Thus, the existing particle-associated $\mathrm{Hg}$ in the streambed of EFPC is a key source that buffers waterborne $\mathrm{Hg}$ concentrations and counteracts upstream $\mathrm{Hg}$ reduction in water. 
Field and laboratory testing of stannous chloride reduction of $\mathrm{Hg}(\mathrm{II})$ to $\mathrm{Hg}(0)$ produced much improved results. Optimization of this technology focused on improvements in the chemistry of the dechlorination and reduction reactions, determination of the best means and locations to add chemicals, and design of an effective air stripping system to remove $\operatorname{Hg}(0)$ from water. Laboratory work showed that sodium borohydride was effective at reducing $\mathrm{Hg}$, but it was susceptible to reaction with dissolved oxygen and required substantially greater amounts of reagent to be effective. Ascorbic acid was found to be effective as a dechlorinating agent in laboratory studies. The field test shows that with micromolar $\mathrm{SnCl}_{2}$ and ascorbic acid, $>90 \%$ of the $\mathrm{Hg}$ in the Outfall 200 discharge was converted to the reduced form $\mathrm{Hg}(0)$. Engineering feasibility was assessed for purging dissolved gaseous $\mathrm{Hg}(0)$ from $7,000-\mathrm{m}^{3} / \mathrm{d}$ flow and found that technologies exist to efficiently remove volatile constituents from such flows. The footprint required was approximately the size of the existing concrete apron underlying EFPC at Outfall 200. Natural evasion (volatilization) within the storm drain system itself also appeared to be effective in decreasing total $\mathrm{Hg}$ concentration at Outfall 200. Because tin can be methylated in the environment and transmethylation may occur between methyltin and $\mathrm{Hg}$, long-term effects of using $\mathrm{SnCl}_{2}$ on the natural stream environment need to be evaluated before considering full scale implementation.

In 2009, we initiated preliminary modeling to better identify mercury sources. Working with various parties at Oak Ridge Reservation, we contributed to the development of a Hg remediation strategy at Y12. A separate effort was initiated to develop a conceptual model describing $\mathrm{Hg}$ sources and fluxes in EFPC within the Y-12 NSC in collaboration with Savannah River National Laboratory. Collaborative interaction with Y-12 staff was undertaken in detailed investigations of $\mathrm{Hg}$ inputs to the subsurface storm drain network within the West End Mercury Area (WEMA). A systems analysis was also employed to map high risk subsurface contaminant flow paths. The bounds of known and suspected transport pathway features were documented using geographic information system (GIS) technology (ARCGIS 9.2 ${ }^{\mathrm{TM}}$ ), assigned a value associated with the risk of migration and joined in the GIS program. Results of these efforts indicate that the primary sources of waterborne $\mathrm{Hg}$ in UEFPC are from individual subsurface storm drains, where metallic $\mathrm{Hg}$ within and near the drain pipes dissolves and infiltrates into the flowing pipes. The presence of residual chlorine from cooling water and water line leaks can accelerate the dissolution of the subsurface metallic mercury.

Future activities of this project will continue developing alternative treatment technologies to decrease waterborne mercury. The knowledge gained in the last two years in evaluating the chemical reduction technology will be transferred to Y-12 NSC for additional pilot testing. Mercury transport modeling will be incorporated into other EM efforts, such as Advanced Simulation Capability for Environmental Management (ASCEM) program and our major focus will be technologies for identifying and characterizing sediment and soil-bound mercury and for immobilizing $\mathrm{Hg}$ in shallow soils. 


\section{INTRODUCTION}

The mercury remediation development project focuses on providing improved technologies and methods for controlling and minimizing mercury fluxes transporting from source areas to surface water systems. Mercury is a dominant environmental contaminant in the DOE complex, including the Y-12 National Security Complex, Oak Ridge National Laboratory, Savannah River Site, Hanford Site, and others. At the Y-12 NSC, uses of a large quantity of Hg during the 1950's and early 1960's resulted in soil and groundwater contamination in source areas and subsequent transport of mercury into the East Fork Poplar Creek leading to serious contamination off DOE lands.

On the Oak Ridge Reservation, mercury contamination exists as both diffused and point sources. The distribution of mercury in building rubbles and subsurface soils is yet to be characterized. Mercury in the headwaters of East Fork Poplar Creek (EFPC) originates primarily from a discharge point (Outfall 200) draining historic $\mathrm{Hg}$ use areas and from contaminated streambed sediments throughout the length of EFPC within Y-12 NSC. A localized reach near Outfall 200 contains high concentrations of dissolved inorganic $\mathrm{Hg}$ within the streambed, which releases $\mathrm{Hg}$ to the surface flow. Although detailed mechanisms are unknown, inorganic mercury has been converted to methylmercury by microbes and subsequently accumulated and biomagnified within the aquatic food chain at EFPC. In a long run, a fundamental understanding is required to decrease the bioavailability of inorganic $\mathrm{Hg}$ precursors for the formation of methylmercury in stream waters. In the absence of sufficient scientific understanding of mercury methylation in the environment, the short term goal is to decrease mercury loading to the surface water of EFPC to meet the compliance goals agreed by DOE and EPA.

Earlier review of DOE site needs yields three major applied R\&D themes that will result in more effective and less costly treatment methodologies to stabilize mercury from various sources at contaminated sites. These themes are as follows:

- Theme 1: Remediation of Waterborne Mercury

Develop treatment technologies that will reduce the level of mercury contamination (primarily focused on addressing contaminated stream water).

- Theme 2: Soil Treatment Develop treatment technologies (in situ and ex situ) for remediating contaminated soil. Mercury immobilization methods are included.

- Theme 3: Source Identification and Advanced modeling

Develop measurement tools (including in situ, real time methods) for evaluating the amount and distribution of mercury at contaminated sites (including air-borne as well as groundwater contamination). Tools applicable to long-term monitoring also are needed. Develop advanced modeling methods to understand the processes that contribute to the mercury flux in streams such as UEFPC at Y-12.

This is a multi-year project. Beginning in year 2008, we primarily addressed the research outline in Theme 1, investigating remediation methods for waterborne mercury (Southworth et al. 2009). Using Y12 NSC as a field site, the 2009 project aims to demonstrate treatment technologies that reduce the concentration and loading of waterborne mercury discharges to the upper East Fork Poplar Creek (UEFPC), thus minimizing mercury uptake by fish. The specific objectives in year 2009 were:

1. Continue testing of flow augmentation to determine effects on the Hg levels at the compliance point, 
2. Continue study of chemical reduction of mercury with stannous chloride treatment, with a focus to improve the efficiency of mercury removal,

3. Begin development of site conceptual model to identify risk and uncertainties to be used for future programs and coordination with decontamination and decommission efforts.

Removal of waterborne mercury from source zones at the Y-12 site builds on our research started in 2008. A summary of the mercury problem in Oak Ridge and the results of the 2008 studies is provided in Southworth et al. 2009, and not repeated here. The 2008 studies focused on two options for reducing mercury inputs from the Y-12 facility into UEFPC: 1) reduce flow augmentation into UEFPC, and 2) use a site-specific stannous chloride treatment approach within storm drain pipe entering outfall 200. These two options were more thoroughly evaluated in 2009 by conducting field and laboratory studies.

Preliminary modeling of the potential flow management changes was performed and evaluations of chemical reduction followed by engineered air stripping to remove volatile $\mathrm{Hg}(0)$ was performed by $\mathrm{MSE}$ staff.

For the flow management option, the 2008 study found that a $50 \%$ reduction in flow augmentation to upper EFPC reduced $\mathrm{Hg}$ inputs from the streambed source reach by about $50 \%$ over a two-week period (Southworth et al. 2009). A longer-term field evaluation was planned in 2009 to understand the magnitude and persistence of the removed mercury from UEFPC. Experiments were planed to cover at least two seasons with a relatively low and high rainfalls, respectively, to observe seasonal influence to stream flow. The 2009 flow management tests focused on winter/spring sampling. The study was somewhat limited, as it relied on the Y-12 NSC operation, which could not provide the necessary changes in flow. In the absence of desirable flows for a long-term study, various flow management options were modeled in 2009 based on the best available site data.

The largest source of $\mathrm{Hg}$ to EFPC is the Outfall 200 discharge, which contributes 6 to $8 \mathrm{~g} / \mathrm{d}$ of $\mathrm{Hg}$ to the surface flow. The 2009 chemical reduction studies of mercuric mercury, $\mathrm{Hg}$ (II), focused on optimization of this technology by improving the dechlorination and chemical reduction reactions, determining the best means and locations for adding chemicals, and designing a cost effective, efficient air stripping system to remove $\mathrm{Hg}(0)$ from water. Laboratory work aimed at investigating alternative and mixtures of chemicals as dechlorinating agents. Follow-on field test included changing the types of dechlorination chemicals and the means of mixing the chemicals (by using appropriate location to maximize mixing in storm drain flow). An engineering evaluation of various options following the chemical reduction for purging and stripping the elemental mercury, $\operatorname{Hg}(0)$ was conducted for this project.

This report also summarizes activities that generally aim to advance the technological solutions to the mercury issues. The research team hosted an on site meeting as a part of the development of site conceptual model to identify risk and uncertainties to mercury remediation. Additionally, ORNL staff provided technical expertise to an Oak Ridge Technology Development forum and participated in developing a mercury remediation strategy. In the fall of 2009, we contributed a DOE EM-32 Mercury Summit conference, discussing issues and possible solutions to mercury contamination. Throughout the year, staff conducted mercury analysis for the Y-12 West End Mercury Area (WEMA) project, collaborated with regulators in developing TMDL strategies, participated in development of systemsbased approach to Site D\&D and remediation, and collaborated with basic science program on field investigations.

In summary, this document reports the findings of the 2009 research that was conducted by ORNL staff and is organized as follows: Chapter 1 provides a brief introduction of the 2009 project's objectives, scope, and report organization, Chapter 2 summarizes the flow management field studies and modeling, 
Chapter 3 describes the laboratory and field chemical reduction studies and engineering options, Chapter 4 highlights the development of site conceptual model and associated activities in 2009, and Chapter 5 provides a short description of future plans. 



\section{EFFECTS OF FLOW MANAGEMENT DIVERSION ON WATERBORNE MERCURY FLUX IN UPPER EAST FORK POPLAR CREEK}

\subsection{BACKGROUND}

Decreased water usage within the Y-12 NSC in the early 1990s resulted in a substantial reduction in flow in Upper East Fork Poplar Creek. Restoration of minimum flow to levels typical of the late 1980s was viewed as an action beneficial to the ecology of the stream, lessening effects of Y-12 discharges and groundwater inputs on water quality. In a negotiated agreement with the Tennessee Department of Environment and Conservation (TDEC), a flow augmentation system (referred to as 'flow management') was emplaced in late 1996. The addition of $17,000 \mathrm{~m}^{3} / \mathrm{d}$ of water from Melton Hill Lake on the Clinch River to UEFPC at the stream head (also known as Outfall 200), where the subsurface storm drain emerges within the Y-12 facility (Fig. 1), was found to result in a gradual increase in waterborne mercury concentration along a 250-m reach of stream a short distance downstream from where the Melton Hill Lake water was added. A 1998 study (BJC 1998) found high concentrations of dissolved Hg deep within streambed sediments in this reach. A large fraction of that dissolved $\mathrm{Hg}$ was elemental $\mathrm{Hg}(\mathrm{Hg}(0))$, indicating the likely presence of metallic $\mathrm{Hg}$ deposits within the streambed. Advection of the highly contaminated interstitial water into the surface flow of EFPC could readily account for the observed increase in $\mathrm{Hg}$ concentrations in the stream along this reach.

In 2008, a short-term study was conducted to investigate whether reducing the volume of water added by the flow management system 50\% would result in decreased input of $\mathrm{Hg}$ from the reach of stream where contaminated sediments acted as a Hg source to the surface flow (Southworth et al. 2009). That study found that $\mathrm{Hg}$ input from the source reach was decreased from $1.1 \mathrm{~g} / \mathrm{d}$ to $0.5 \mathrm{~g} / \mathrm{d}$ when flow management was cut by $50 \%$. Although promising, there are several uncertainties concerning whether such changes would persist over time. Transfer of waterborne $\mathrm{Hg}$ to the streambed is a concentration-driven process for both particle-associated and dissolved $\mathrm{Hg}$ fractions. By removing dilution water, reductions in flow management inputs necessarily raise waterborne $\mathrm{Hg}$ concentrations in the reach of stream immediately downstream from monitoring Station C11 (Fig. 1). The higher Hg concentration in the surface flow would result in greater transfer of $\mathrm{Hg}$ to the streambed than occurred when flow management was at $100 \%$. This process could account for some of the decreased $\mathrm{Hg}$ input observed in the 2008 study. Over time, $\mathrm{Hg}$ concentrations in the streambed biofilm would increase as a result of the higher rate of transfer of $\mathrm{Hg}$ to the surface. Since transfer of $\mathrm{Hg}$ from the surface to the water is also concentration dependent, it would be likely to rise over time, resulting in increased flux of $\mathrm{Hg}$ from the streambed to the surface flow after changes in flow management are made permanent.

A similar trend would be possible under the scenario in which advection of interstitial water is the dominant source of the $\mathrm{Hg}$ input from the streambed. It is likely that dissolution of $\mathrm{Hg}$ from deposits of metallic $\mathrm{Hg}$ within the streambed is the ultimate source of $\mathrm{Hg}$ to the interstitial water. The rate of that process is expected to be relatively constant; hence the interstitial $\mathrm{Hg}$ concentration would reflect an approximate steady-state between dissolution and advective removal. If the advection rate is decreased while dissolution remains constant, interstitial $\mathrm{Hg}$ concentrations would be expected to build up, and eventually the advection of a smaller volume of water could deliver as much $\mathrm{Hg}$ to the surface flow as was previously observed at higher flow rates. Although possible, neither of these mechanisms is necessarily dominant in this system. The observation that the reach did not act as a net source of $\mathrm{Hg}$ to the surface flow in the absence of flow management suggests that the changes observed over the 2008 short-term experiment may indeed persist over the long term. The existence of these mechanistic uncertainties highlights the need for a $\mathrm{Hg}$ transport model for UEFPC that can address such questions. The 2009 effort was intended to evaluate whether or not changes associated with flow management reduction would persist. 


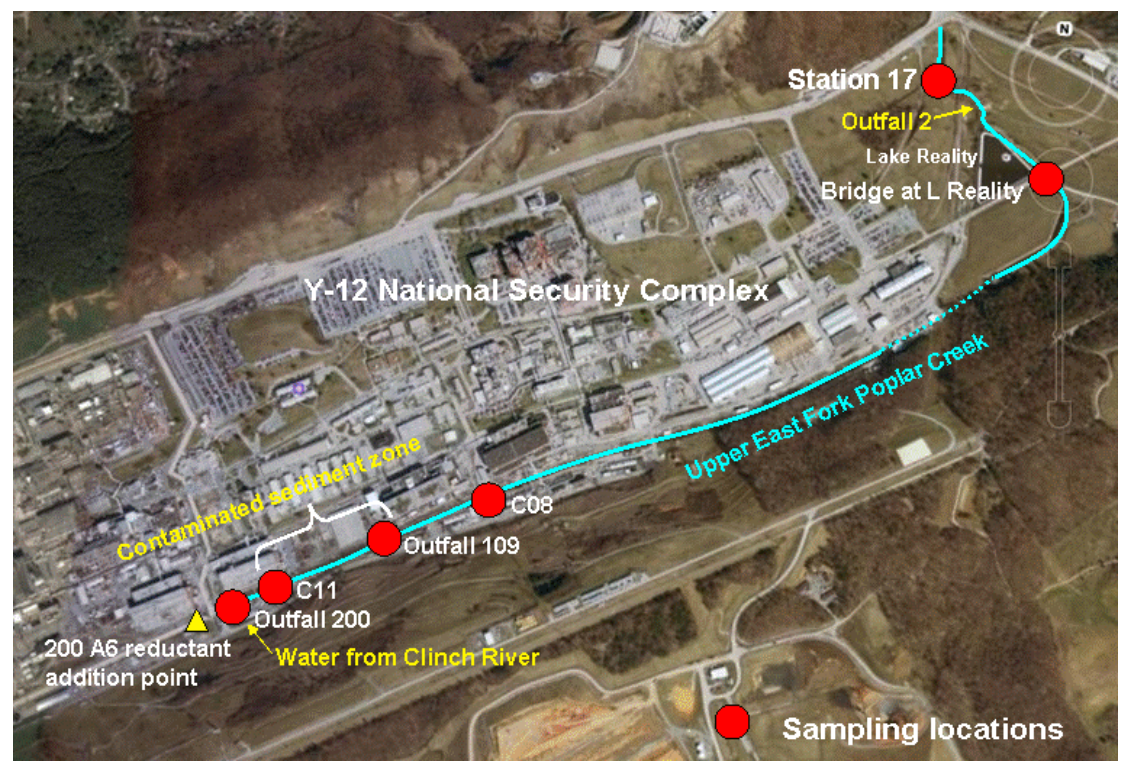

Fig. 1. Key surface water sampling locations for flow management diversion and chemical reduction (using reduced tin) tests conducted in year 2008 at Y-12 National Security Complex. Location at which Melton Hill Lake water is added via flow management system is shown.

The flow management system at Y-12 NSC was built to take advantage of a pre-existing water line tapping the main trunk line that supplies the Melton Hill Lake water for the city of Oak Ridge, TN water treatment plant. It did not have a system of control valves that allowed flow to be accurately controlled, but rather required altering the flow rates on several large pumps on the trunk line to modify flow into the spur leading into Y-12. This carried a significant risk of over-pressurizing segments of the water lines leading into the Y-12 facility. Indeed, this did occur, which led to one large leak during the 2008 study. Staff at the Y-12 NSC therefore decided not to attempt long-term alteration of the flow management input to UEFPC until the system could be modified to control flow without overpressurizing old degraded pipes. That proved to require a major engineering design and implementation effort, and therefore the plan to conduct a long term study in 2009 was not possible. However, we had initiated an effort to monitor baseline mercury flux in the system at the full (100\%) flow management augmentation rate. That effort was discontinued upon learning that the modifications to the system would not occur in 2009 . The baseline sampling turned out to be useful because we did additional sampling during a water-line break that forced the flow management system to be shut off for several days. The data collected from these sampling events provided an opportunity to gain further insight into the effect of the flow management system on $\mathrm{Hg}$ transport in EFPC.

\subsection{METHODS}

The field test was initiated on January 14, 2009 and lasted for approximately 2 weeks. Monitoring consisted of measuring in-situ water quality parameters, such as $\mathrm{pH}$, temperature, and electric conductivity. Additional sampling was conducted on March 31, April 4, and April 6, 2009 when the flow management system was completely shut off for repairs. All monitoring was restricted to dry weather conditions when stream discharge was typical of seasonal baseflow.

Stream flow was monitored at gauging stations (Station 17, Station C08, and Station C11; Fig. 1) by Y-12 NSC staff. Duplicate water samples were collected daily from each of six locations in UEFPC: Outfall 200, the Melton Hill Lake water input point, C11, Station C08, Station 17 and the main channel of 
UEFPC immediately upstream from Outfall 109. Samples were immediately preserved and digested using bromine monochloride/ $\mathrm{HCl}$ solution according to EPA procedure 1631. Water samples were subsequently treated with hydroxylamine and stannous chloride, to reduce $\mathrm{Hg}$ (II) to $\mathrm{Hg}(0)$, and analyzed for total mercury by cold vapor atomic absorption spectrometry using a Lumex RA915+ Zeeman effect mercury analyzer. Mercury fluxes were calculated by using gauged stream flow rate at the time of sampling multiplied by the mean values of duplicate mercury measurements at each sampling location. Total suspended solids were measured by filtering $500-1000 \mathrm{ml}$ of water through a tared glass fiber filter and gravimetrically determining the mass of the filtered solids. The nominal pore size for Whatman $\mathrm{GF} / \mathrm{C}$ is $1.2 \mu \mathrm{m}$.

The Oak Ridge National Laboratory Science Focus Area (ORNL-SFA) Program funded by the Office of Science (BER ERSP program) conducted additional sampling during the experiment to investigate the effects of flow reduction on the chemistry of subsurface mercury sources. That effort provided measures of the gradient in interstitial $\mathrm{Hg}$ concentrations with depth and the rate of dissolution of $\mathrm{Hg}$ away from the interface of metallic $\mathrm{Hg}$ in water.

\subsection{RESULTS}

Streamflow ( \pm SD) during the January 2009 baseline monitoring averaged $21400 \pm 820 \mathrm{~m}^{3} / \mathrm{d}$ at monitoring Station C11 and $35200 \pm 680$ at Station 17 (Fig. 1). Discharge at these sites during the July 2008 baseline study was similar $\left(20,700 \pm 950 \mathrm{~m}^{3} / \mathrm{d}\right.$ at $\left.\mathrm{C} 11\right)$, where most of the flow is comprised of cooling water discharges from Y-12 and the flow management input. The July 2008 flow at Station 17 $\left(28,000 \pm 730 \mathrm{~m}^{3} / \mathrm{d}\right)$ was less than that observed in January 2009, as might be expected as a seasonal difference in groundwater contributions to baseflow.

When flow management was shut off in April 2009, mean flow at C11 $\left(7100 \pm 170 \mathrm{~m}^{3} / \mathrm{d}\right)$ was much lower than in January. Discharge at Station 17 was maintained at a high level by the addition of augmentation water at Outfall 2 (Fig. 1), and averaged 24,000 $\pm 800 \mathrm{~m}^{3} / \mathrm{d}$. The complete data sets for this study are included in the appendix of the report (Appendix A). For simplicity, the average values are shown in Figures presented in this section.

Total mercury concentrations in UEFPC surface water during the January 2009 baseflow and April 2009 flow management shut-off are presented in Fig. 2. A clear increase in $\mathrm{Hg}$ concentration between $\mathrm{C} 11$ and Outfall 109 is evident in both data sets. In the January baseflow study, mean $\mathrm{Hg}$ concentration $( \pm \mathrm{SE})$ increased from $341 \pm 29 \mathrm{ng} / \mathrm{L}$ at C11 to $436 \pm 34 \mathrm{ng} / \mathrm{L}$ at Outfall 109. Surprisingly, an even larger increase was observed in the April data, going from $961 \pm 63 \mathrm{ng} / \mathrm{L}$ at C11 to $1197 \pm 61 \mathrm{ng} / \mathrm{L}$ at Outfall 109. Waterborne $\mathrm{Hg}$ concentration decreased downstream from Outfall 109 in both the January and April data sets.

The estimated mean downstream mass flux of $\mathrm{Hg}$ at sites in upper EFPC is depicted in Fig. 3. (Flux at ungauged Outfall 200 was calculated by assuming flow at Outfall 200 was $25 \%$ of the flow at C11 in January and $100 \%$ of the flow at C11 in April when flow management was turned off. The increase in $\mathrm{Hg}$ flux between $\mathrm{C} 11$ and Outfall 109 is obvious. The mean amount of $\mathrm{Hg}$ added within that streambed source was $2.1 \pm 0.25 \mathrm{~g} / \mathrm{d}$ in January 2009 and $1.9 \pm 0.92 \mathrm{~g} / \mathrm{d}$ in April (Table 1). Mean flux at C11 was $7.3 \mathrm{~g} / \mathrm{d}$ in January and $6.7 \mathrm{~g} / \mathrm{d}$ in April (Table 1). The contribution from the streambed source reach thus was $22 \%$ of the flux at Outfall 109 in both January and April. In both data sets, the mass flux of $\mathrm{Hg}$ exiting the watershed at Station 17 was substantially less than that upstream, indicating in-stream retention and storage. Retention of $\mathrm{Hg}$ within the system occurs as a result of direct uptake of dissolved $\mathrm{Hg}$ by the surface biofilm on the streambed substrate and deposition of particle-associated $\mathrm{Hg}$ to the streambed. The latter process is likely to dominate, since most waterborne $\mathrm{Hg}$ is particle-associated near 


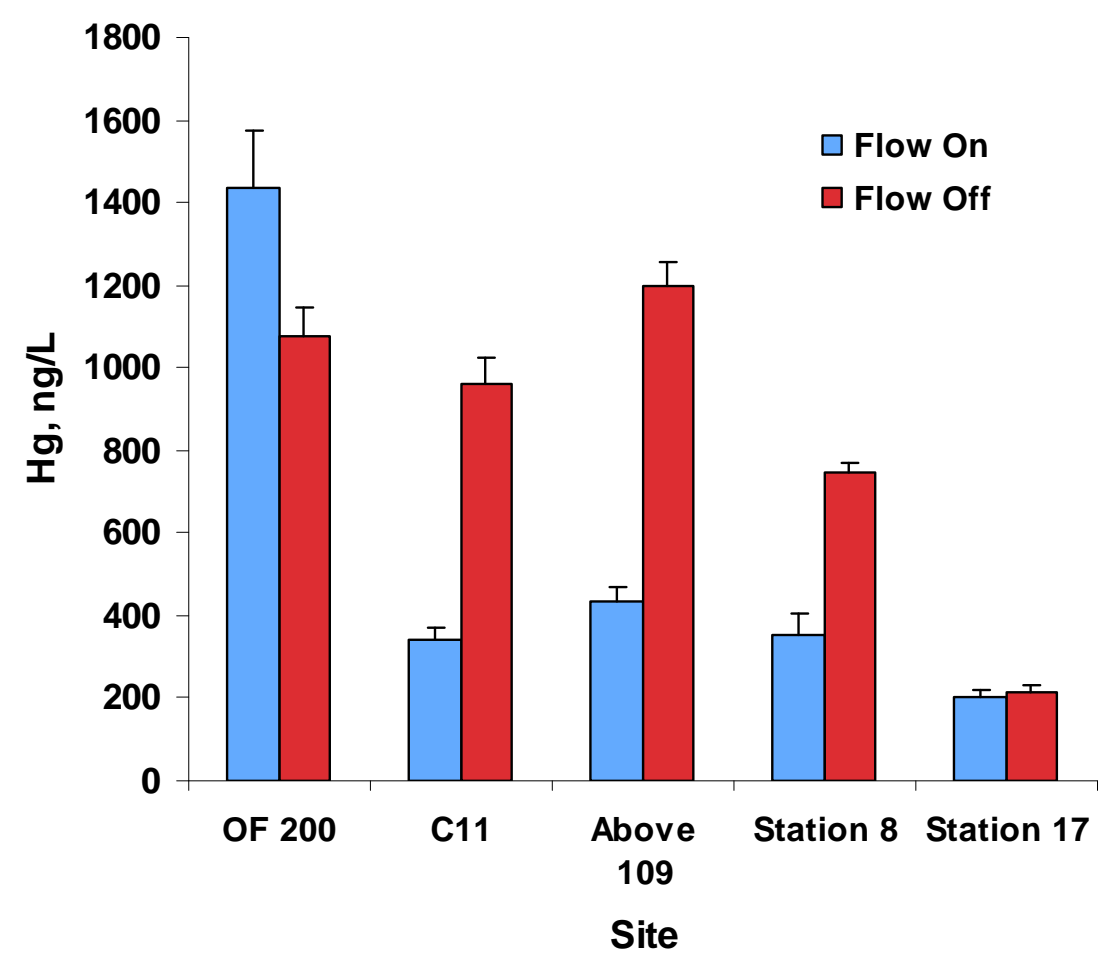

Fig. 2. Mean concentration of total $\mathrm{Hg} \pm \mathrm{SE}$ at sites in upper East Fork Poplar Creek in January 2009 monitoring (flow management on) and April 2009 (flow management off).

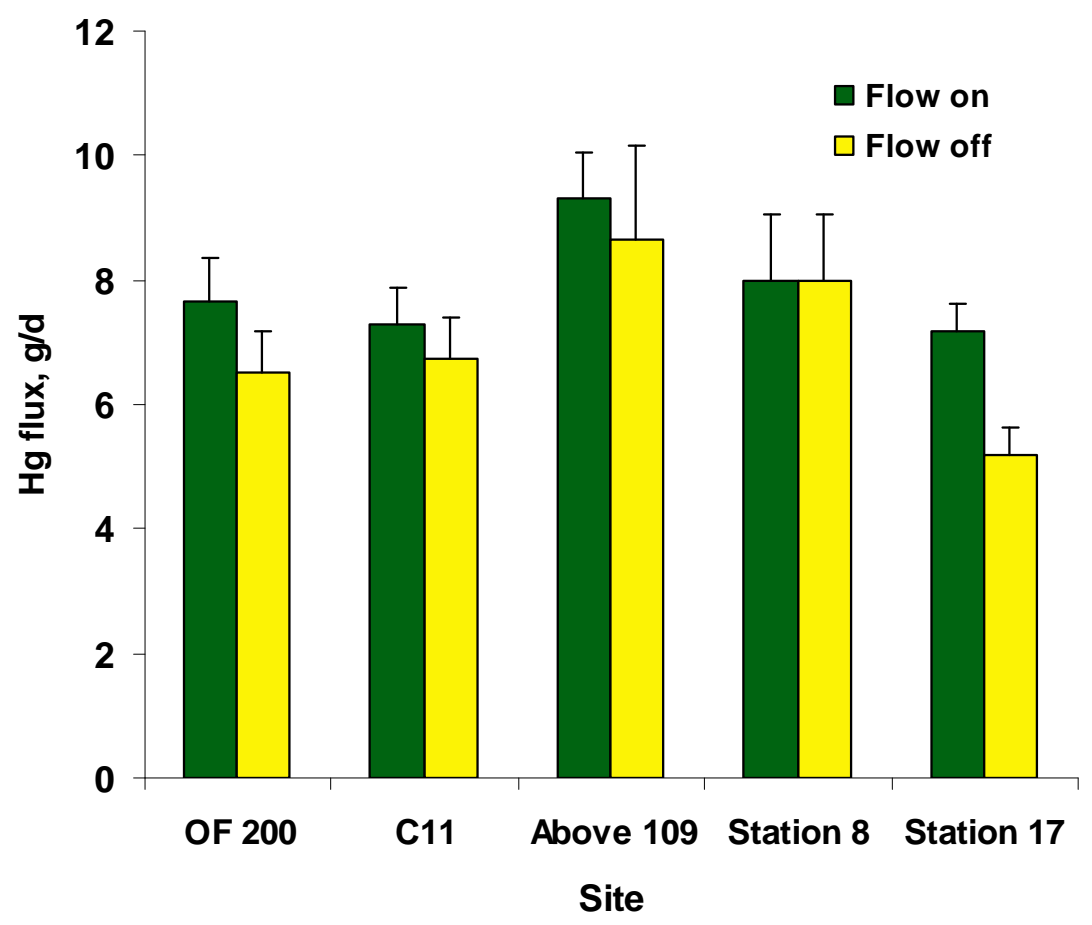

Fig. 3. Mean downstream flux of total $\mathrm{Hg} \pm \mathrm{SE}$ at sites in upper East Fork Poplar Creek in January 2009 monitoring (flow management on) and April 2009 (flow management off). 
Table 1. Flux of Hg in EFPC under varied addition of water from the flow management system

\begin{tabular}{lccccc}
\hline Period & $\begin{array}{c}\text { Flow } \\
\text { management } \\
\text { status }\end{array}$ & $\mathbf{N}$ & $\begin{array}{c}\text { Hg flux, } \\
\text { Station C11 } \\
\text { g Hg/d }\end{array}$ & $\begin{array}{c}\text { Flux change, } \\
\text { C11 - Outfall 109 } \\
\text { g Hg/d }\end{array}$ & $\begin{array}{c}\text { Hg flux, } \\
\text { Station 17 } \\
\text { g Hg/d }\end{array}$ \\
\hline January 2009 & $100 \%$ & 9 & $7.2 \pm 0.80$ & $2.1 \pm 0.32$ & $6.4 \pm 0.5$ \\
July 2008 & $100 \%$ & 10 & $6.4 \pm 0.30$ & $1.1 \pm 0.28$ & $7.1 \pm 0.43$ \\
August 2008 & $50 \%$ & 10 & $4.6 \pm 0.15$ & $0.50 \pm 0.10$ & $5.9 \pm 0.19$ \\
April 2009 & $0 \%$ & 3 & $6.7 \pm 0.70$ & $1.9 \pm 0.92$ & $5.2 \pm 0.40$ \\
\hline
\end{tabular}

Outfall 109 and the streambed contains a rich biofilm containing numerous filter-feeding organisms that strain particulates from the water.

The comparison of 2008 and 2009 monitoring results in Table 1 shows the consistency of the daily $\mathrm{Hg}$ flux exiting Outfall 200, typically averaging around 5-7 g/d. Flux from the streambed source varied much more proportionately, but was of course influenced by the varied flow regime. In three of the four data sets, a fraction of the $\mathrm{Hg}$ added to the surface flow in the stream headwaters was retained before it reached the facility border at Station 17. In the August 2008 period when flow management was reduced $50 \%$, the lower reach of stream (Outfall 109-Station 17) exported rather than retained $\mathrm{Hg}$.

The April 2009 flow management shut-off provided an opportunity to gain insight into the dynamics of particulate transport in EFPC. The Melton Hill Lake water added to upper EFPC typically contains 5-10 ppm total suspended solids. In contrast, water exiting Outfall 200 is generally crystal clear, containing less than $1 \mathrm{ppm}$ TSS. When flow management was running, the suspended solids load was set by the augmented water discharge (Clinch River water contained $5.0 \pm 0.3 \mathrm{mg} / \mathrm{L}$ TSS) and remained relatively constant with distance downstream.

When flow management was off, suspended solid concentrations appeared to increase with distance downstream, presumably from resuspension of streambed particulates (Fig. 4). Since these particulates contain high concentrations of $\mathrm{Hg}$, it represents a source that replenishes $\mathrm{Hg}$ in the water, and at times may offset actions taken to remove $\mathrm{Hg}$ from the Outfall 200 discharge. The effects of this buffering on $\mathrm{Hg}$ concentrations downstream need to be evaluated for source removal actions and remedial effectiveness.

Studies being carried out by the ORNL-SFA Program to better understand the dynamics of $\mathrm{Hg}$ in upper EFPC have been used to leverage the EM-32 funded effort. In a study investigating $\mathrm{Hg}$ concentrations in interstitial water versus depth in the $\mathrm{Hg}$ source reach between $\mathrm{C} 11$ and Outfall 109 we found a very strong and distinct concentration gradient within the upper $25 \mathrm{~cm}$ of the streambed (Fig. 5). Dissolved $(<$ $0.45 \mu \mathrm{m}$ filtered) $\mathrm{Hg}$ concentrations in interstitial water ranged from $>300,000 \mathrm{ng} / \mathrm{L}$ at $30-\mathrm{cm}$ depth to $\sim 200 \mathrm{ng} / \mathrm{L}$ at the surface. Interstitial water contained high concentrations of dissolved $\mathrm{Hg}(0)$, with the highest concentration nearly $1 / 3$ of the solubility limit of $\operatorname{Hg}(0)$. At this concentration, a daily replacement of interstitial water in the upper $30 \mathrm{~cm}$ of the streambed reach between C11 and Outfall 109 would add $2 \mathrm{~g} / \mathrm{d}$ of $\mathrm{Hg}$ to the surface flow by advection. This rate is consistent with the 1998 streambed piezometer study (BJC 1999). If advection carries fine particles, much less water replacement would be needed. Additionally we observed that most of the dissolved $\mathrm{Hg}$ in the interstitial water is in the oxidized rather than the dissolved gaseous form (Fig. 5).

The presence of near saturation levels of dissolved $\mathrm{Hg}(0)$ in interstitial water is strong evidence of the presence of metallic $\operatorname{Hg}(0)$ in the streambed. Laboratory studies were conducted to obtain kinetic 


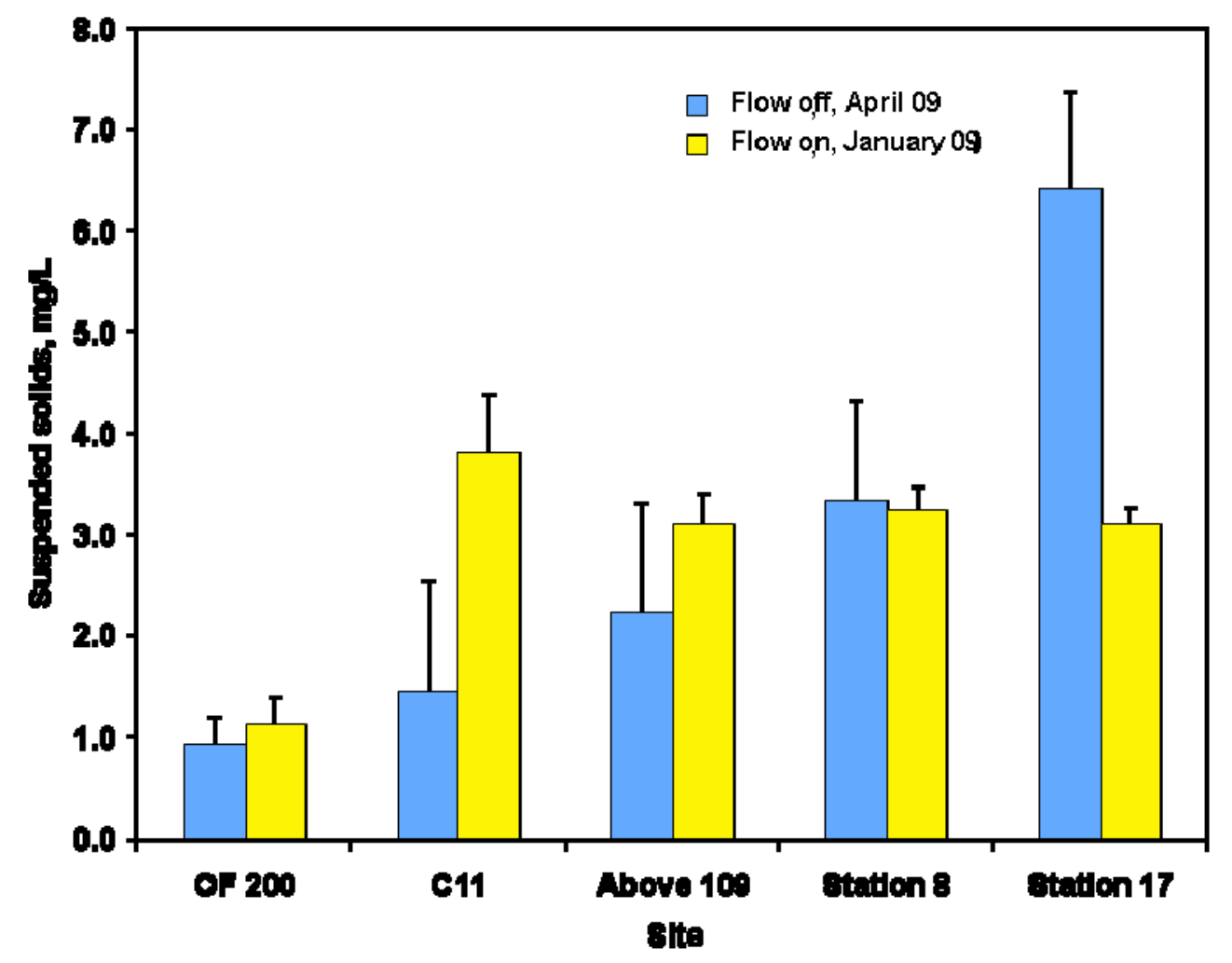

Fig. 4. Mean concentrations ( \pm SE) of total suspended solids in EFPC in January 2009 monitoring (flow management on) and April 2009 (flow management off).

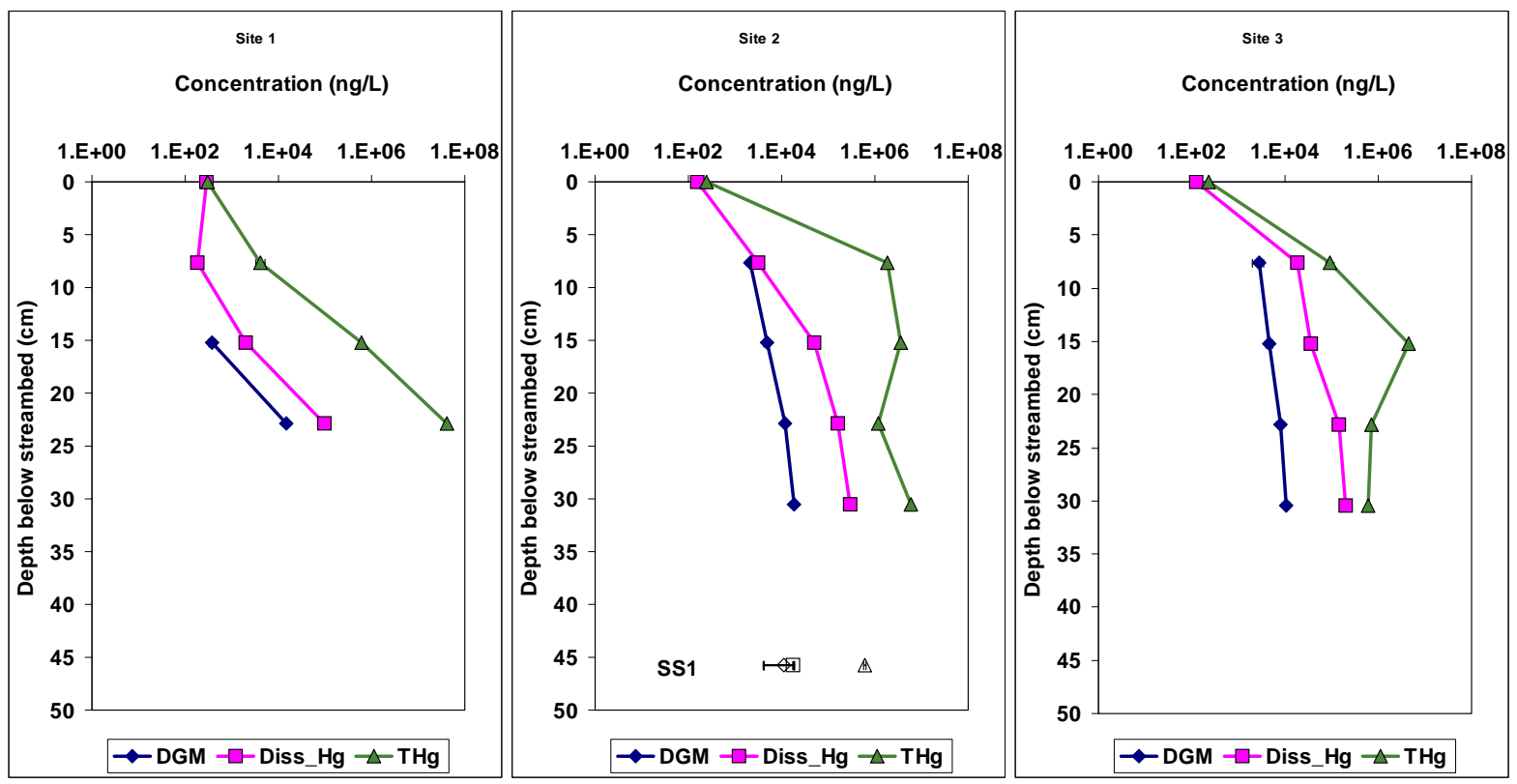

Fig. 5. Gradients in concentrations of dissolved gaseous $\mathrm{Hg}(\mathrm{Hg}(\mathbf{0})$, dissolved total $\mathrm{Hg}$ (degassed, $<0.45$ $\mu \mathrm{m}$ filtered, and total $\mathrm{Hg}$ (contains particulates) with depth in a transect of EFPC with the streambed Hg source reach). 
information on dissolution of $\mathrm{Hg}$ away from a bead of metallic $\mathrm{Hg}$ into dionized water (Fig. 6). The process occurs via two mechanisms - the direct dissolution of $\mathrm{Hg}(0)$ and the oxidation of $\operatorname{Hg}(0)$ to $\operatorname{Hg}(\mathrm{II})$ at the surface of the metal (Amyot et al. 2003). The rapid dissolution observed initially may results from the simultaneous action of both mechanisms. As the $\operatorname{Hg}(0)$ concentration in the water approaches saturation, only the oxidative dissolution continues, and hence the rate of dissolution slows. Very high concentrations of dissolved $\mathrm{Hg}$ can be attained in water adjacent to metallic $\mathrm{Hg}$. Figure 6 shows that in $10 \mathrm{ml}$ of water contacting a $1-\mathrm{cm}^{2}$ metallic $\mathrm{Hg}$ surface, a concentration of 450,000 $\mathrm{ng} / \mathrm{L}$ was reached in 20 hours. Most of that $\mathrm{Hg}$ was in the oxidized form $\mathrm{Hg}(\mathrm{II})$, as was observed in the interstitial water of the EFPC streambed. Using the initial rate of dissolution, $10 \mathrm{ng} / \mathrm{cm}^{2} / \mathrm{min}$, approximately $14 \mathrm{~m}^{2}$ of $\mathrm{Hg}$ surface would be needed to generate a $2 \mathrm{~g} / \mathrm{d}$ flux. However, the oxidation of $\mathrm{Hg}$ can be catalyzed by the presence of halides and probably other solutes that may be present in these waters, in which case much less $\mathrm{Hg}$ may be required to generate such a source term.

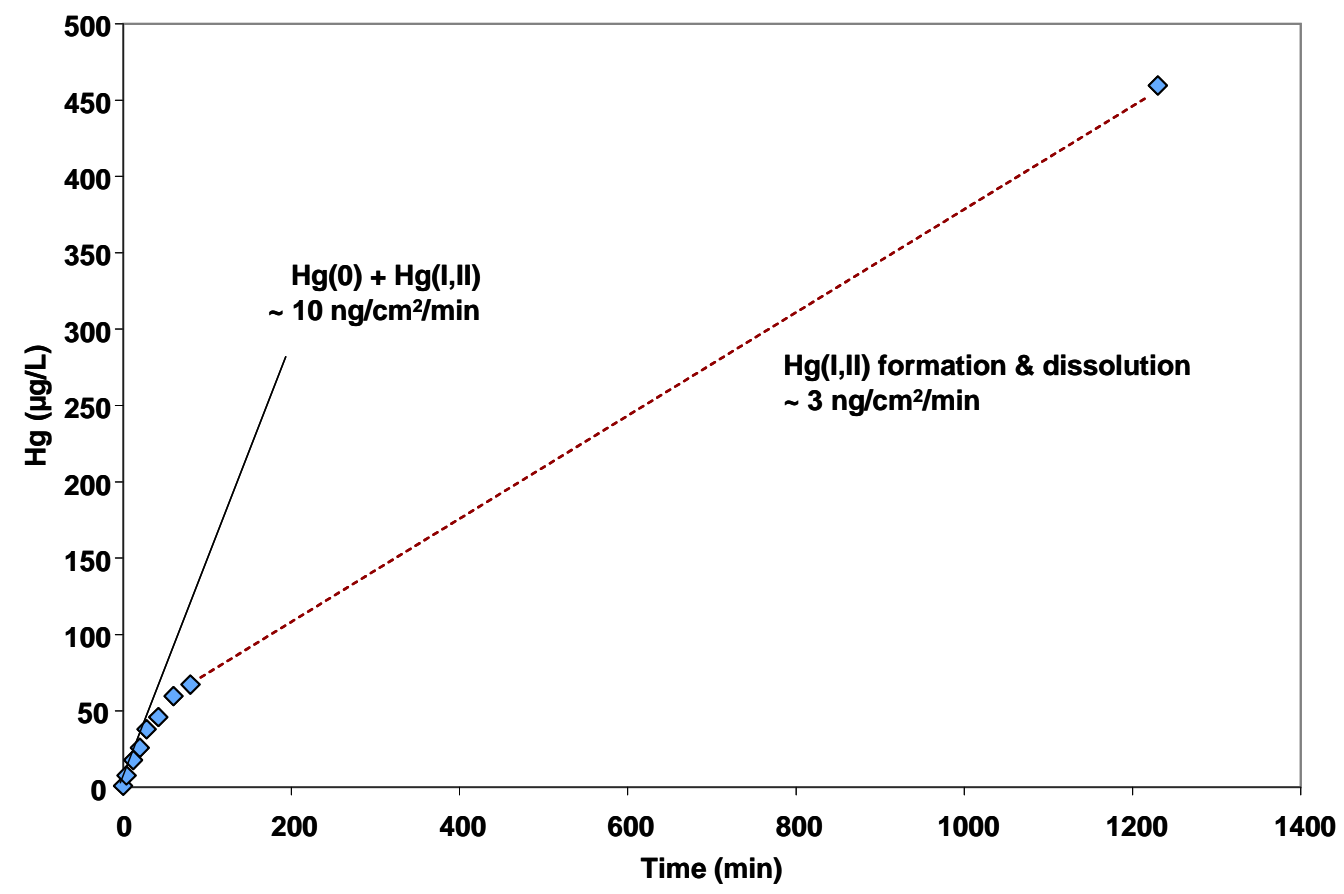

Fig. 6. Rate of dissolution of $\mathrm{Hg}$ from the surface of metallic $\mathrm{Hg}$ into deionized water.

\subsubsection{Results of Modeling Flow Management Alternatives}

\subsubsection{Modeling tool}

A steady state flow model was constructed using site specific channel cross-sections and flow information. The purpose of the modeling exercise was to provide a conceptual understanding of the potential impact of flow and suspended load and stream bed erosion on $\mathrm{Hg}$ cycling. Because the model does not include site-specific sediment information, storm events, or current outfall flows the model is not expected to match site specific field conditions exactly.

We use WASH123D as our primary modeling tool. WASH123D is a finite element watershed model to simulate water flow, heat transfer, sediment and reactive transport in river/stream networks, surface runoff and ground water (Yeh et al. 2005). In the model, sediments are categorized based on their 
physical and chemical properties. For each category of sediment, we include mobile suspended sediment particles within the water column and immobile sediment in the streambed that is not subject to longitudinal transport. For chemical species, six phases and three forms can be defined. As shown in Fig. 7, the six phases are suspended sediment, bed sediment, mobile water, immobile water, suspended precipitates, and bed precipitate phases, and the three forms are dissolved chemicals, chemicals sorbed on sediment, and precipitates (Zhang et al. 2008).
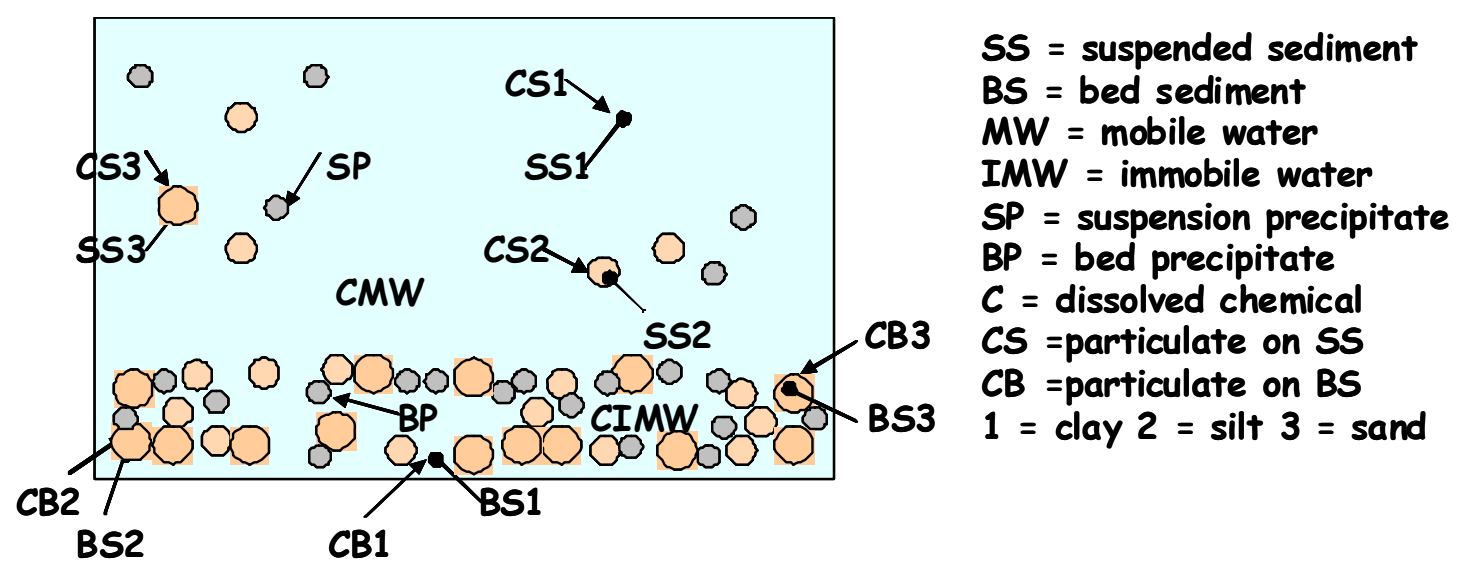

Fig. 7. Sediments and chemicals simulated in surface water systems.

\subsubsection{Hydrogeochemical modeling}

Model domain and cross section profiles: UEFPC channel from Outfall 200 to Station $17(8,400 \mathrm{ft})$ (Fig. 1) was discretized into 1-D equal size elements of $30 \mathrm{ft}$ each.

The elevation profile at the grid nodes (Fig. 8) is interpolated from the channel Station Survey (Moran 1996). The elevations correspond to the deepest section of the channel. The creek was divided into four main segments (Table 2) according to cross section characters (Moran 1996).

Table 2. Cross section characters of the four main segments of UEFPC

\begin{tabular}{|c|c|c|c|}
\hline Segments & Channel type & Cross section geometry & Manning's n \\
\hline $\begin{array}{l}6813 \sim 2052 \mathrm{ft} \\
517 \sim-1587 \mathrm{ft}\end{array}$ & $\begin{array}{l}\text { Excavated, } \\
\text { trapezoidal, } \\
\text { open channel type } 1\end{array}$ & $\begin{array}{l}\text { Average bottom width of } 15 \mathrm{ft} \text { and } \\
\text { average horizontal/vertical side slopes of } 2.5 / 1 \\
\text { Average top width of } 61.08 \mathrm{ft}\end{array}$ & $\begin{array}{l}0.035 \\
(0.03 \sim 0.04)\end{array}$ \\
\hline $2052 \sim 1130 \mathrm{ft}$ & Closed culvert & Average diameter of 67.8 in & 0.024 \\
\hline $1130 \sim-517 \mathrm{ft}$ & $\begin{array}{l}\text { Excavated, } \\
\text { trapezoidal, } \\
\text { open channel type } 2\end{array}$ & $\begin{array}{l}\text { Average bottom width of } 16.5 \mathrm{ft} \text { and } \\
\text { average horizontal/vertical side slopes of } 1.5 / 1 \\
\text { Average top width of } 41.86 \mathrm{ft}\end{array}$ & 0.014 \\
\hline
\end{tabular}




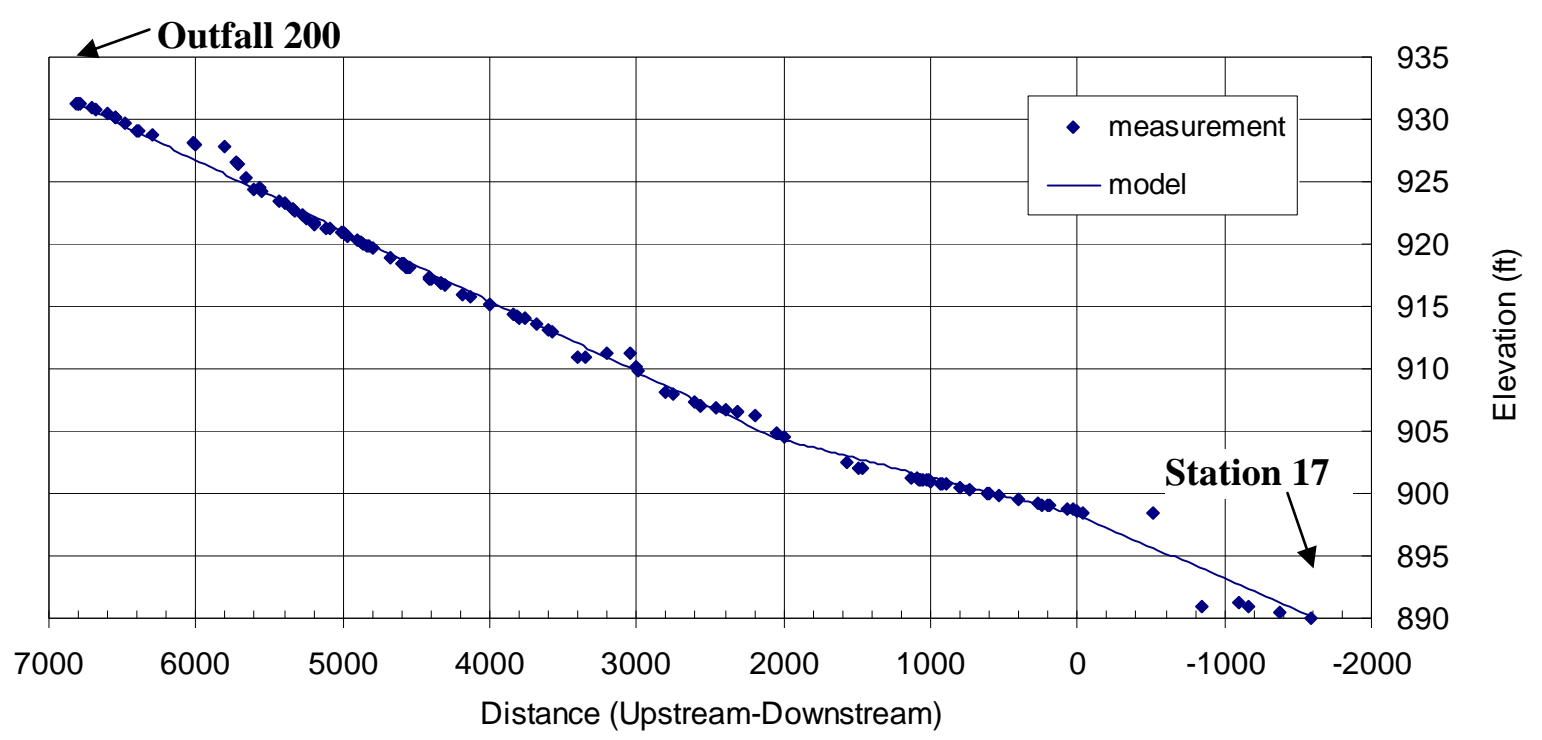

Fig. 8. Elevation profile of the UEFPC channel: the distances (x) are measured upstream and downstream from the center of Second Street Culvert Bridge at Lake Reality.

\section{Hydrology model}

Seventeen NPDES (the National Pollutant Discharge Elimination System) outfalls were identified to be responsible for the generation of UEFPC baseflow during a dry season (Jul. Dec. 1993) and treated as upstream inflow boundary or point source at approximate gridding nodes (Table 3) (Moran 1996).

Table 3. Average baseflow at NPDES outfalls along UEFPC

\begin{tabular}{ccc}
\hline NPDES outfalls & Location $\mathbf{x}(\mathbf{f t})$ & Average baseflow (CFS) \\
\hline 200 & 6813 & 2.5 \\
135 & 6798 & 0.69 \\
113 & 6020 & 0.01 \\
109 & 5654 & 0.26 \\
99 & 5568 & 0.008 \\
88 & 5343 & 0.005 \\
71 & 5110 & 0.02 \\
67 & 5000 & 0.05 \\
55 & 4560 & 0.163 \\
51 & 4418 & 0.193 \\
48 & 4331 & 0.02 \\
47 & 4329 & 0.19 \\
42 & 4139 & 0.049 \\
34 & 3842 & 0.23 \\
21 & 3572 & 0.24 \\
17 & 2571 & 0.026 \\
14 & 2317 & 0.005 \\
\hline
\end{tabular}


A steady state flow was first modeled to simulate the baseflow under dry weather condition. A constant incoming normal base flow rate of $2.5 \mathrm{cfs}$ was applied to the upstream boundary at Outfall 200. A depthdependent outgoing normal flow rate (based on elevation profile, manning's $\mathrm{n}$ and cross section geometry) was applied to the downstream boundary close to USGS Stream gage Station 17 . No rainfall or infiltration is considered. The steady state flow was obtained by running a transient simulation with a fixed time step size of 1.0s until the output flow solution does not change with time. The initial water depth and flow velocity was set to $0.1695 \mathrm{ft}$ and $0.957 \mathrm{ft} / \mathrm{s}$, respectively. Figure 9 shows the baseflow water depth simulation. Since the change of water depth is almost unobservable after time $=7200 \mathrm{~s}$, a steady state is presumed to have reached thereafter. In order to avoid numerical oscillation, the small part of closed culvert was approximated by the first type of open channel (Table 2). In Fig. 9, the biggest hydraulic jump is observed at $\mathrm{x}=1130 \sim-517 \mathrm{ft}$ where the channel type changes; secondary hydraulic jumps are observed at $x=2043$ and -687 where the bottom slope changes; other hydraulic jumps are observed at outfalls where water sources are introduced.

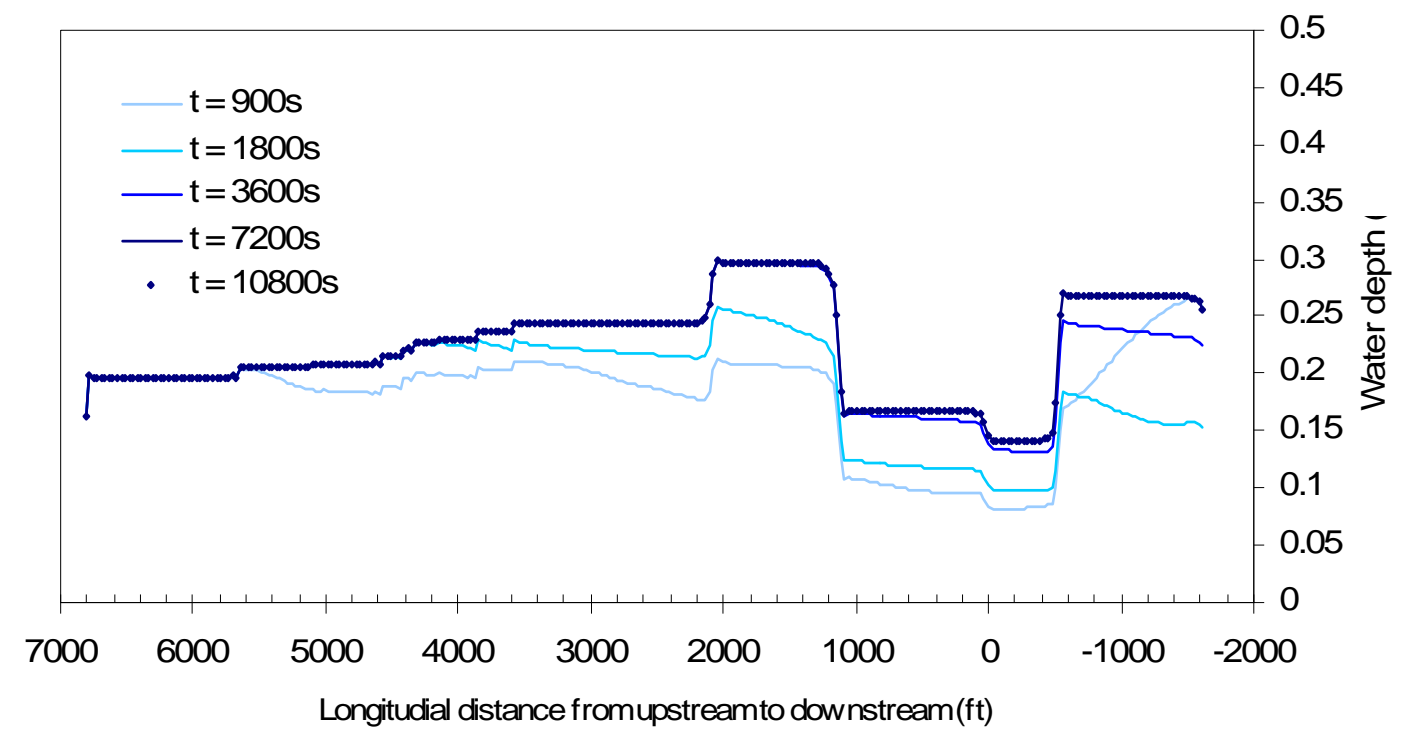

Fig. 9. Baseflow water depth simulation of the UEFPC channel.

Assumed flow rate coming from the Melton Hill Lake is $5.0 \mathrm{cfs}$ during flow augmentation scenarios. Steady state simulations are performed for two more cases: Case 1 with $2.5+5.0=7.5 \mathrm{cfs}$ coming in at outfall 200 representing full flow augmentation condition and Case 2 with $2.5+5.0 / 2=5.0$ cfs coming in at outfall 200 and 5.0/2 $=2.5 \mathrm{cfs}$ added at outfall 2 representing flow diversion condition. Simulated flow velocities at different locations along the creek are compared in Fig. 10.

\section{Sediment transport model}

Only one hypothetical size of cohesive sediment is taken into account with settling speed of $1.5 \times 10^{-5}$ $\mathrm{m} / \mathrm{s}$, erodibility of $1.0 \times 10^{-3} \mathrm{~g} / \mathrm{m}^{2} / \mathrm{s}$, critical shear stresses for deposition of $2.85 \mathrm{~g} / \mathrm{m} / \mathrm{s}^{2}$, and critical shear stresses for erosion of $2.48 \mathrm{~g} / \mathrm{m} / \mathrm{s}^{2}$. Initially, only bed sediment exists in the domain of interest with abundant concentration. As simulation starts, Dirichlet boundary conditions are applied to the upstream boundary node, where suspended sediment has a constant concentration of $0 \mathrm{~g} / \mathrm{m}^{3} \mathrm{n}$. Out-flow variable boundary conditions are applied to the downstream boundary node. Figure 11 shows the suspended sediment simulation under the different flow scenarios, assuming the baseflow at Outfall 200 contains 0.1 $\mathrm{g} / \mathrm{m}^{3}$ suspended sediment (SS) and water flow from Melton Hill Lake contains $8.0 \mathrm{~g} / \mathrm{m}^{3} \mathrm{SS}$. Reduced 


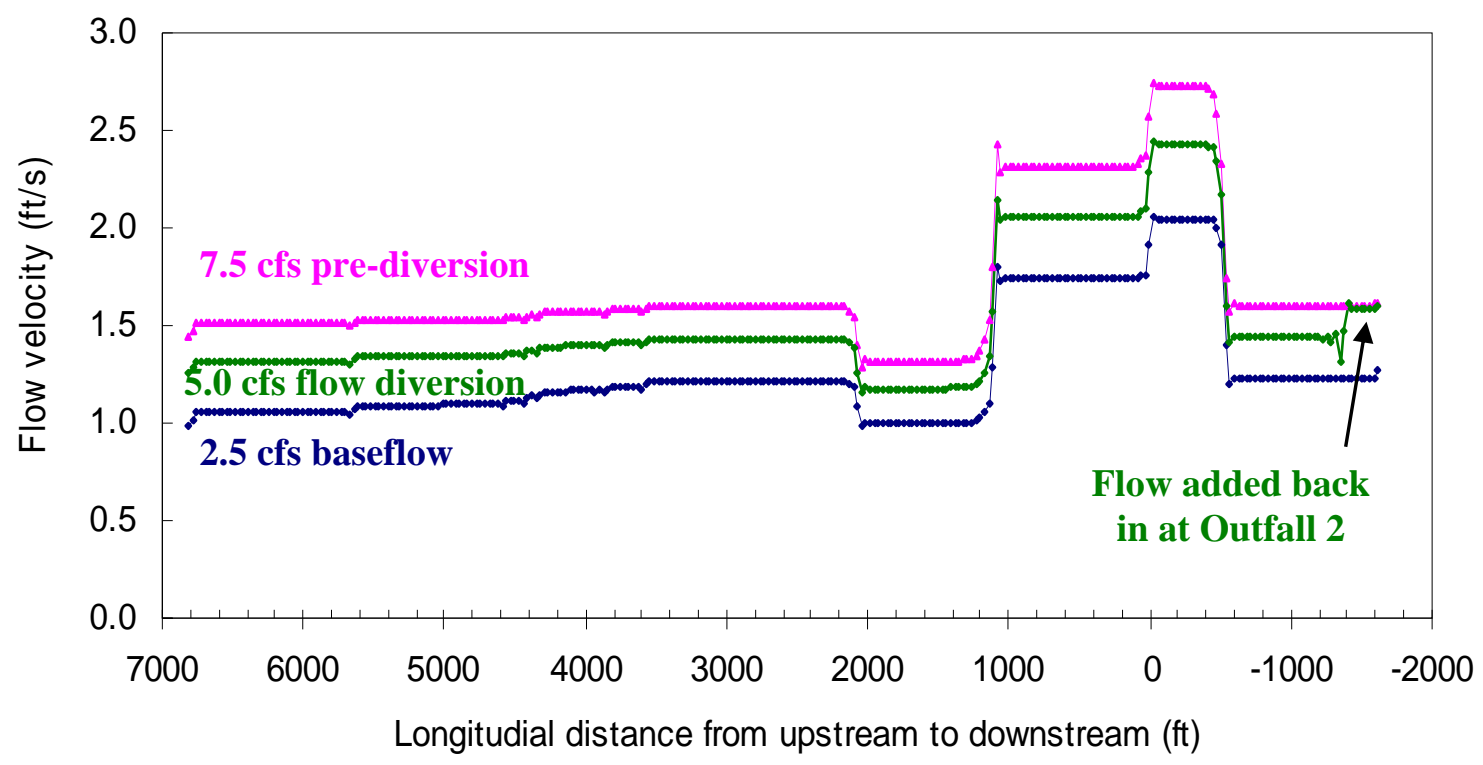

Fig. 10. Simulation of flow velocity under different scenarios for the UEFPC channel.

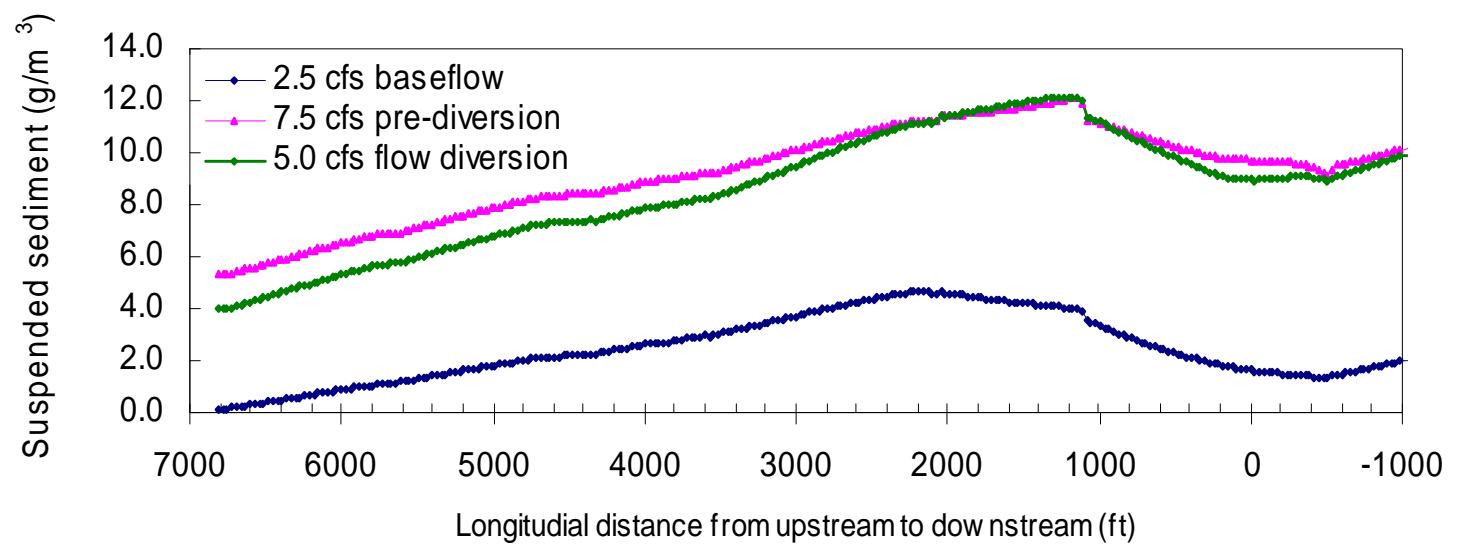

Fig. 11. Simulated suspended sediment concentration for the UEFPC channel.

flow rate resulted in less erosion of bed sediment and lower suspended load in the creek. However, due to the smaller water volume, the concentration of suspended sediment (SS) may be higher for the reduced flow.

\section{Hg reactive transport model}

Reactive transport simulation was performed for $\mathrm{Hg}$ in the creek assuming the longitudinal dispersivity to be $100 \mathrm{ft}$ and total $\mathrm{Hg}$ load at upstream is $1100 \mathrm{ng} / \mathrm{L}$ in the Outfall 200 baseflow and $2.0 \mathrm{ng} / \mathrm{L}$ in the Melton Hill Lake flow-augmentation water. Two reactions are considered as follows

Sorption of dissolved mercury onto suspended sediment

$$
\mathrm{Hg} \stackrel{\mathrm{Kd}}{\longleftrightarrow} \mathrm{Hg}-\mathrm{SS} \quad \mathrm{Kd}=10^{6}(\mathrm{~mol} / \mathrm{kg}) /(\mathrm{mol} / \mathrm{L})
$$


Erosion of Hg-BS (bed sediment) and deposition of $\mathrm{Hg}-\mathrm{SS}$

$$
\mathrm{Hg}-\mathrm{SS} \longleftrightarrow \mathrm{Hg}-\mathrm{BS} \quad \mathrm{R}_{\mathrm{f}}=\text { deposition rate; } \mathrm{R}_{\mathrm{b}}=\text { erosion rate }
$$

Simulated dissolved and total $\mathrm{Hg}$ is shown in Fig. 12. It is shown that: (1) dissolved $\mathrm{Hg}$ concentration approaches asymptote due to the sorption; (2) reduced flow results in reduced total $\mathrm{Hg}$ concentration due to less erosion of $\mathrm{Hg}$ in the bed sediment or more deposition of $\mathrm{Hg}$ in the suspended sediment; (3) $\mathrm{Hg}$ concentration does not rise proportionally with the loss of dilution.
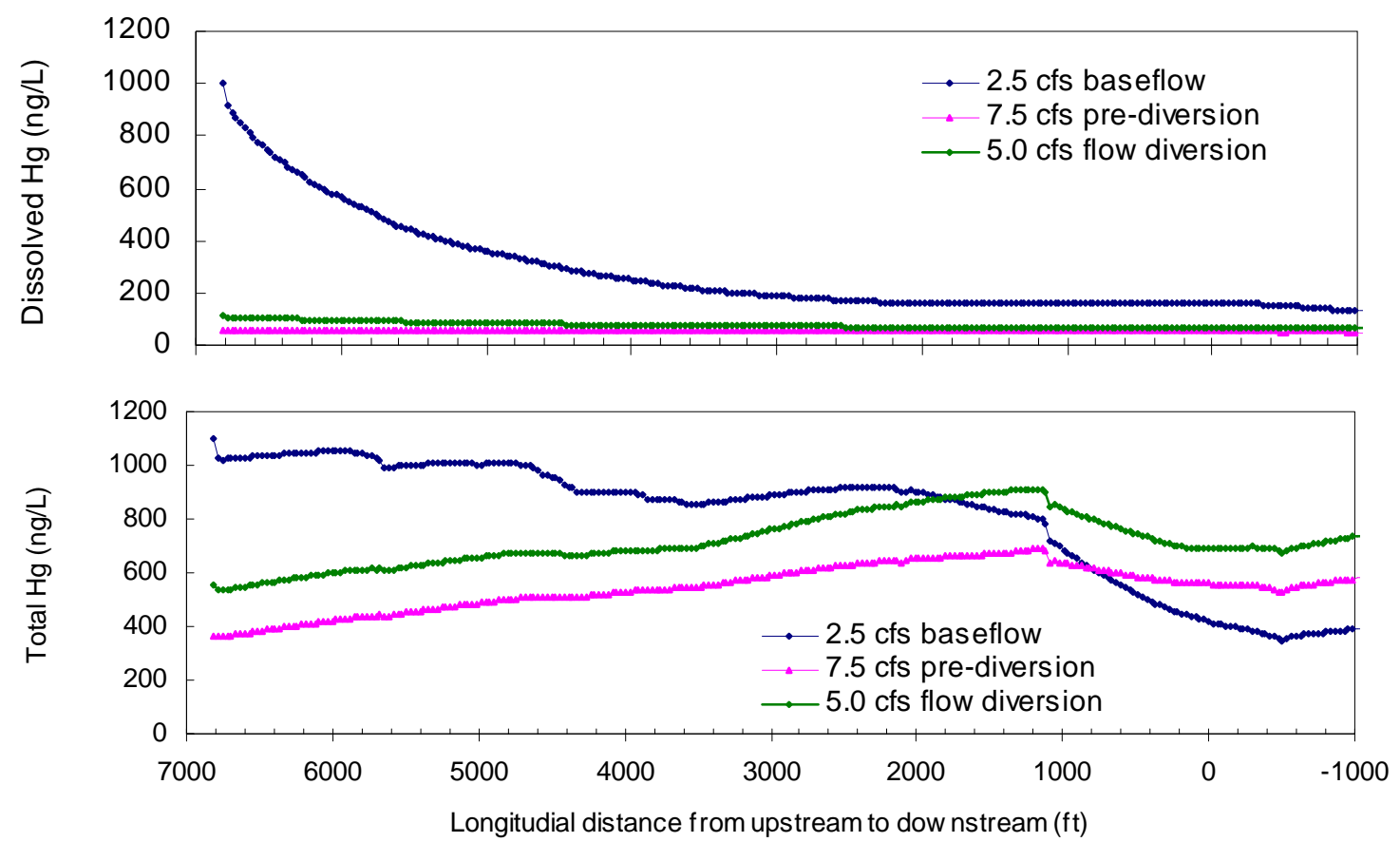

Fig. 12. Simulated dissolved and total Hg concentrations for the UEFPC channel.

The total load of suspended sediment and Hg are plotted in Fig. 13. Due to the erosion of bed sediment, higher flow equates to higher flux of suspended sediment. Lower flow produces lower Hg flux but there is a threshold probably related to assumed sediment characteristics.

\subsubsection{Summary}

A steady state flow model constructed using site-specific channel cross-sections and flow information simulates: (1) baseflow with no flow augmentation; (2) full flow augmentation at Outfall 200; and (3) $50 \%$ flow augmentation at Outfall 200, other 50\% added back in at Outfall 2.

Steady state transport simulation does not include site-specific sediment information, storm events, current outfall flows, etc. Since the above simulation is performed with hypothetical flow rate, $\mathrm{Hg}$ load, and sediment properties, the modeling study only illustrates possible mechanisms to explain the field experiment. The modeling study provides conceptual understanding of potential impact of flow and suspended load and streambed erosion on Hg cycling, illustrating the importance of considering flow and 

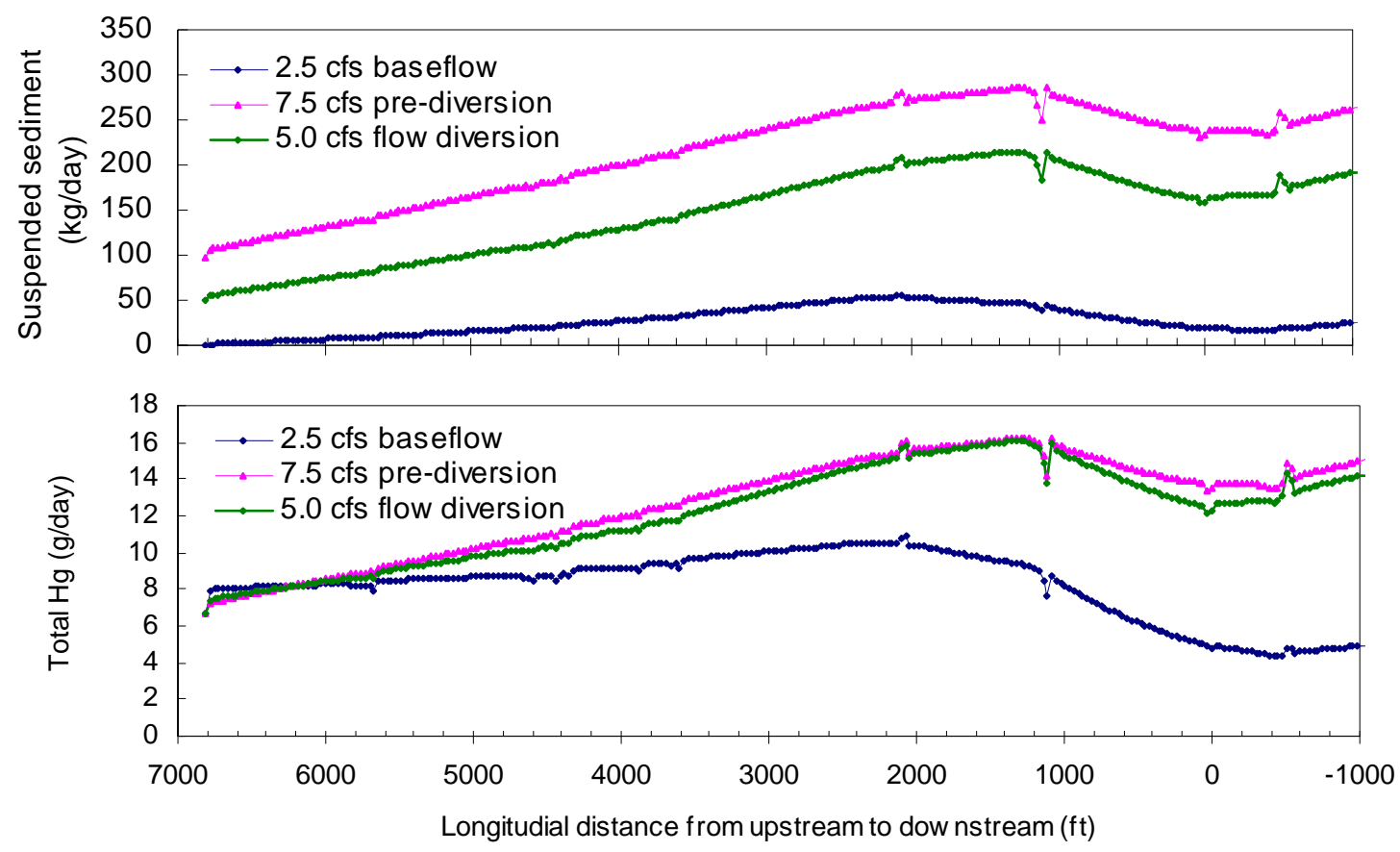

Fig. 13. Simulated total load of suspended sediment and Hg for the UEFPC channel.

suspended and bed load sediment characteristics on Hg cycling in UEFPC and for selecting remedial actions.

More site-specific characterization data is needed in the future for the surface water model input and calibration.

- Updated baseflow at outfalls.

- Rate of flow from the Melton Hill Lake flow augmentation.

- Sediment type and erosion/deposition properties.

- Suspended sediment load along the creek.

- Conditions in upper reaches of UEFPC that result in increased Hg flux during flow augmentation (water contact with $\mathrm{Hg}$ contamination).

- Hg partitioning and transformation reaction coefficients.

\subsection{CONCLUSIONS}

The results of the 2009 efforts to understand the role of flow augmentation highlight the importance of the EFPC streambed in the overall transport of mercury in the system. The streambed supplies an unknown amount of metallic mercury that is a source of dissolved $\mathrm{Hg}(0)$ and $\mathrm{Hg}(\mathrm{II})$ within the stream reach between monitoring Station C11 and Outfall 109 (Fig. 1) and roughly 50-100 kg of $\mathrm{Hg}$ (II) associated with the fine particulate fraction of streambed sediments throughout the length of EFPC upstream from the Station 17 monitoring point that measures the cumulative export of $\mathrm{Hg}$ from the Y-12 NSC. The initial efforts to model the effects of changes in headwater flow augmentation on the transport of mercury and suspended solids generated predictions that were consistent with some of the key findings of the baseline field studies. Both the model and empirical observations indicated that the streambed acts as both a source and sink for waterborne $\mathrm{Hg}$, with greater export under conditions of higher volumetric discharge at the headwaters. Eliminating flow augmentation and its substantial suspended solids input did not result 
in lower concentrations of TSS at the Station 17 exit point, nor did total $\mathrm{Hg}$ flux at Station 17 decrease below the range observed in 2008 and 2009 when flow augmentation was at $100 \%$.

The continued addition of approximately $2 \mathrm{~g} / \mathrm{d}$ of $\mathrm{Hg}$ to the surface flow of EFPC from the reach between C11 and Outfall 109 during the short period when flow management was off was unexpected. It may have been a consequence of drainage of bank storage back into the creek under sharply reduced flow. This observation demonstrates the need to evaluate the effect of flow management changes on a long-term basis before more definitive conclusions can be reached about the effect of such an action on $\mathrm{Hg}$ export from the Y-12 complex. 


\section{CHEMICAL REDUCTION TO REMOVE MERCURY FROM STORM DRAIN DISCHARGES AT THE Y-12 NATIONAL SECURITY COMPLEX}

\subsection{BACKGROUND}

The chemistry of mercury exiting the Y-12 storm drain at Outfall 200 is unique because residual chlorine $(\sim 2 \mathrm{ppm}$ total residual chlorine, i.e., TRC) from process water maintains the mercury in a highly reactive dissolved form. This is in stark contrast to mercury within the surface waters of EFPC a relatively short distance downstream from Outfall 200, where the dissolved reactive inorganic $\mathrm{Hg}$ becomes rapidly associated with suspended particulates, dissolved organic matter, and the streambed bio-film. Because mercury within the storm drain system is in a form that can undergo rapid chemical reactions with reductants, complexants, or precipitants, the system provides an exceptional opportunity to chemically reduce $\mathrm{Hg}$ and remove it from the water. Dissolved elemental mercury exists in water as a volatile gas that can be readily purged by air stripping or simple evasion across the air: water interface. If a large fraction of the $\mathrm{Hg}$ upstream from Outfall 200 could be converted to $\mathrm{Hg}(0)$ before it reaches the discharge point it could theoretically be removed and captured from the gas phase by activated carbon.

In 2008, an in-situ pilot-scale test of reduction of $\mathrm{Hg}(\mathrm{II})$ to $\mathrm{Hg}(0)$ was completed using $\mathrm{Sn}$ (II) solution addition to the drainage piping system immediately upstream of Outfall 200 where UEFPC emerges into an open channel. A substantial fraction (33\%) of the baseflow $\mathrm{Hg}$ (II) load in this subterranean reach of UEFPC was converted to dissolved gaseous mercury (DGM) under the specific in-situ test conditions (Southworth et al. 2009). However, in laboratory tests performed and reported earlier, treatment of samples of drainage water collected from Outfall 200 with $\mathrm{SnCl}_{2}$ could achieve approximately $90 \%$ reduction of $\mathrm{Hg}(\mathrm{II})$ to $\mathrm{Hg}(0)$. The lower degree of $\mathrm{Hg}(\mathrm{II})$ reduction in the field test was hypothesized to arise from several potential constraints imposed by specific in-situ test conditions. In the 2008 in-stream tests, reagents [ $\mathrm{SnCl}_{2}$ for $\mathrm{Hg}(\mathrm{II})$ reduction and sodium thiosulfate $\left(\mathrm{Na}_{2} \mathrm{~S}_{2} \mathrm{O}_{3}\right)$ for reduction of total residual chlorine] were added concurrently but separately through a length of pipe through surface grate and into drainage water within the 200A6 drainpipe plenum/box which lies approximately 64 meters upstream of the Outfall 200 drain discharge where results were monitored. Reagent mixing with drainage water relied on ambient turbulence within the plenum and pipeway between 200A6 and Outfall 200 to effect concurrent dechlorination with thiosulfate and reduction of $\mathrm{Hg}(\mathrm{II})$ by $\mathrm{Sn}(\mathrm{II})$. Because both $\mathrm{Sn}$ (II) and thiosulfate are reactively consumed by TRC in the drainage water, the kinetics and degree of ambient mixing of the three independent flows (two treatment solution flows into one drainage pipe flow) at a single location (200A6) was problematic to assess. Oxidation of Sn(II) by dissolved chlorine or oxygen prior to its necessary reactive contact with $\mathrm{Hg}$ (II) could reduce its effectiveness in $\mathrm{Hg}$ (II) reduction. Alternately, antecedent complexation of $\mathrm{Hg}$ (II) and/or $\mathrm{Sn}$ (II) by thiosulfate may diminish the effectiveness of $\mathrm{Sn}$ (II) as a reducing agent for $\mathrm{Hg}$ (II). In addition, the solubility of the acid-stabilized and concentrated (1\%) $\mathrm{SnCl}_{2}$ feed solution, which was used during this test, may have been problematic to maintain during dilution and over the interval of addition into the 200A6 drainage water.

The 2009 effort focused on solving two shortcomings of the 2008 study - the temporary mobilization of $\mathrm{Hg}$ from pipe walls by thiosulfate, and the relatively low fraction of $\mathrm{Hg}$ that was converted to dissolved gaseous mercury (Southworth et al. 2009). We assumed that the low conversion efficiency was a result of simultaneous addition of reductant and dechlorinating agent, which may have allowed some residual chlorine or dissolved oxygen to consume part of the $\mathrm{SnCl}_{2}$ before it had a chance to react with $\mathrm{Hg}$ (II).

\subsection{TECHNICAL APPROACH}

The potential chemical interactions, during additions of stannous chloride and thiosulfate to drainage water containing total residual chlorine (TRC), $\mathrm{Hg}(\mathrm{II})$, oxygen et al., established a need for further 
laboratory and field tests of $\mathrm{Hg}$ (II) reduction to devise techniques to increase the in-situ $\mathrm{Hg}$ (II) reduction from the 33\% achieved in 2008 to something closer to the $90 \%$, which has been achieved in well-mixed laboratory tests on the same drainage water.

The experiments focused on three potential enhancements to increase in-situ $\mathrm{Hg}$ (II) reduction. First, since $\mathrm{Hg}$ (II) reduction by $\mathrm{Sn}$ (II) cannot be achieved without first reducing the TRC in the drainage water, alternate dechlorinating (reducing) reagents to the previously used $\mathrm{Na}_{2} \mathrm{~S}_{2} \mathrm{O}_{3}$ were examined. Second, alternate stabilizing agents for $\mathrm{SnCl}_{2}$ solubility other than acid were examined. Third, alternate reducing agents for $\mathrm{Hg}(\mathrm{II})$ other than $\mathrm{SnCl}_{2}$ were examined.

The basis for this re-examination of potential reactive reagents comes from the pertinent water chemistry. The drainage water in the pipe between 200A6 and Outfall 200 contains at least three pertinent reducible species: $\mathrm{Hg}(\mathrm{II}), \mathrm{TRC}\left(\mathrm{Cl}_{2}\right.$ or $\left.\mathrm{HClO}\right)$, and $\mathrm{O}_{2}$. [The dominance of the $\mathrm{Hg}$ as $\mathrm{Hg}(\mathrm{II})$ in this water likely results from reaction of metallic $\mathrm{Hg}(0)$ in proximate contaminated materials (soils, buildings, drains, etc.) when contacted by chlorinated process water imported for general use within the Y-12 facility; however, that issue remains speculative and tangential to the current problem of $\mathrm{Hg}(\mathrm{II})$ in the drainage water upstream of Outfall 200.] Stannous chloride, $\mathrm{SnCl}_{2}$, can reduce $\mathrm{Hg}(\mathrm{II}), \mathrm{TRC}$, and $\mathrm{O}_{2}$ if added in sufficient soluble amounts. The use of $\mathrm{SnCl}_{2}$ for these in-situ tests has evolved due to the larger analytical chemistry community's familiarity with and use of this reductant for $\mathrm{Hg}$ (II) volatilization within the standard total $\mathrm{Hg}$ analyses after $\mathrm{Hg}$ (II) is formed in a water sample by oxidation with $\mathrm{BrCl}$ (USEPA Method 1631). However, because Sn(II) has been viewed as moderately hazardous, Sn has a negotiated regulatory compliance discharge limit of $5 \mu \mathrm{g} / \mathrm{L}(\mathrm{ppb})$ at EFPC monitoring station $\mathrm{C} 11$. Even the twentyfold excess stoichiometric amounts of $\mathrm{Sn}(\mathrm{II})$ required to reduce $\mathrm{Hg}(\mathrm{II})$ concentrations (typically $0.04 \mu \mathrm{M}$ ) at Outfall 200 could be added to UEFPC without exceeding the C11 discharge limit if dilution only within the waterway were assumed for all the added $\mathrm{Sn}$ (II). However, stoichiometric amounts of $\mathrm{Sn}(\mathrm{II})$, if required to reduce both $\mathrm{Hg}(\mathrm{II})$ and $\mathrm{TRC}$, will exceed $\mathrm{C} 11$ discharge limits if not fully consumed and removed from the drainage water. Thus, an alternate reducing agent for TRC (thiosulfate) was selected in 2008 to reduce the much larger concentration of TRC (typically $28 \mu \mathrm{M}$ or $2 \mathrm{mg} \mathrm{TRC} / \mathrm{L}$ ) in drainage water upstream of Outfall 200. It is this 5,600-fold excess of TRC over $\mathrm{Hg}$ (II) which necessitated the selection of the combined thiosulfate-Sn(II) reduction approach used in 2008. Importantly, thiosulfate is not particularly toxic to fish nor does it have a discharge limit at the $\mathrm{C} 11$ monitoring station. The pertinent equations for reductants, reactions, and solubility of Sn during in-situ treatments of drainage water are summarized below:

$$
\begin{aligned}
& \mathrm{Cl}_{2}(\mathrm{TRC})+2 \mathrm{e}^{-} \rightarrow 2 \mathrm{Cl}^{-} \text {(drainage water is } c a .28 \mu \mathrm{M} \text { TRC) [Eq. 1] } \\
& \mathrm{Hg}^{2+}+2 \mathrm{e}^{-} \rightarrow \mathrm{Hg}(0) \text { (drainage water is ca. } 0.005 \mu \mathrm{M} \mathrm{Hg}^{2+} \text { ) [Eq. 2] } \\
& \mathrm{Sn}^{2+}-2 \mathrm{e}^{-} \rightarrow \mathrm{Sn}^{4+} \quad \text { (diluted addition was ca. } 0.168 \mu \mathrm{M} \mathrm{Sn}^{2+} \text { ) [Eq. 3] } \\
& \mathrm{Sn}^{4+}+4 \mathrm{H}_{2} \mathrm{O} \rightarrow \mathrm{Sn}(\mathrm{OH})_{4} \downarrow+4 \mathrm{H}^{+} \\
& \mathrm{Sn}^{2+}+2 \mathrm{H}_{2} \mathrm{O} \rightarrow \mathrm{Sn}(\mathrm{OH})_{2} \downarrow+2 \mathrm{H}^{+} \\
& 2 \mathrm{~S}_{2} \mathrm{O}_{3}^{-2} \text { (thiosulfate) }-2 \mathrm{e}^{-} \rightarrow \mathrm{S}_{4} \mathrm{O}_{6}^{-2} \text { (diluted addition was ca. } 63 \mu \mathrm{M} \text { ) [Eq. 6] } \\
& 2 \mathrm{~S}_{2} \mathrm{O}_{3}^{-2} \text { (thiosulfate) }+\mathrm{Hg}^{2+} \rightarrow \mathrm{HgS}_{2} \mathrm{O}_{3} \text { (soluble complex) [Eq. 7] } \\
& \left.\mathrm{O}_{2} \text { (dissolved oxygen) }+2 \mathrm{e}^{-} \rightarrow 2 \mathrm{O}^{-} \quad \text { (drainage water is ca. } 230 \mu \mathrm{M}\right) \quad \text { [Eq. 8] }
\end{aligned}
$$


From these equations, it can be seen that during the 2008 in-situ tests (Southworth et al. 2009), although $\mathrm{Sn}^{2+}$ was added at about 34 times the stoichiometric requirement for $\mathrm{Hg}^{2+}$ reduction, that amount of added $\mathrm{Sn}^{2+}$ would reduce only about $1 \%$ of the TRC stoichiometric requirement. In addition, the in-situ neutralization of added acidified $\mathrm{Sn}^{2+}$ within the circum-neutral drainage water could limit solubility by precipitating $\mathrm{Sn}(\mathrm{OH})_{2}$ [Eq. 5] possibly limiting its reducing power. Once $\mathrm{Sn}^{2+}$ is oxidized by either $\mathrm{Hg}^{2+}$ or $\mathrm{Cl}_{2}, \mathrm{Sn}(\mathrm{IV})$ may react with water and precipitate as $\mathrm{Sn}(\mathrm{OH})_{4}$ (Eq. 4), which would restrict total $\mathrm{Sn}$ solubility and aqueous concentration at monitoring station $\mathrm{C} 11$. Thiosulfate $\left(\mathrm{S}_{2} \mathrm{O}_{3}{ }^{-2}\right)$ was added in 2008 at about a two-fold excess of the stoichiometric requirement for reduction of the TRC. Thiosulfate is generally considered to have insufficient power to reduce $\mathrm{Hg}^{2+}$ at any realistic in-situ concentration, although $\mathrm{Hg}(\mathrm{II})$ does form soluble complexes with thiosulfate [Eq. 7]. The complexation reaction was strong enough to mobilize surface bound $\mathrm{Hg}$, as observed in the 2008 study. The reduction potential of thiosulfate is also insufficient to reduce dissolved oxygen [Eq. 8].

In modifying or replacing these reagents to effect increased in-situ reduction of $\mathrm{Hg}$ (II) at Outfall 200R, it is necessary to ensure that any alternative or modified reagents, or their reaction byproducts, should not:

- be acutely toxic to aquatic life in UEFPC,

- perturb either dissolved oxygen or $\mathrm{pH}$ of stream water sufficiently to harm aquatic life indirectly,

- result in the discharge concentrations of any chemical species (e.g., $5 \mu \mathrm{g} / \mathrm{L}$ for $\mathrm{Sn}$ ) being exceeded at monitoring Station C11 approximately $200 \mathrm{~m}$ downstream of Outfall 200,

- contribute to mercury methylation downstream of the point of discharge.

In addition to these requirements, alternative or modified reagents should have the following preferred characteristics:

- Of minimal composition requiring fewer components and with little potential to react with each other at the concentrations in the stock solutions for metering into the drainage water.

- Be nonreactive with other chemical components of the drainage water.

- Have a wider concentration range for effectiveness than the specific stoichiometry imposed by either $\mathrm{Hg}(\mathrm{II})$ or TRC concentrations.

- Be less expensive than previously tried reagents.

If it is desired to retain the fundamental approach to use $\mathrm{Sn}^{2+}$ as the reductant for $\mathrm{Hg}(\mathrm{II})$, then two enhancements seemed possible: 1) an alternate stabilizing agent other than hydrochloric acid for the concentrated (1\%) $\mathrm{SnCl}_{2}$ stock solution for drainage water additions and 2) an alternate reducing agent other than thiosulfate for TRC reduction. As an alternate to $\mathrm{Sn}(\mathrm{II})$ as the reductant for $\mathrm{Hg}$ (II), sodium borohydride $\left(\mathrm{NaBH}_{4}\right)$ was investigated as it is a well known water-soluble reductant for many metal ions including $\mathrm{Hg}$ (II) and organic Hg (Margel and Hirsh 1984; Lanning 1993) as well as for TRC. The contribution of added chemicals, whether tin or other compounds, to stream methylation has not been investigated for the EFPC system. These processes and their effects need to be carefully studied before any large-scale applications of these compounds, including $\mathrm{SnCl}_{2}$, are pursued.

\subsection{EXPERIMENTAL METHODS}

\subsubsection{Laboratory Studies}

\subsubsection{Alternate reducing agents for total residual chlorine}

The effectiveness of various reducing agents on the reduction of total residual chlorine was measured using standard solutions of these reagents as iodometric titrants for standard additions of $\mathrm{Cl}_{2}$ to distilled 
water. All titrations used the same standard reagent addition chemicals (potassium iodide, acetate buffer, and starch indicator solution) and the titrametric methods as described in Hach Method 8209 [Total Chlorine, Iodometric Method] for the Hach Digital Titrator (Hach Company 2006). Commercial Chlorox ${ }^{\circledR}$ bleach was used to prepare a standard $\mathrm{Cl}_{2}$ solution of nominal $63 \mathrm{mg} / \mathrm{L}$ by preparing a 1:1000 dilution into distilled/deionized water. Five $\mathrm{mL}$ of this standard TRC solution was transferred to $100 \mathrm{~mL}$ of distilled water, followed by $2 \mathrm{~mL}$ of acetate buffer $(\mathrm{pH} 4.0)$, one KI powder pillow, and $1 \mathrm{~mL}$ of starch indicator solution, and titrated to the disappearance of the blue color. Exact measurement of this TRC standard was determined using the Hach Digital Titrator with standardized $0.02256 \mathrm{~N} \mathrm{Na}_{2} \mathrm{~S}_{2} \mathrm{O}_{3}$ (sodium thiosulfate) in the Hach titration cartridge. Another sodium thiosulfate solution at $0.01 \mathrm{~N}$ was prepared from reagent grade $\mathrm{Na}_{2} \mathrm{~S}_{2} \mathrm{O}_{3} \cdot 5 \mathrm{H}_{2} \mathrm{O}$ and placed in a 1-mL plastic syringe fitted with a 2-inch stainless-steel needle which was used to deliver titrant solutions manually to the $100-\mathrm{mL}$ volume of standard TRC solution with stirring in a $125-\mathrm{mL}$ flask. Solutions of the other reducing agents (sodium sulfite, hydroxylamine hydrochloride, hydrogen peroxide, ascorbic acid, sodium borohydride, and stannous chloride) were prepared from reagent grade chemicals at $0.01 \mathrm{~N}$ and were used to tritrate the same standard solution of TRC also using a 1-mL syringe graduated in $0.01-\mathrm{mL}$ intervals.

The effect of ascorbic acid on the stability of $\mathrm{SnCl}_{2}$ solutions was not measured quantitatively but rather qualitatively by observing turbidity in relatively concentrated $(0.01 \mathrm{~N})$ solutions of $\mathrm{SnCl}_{2}$ versus $0.005 \mathrm{~N}$ $\mathrm{SnCl}_{2}$ plus $0.005 \mathrm{~N}$ ascorbic acid. Stannous chloride solutions at almost any concentration above 100 $\mathrm{mg} / \mathrm{L}$ tend to form a cloudy suspended precipitate [presumably $\mathrm{Sn}(\mathrm{OH})_{4}$ and/or $\left.\mathrm{Sn}(\mathrm{OH})_{2}\right]$.

\subsubsection{Effects of reducing agents on dissolved oxygen and $\mathrm{pH}$ of stream water}

As a convenience, the stream water selected for testing effects of reducing agents on dissolved oxygen and $\mathrm{pH}$ was from the Northwest Tributary (NWT) of White Oak Creek within Bethel Valley on the west side of the main ORNL complex. This tributary water is very similar in gross chemical characteristics to that of UEFPC, being circum-neutral in $\mathrm{pH}(6-8)$ and having dissolved $\mathrm{O}_{2}$ in equilibrium with the atmosphere (i.e., 8-9 $\mathrm{mg} \mathrm{O}_{2} / \mathrm{L}$ ). Both stream waters were free of detectable TRC although several plant drainage pipes at Y-12, including Outfall 200, are actively dechlorinated before discharge into UEFPC. The NWT water exhibited no detectable TRC, a total hardness of $223 \mathrm{mg} \mathrm{CaCO} / \mathrm{L}$, an alkalinity of 134 $\mathrm{mg} \mathrm{CaCO} / \mathrm{L}$, and an electrical conductivity of $382 \mu \mathrm{mhos} / \mathrm{cm}$ when sampled on May 27, 2009. Alkalinity, hardness, and electrical conductivity of UEFPC water usually exhibit similar values.

Three reducing agents were selected for testing effects on $\mathrm{pH}$ and dissolved oxygen: $\mathrm{SnCl}_{2} \cdot 2 \mathrm{H}_{2} \mathrm{O}(\mathrm{FW}=$ $225.63 \mathrm{~g} / \mathrm{mole}), \mathrm{NaBH}_{4}(\mathrm{FW}=37.83 \mathrm{~g} / \mathrm{mole})$, and ascorbic acid $\left(\mathrm{C}_{6} \mathrm{H}_{8} \mathrm{O}_{6}, \mathrm{FW}=176.12 \mathrm{~g} / \mathrm{mole}\right)$. Initial concentrated solutions of approximately $100,000 \mathrm{mg} / \mathrm{L}$ were prepared in fresh NWT water for each reducing agent. Each solution was then diluted sequentially by factors of $10^{-1}, 10^{-2}, 10^{-3}, 10^{-4}$, and $10^{-5}$ with additional NWT water resulting in diluted solution of each reducing agent with nominal concentrations of 10,000,1,000,100,10, and $1 \mathrm{mg} / \mathrm{L}$. Approximately $90 \mathrm{~mL}$ of each diluted solution were placed in 100-mL capacity plastic disposable beakers. After approximately 1 hour, each solution was assayed for temperature and dissolved oxygen using a luminescence $\mathrm{O}_{2}$ sensor (LDO ${ }^{\circledR} \mathrm{HQ} 10$ Portable Dissolved Oxygen Meter, Hach Co.) by insertion until the reading had stabilized. Within 4 hours an initial $\mathrm{pH}$ was measured using a $\mathrm{pH}$ electrode calibrated with standard buffers at $\mathrm{pH}=4.00$, 7.00, and 10.00. Dissolved oxygen and temperature of each solution were measured repeatedly after 4, $20,27,43$, and 51 hours; $\mathrm{pH}$ of each solution was measured again after 24 and 44 hours.

\subsubsection{Reduction of $\mathrm{Hg}(\mathrm{II})$ by sodium borohydride $\left(\mathrm{NaBH}_{4}\right)$}

Testing the effects of $\mathrm{NaBH}_{4}$ and other potential reducing agents on reduction and volatilization of $\mathrm{Hg}$ from water and/or aqueous solutions was carried out using an RA-915+ Mercury Analyzer (Ohio Lumex 
Co., Inc., Twinsburg, Ohio) for cold-vapor atomic absorption method for $\mathrm{Hg}(0)$ USEPA Method 7470) evolved from a small glass vial containing a nominal $10-\mathrm{mL}$ water or aqueous solution undergoing a continuous bubbling/purging with air. By maintaining a regulated standardized flow rate (e.g., $1.5 \mathrm{~L} / \mathrm{min}$ ) of "zero" air through the sample and analyzer, the integrated analyzer signal over a typical 1-3 minutes produced a peak ( $\mathrm{mV}$-seconds) whose area was proportional to the total amount of $\mathrm{Hg}(0)$ flowing through the analyzer. A series of peak areas versus known additions of $\mathrm{HgCl}_{2}$, in separate pre-cleaned glass vials with a reducing agent, allowed collection of a standard curve for daily calibration of the instrument signal versus $\mathrm{Hg}(\mathrm{II})$ concentration; the standard reducing agent, when performing total $\mathrm{Hg}$ analyses on digested water samples, was a mixture of $1 \%$ sodium citrate, $0.4 \%$ stannous chloride, and $0.6 \%$ hydroxylamine hydrochloride. For investigating the effects of other reducing agents on spiked $\mathrm{Hg}(\mathrm{II}), 0.5 \mathrm{~mL}$ volume of a standard $50 \mu \mathrm{g} / \mathrm{L} \mathrm{Hg}$ (II) solution (as chloride) was added to $10 \mathrm{~mL}$ of water (distilled, de-ionized, tap, creek, solution, etc.) and the sample was analyzed to verify that no $\operatorname{Hg}(0)$ was formed or detectable and, thus, initially present in the sample [or carryover of reducing agent adsorbed on the immersed Teflontubing bubbler used to purge samples]. After completing this check for preexisting $\mathrm{Hg}(0)$ or reductant, an increment of $\mathrm{NaBH}_{4}$ solution (e.g., $25 \mu \mathrm{L}$ of $10 \mu \mathrm{M}$ solution in $0.1 \mathrm{M} \mathrm{NaOH}$ ) was added to the vial and the initial "peak" of evolved $\mathrm{Hg}(0)$ determined. Increments of $\mathrm{NaBH}_{4}$ solution were then repeatedly added to the solution until no significant further $\mathrm{Hg}(0)$ was evolved; this profile of $\mathrm{Hg}(0)$ evolved versus total $\mathrm{NaBH}_{4}$ added yielded a "titration" curve for $\mathrm{Hg}$ reduction in the sample. Three different spikereceiving waters [de-ionized, NWT creek, and tap (chlorinated)] were examined.

\subsubsection{Mercury(II) reduction testing of drainage waters at locations upstream of Outfall 200}

Samples of drainage water from locations upstream of Outfall 200 (200A6, Outfall 160, Outfall 150, and Outfall 163) were collected on July 14, 2009 to assess current Hg and TRC levels prior to detailed planning for the in-situ $\mathrm{Hg}$ (II) reduction testing in August. In addition to in-situ measurements of $\mathrm{pH}$, conductivity, temperature, and TRC (Table 4) during sample collection, measurements of total Hg (EPA Method 7470), $\mathrm{Hg}(\mathrm{II})$ by direct $\mathrm{SnCl}_{2}$ reduction with dechlorination, alkalinity, hardness, and TRC were determined in the laboratory by the methods described previously. The drainage water sample for Outfall 160 exhibited 2,198 $\mathrm{ng} \mathrm{Hg}(0) / \mathrm{L}$ [without adding any reductant, i.e., this fraction of its $\mathrm{Hg}$ was already present as dissolved gaseous $\mathrm{Hg}$ ]. The other drainage water reduction tests were carried out using various dilutions of a standard $\mathrm{SnCL}_{2} \cdot \mathrm{H}_{2} \mathrm{O}$ solution containing $1.186 \mathrm{~g} / \mathrm{L}$ and $23.725 \mathrm{~g} / \mathrm{L}$ ascorbic acid [20-fold weight excess, Pollardwater.com VITA-D-CHLOR ${ }^{\circledR}$, the actual batch used for field stabilization of the $\mathrm{Sn}$ (II) stock solution and up-flow declorination amendment]. A standard dechlorination solution of 30 $\mathrm{g} / \mathrm{L} \mathrm{Na}_{2} \mathrm{SO}_{3}$ (sodium sulfite) was prepared for dechlorination of the various drainage water immediately before addition of $\mathrm{SnCl}_{2}$ or $\mathrm{NaBH}_{4}$; based on TRC in each drainage sample, 80, 100, and $37 \mu \mathrm{L}$ of the sodium sulfite solution was added to $100 \mathrm{~mL}$ of drainage samples from 200A6, Outfall 150, and Outfall 163 , respectively.

\subsubsection{Toxicity testing for sodium borohydride and ascorbic acid}

Because the concentrations of $\mathrm{NaBH}_{4}, \mathrm{SnCl}_{2}$ and ascorbic acid, used for to effect reduction of both $\mathrm{Hg}$ (II) and TRC have little impact on stream water $\mathrm{pH}$ and dissolved oxygen, the effects on aquatic life should also in turn be insignificant. Nonetheless, the remote possibility that such low concentrations might be directly toxic to aquatic organisms was deemed worthy of assessment. A survey of the available scientific literature could not identify any reports of previous acute toxicity testing on aquatic organisms for either sodium borohydride or ascorbic acid. Acute toxicity testing of $\mathrm{SnCl}_{2}$ has been performed previously at ORNL and was reviewed prior to the 2008 in-situ test by adding $\mathrm{SnCl}_{2}$ and $\mathrm{Na}_{2} \mathrm{~S}_{2} \mathrm{O}_{3}$ to the UEFPC drainage. For comparison, $\mathrm{SnCl}_{2}$ has been found by others to have 48 hour- $\mathrm{LC}_{50}$ test values, 19.5-55 mg/L, for Daphnia magna (Howe and Watts 2005). Thus, to assure that no toxic effects might be imposed on UEFPC if either ascorbic acid or sodium borohydride were selected for this year's in-situ 
Table 4. Chemical characteristics of drainage water samples from accessible locations upstream of Outfall 200 in UEFPC sampled on July 14, 2009

\begin{tabular}{lccccc}
\hline \multirow{2}{*}{$\begin{array}{c}\text { Water } \\
\text { Characteristic }\end{array}$} & \multirow{2}{*}{ Units } & \multicolumn{4}{c}{ Location } \\
\cline { 3 - 6 } & & $\mathbf{2 0 0 A 6}$ & Outfall 150 & Outfall 160 & Outfall 163 \\
\hline Field temperature & ${ }^{\circ} \mathrm{C}$ & 25.6 & 29.9 & 23.1 & 22.2 \\
Field pH & $-\log \left[\mathrm{H}^{+}\right]$ & 7.9 & 8.00 & 7.85 & 7.93 \\
Field ORP & $\mathrm{mV}$ & 664 & 647 & 214 & 584 \\
Field conductivity & $\mu \mathrm{S} / \mathrm{cm}$ & 433 & 367 & 507 & 511 \\
Field TRC & $\mathrm{mg} / \mathrm{L}$ & 0.79 & 1.1 & 0 & 0.46 \\
Lab TRC & $\mathrm{mg} / \mathrm{L}$ & 1.10 & 1.55 & $<0.01$ & 0.52 \\
Lab hardness & $\mathrm{mg} \mathrm{CaCO} / \mathrm{L}$ & 188 & 165 & 225 & 228 \\
Lab alkalinity & $\mathrm{mg} \mathrm{CaCO}_{3} / \mathrm{L}$ & 117 & 108 & 136 & 139 \\
Total Hg & $\mathrm{ng} / \mathrm{L}$ & 1353 & 884 & 22470 & 657 \\
Hg(II) & $\mathrm{ng} / \mathrm{L}$ & 1386 & 1082 & $($ as Hg$(0)) 2198$ & 854 \\
\hline
\end{tabular}

$\mathrm{Hg}(\mathrm{II})$ reduction testing, toxicity tests for both ascorbic acid and sodium borohydride were initiated. Testing was carried out on both Ceriodaphnia dubia and fathead minnows (Pimephales promelas) to calculate 48 -hour lethal concentrations for $50 \%$ mortality $\left(\mathrm{LC}_{50}\right)$ for both species using standard methods (USEPA 2002a and 2002b).

\subsubsection{Field Studies}

Mercury reduction was conducted about $64 \mathrm{~m}$ upstream of the Outfall 200 (Fig. 1), where a grating above junction box 200A6 within the Y-12 NSC was utilized as a portal for introducing reductant to the mercury source water. This same location was used to add reductant in the 2008 study (Southworth et al. 2009). Ascorbic acid was added at a site $250 \mathrm{~m}$ upstream of that point, in Outfall 150 a short distance upstream from where it joins the main storm drain that exits at Outfall 200. Outfall 150 contributes about $1 / 4$ of the total flow at Outfall 200. It receives substantial inputs of single-pass cooling water, resulting in elevated temperature $\left(33^{\circ} \mathrm{C}\right)$ and residual chlorine $(1.5 \mathrm{ppm}$ TRC). Flow within the system from Outfall 150 to Outfall 200 was rapid, with an estimated travel time of less than 15 minutes for the $150 \mathrm{~m}$ length of pipe.

The ascorbic acid dechlorinating agent addition was initiated after an approximately one hour period of baseline monitoring, and continued for 1.0 hour with no addition of stannous chloride. The reductant, $\mathrm{SnCl}_{2}$ added 1 hour after the start of dechlorination, and continued for 2 hours. Both stannous chloride and ascorbic acid inputs were stopped at the same time after that and the baseline conditions returned. Water samples were collected at 10- to 15-minute intervals at Outfall 200 for analysis of DGM, post purge $\mathrm{Hg}$ (that remaining after purging the sample for DGM analysis) and total mercury, HgT. Samples were collected at downstream locations of $\mathrm{C} 11$, Outfall 113, C08, and C05 to assess the persistence of $\operatorname{Hg}(0)$ in the open stream water. Downstream profiles were collected prior to reagent addition and during the final 30 minutes of the chemical reductant addition. Those samples were analyzed for $\operatorname{Hg}(0)$ and $\mathrm{HgT}$.

The 2008 study indicated that TRC ranged up to $\sim 2 \mathrm{mg} / \mathrm{L}\left(0.028 \mathrm{mM} \mathrm{Cl}_{2}\right)$. Based on laboratory studies we used ascorbic acid to remove the TRC. The vendor recommendation of $2.5 \mathrm{mg}$ of ascorbic per $\mathrm{mg}$ of TRC was used to calculate the addition rate. We assumed a discharge of $200 \mathrm{~m}^{3} / \mathrm{h}$ at Outfall 200, and added ascorbic acid at a rate intended to provide $5 \mathrm{mg} / \mathrm{L}$ ascorbic acid at that point. Thus, $60 \mathrm{~L}$ of a 54 $\mathrm{g} / \mathrm{L}(0.31 \mathrm{M})$ solution of ascorbic acid in deionized water was added over a three hour period. Measured TRC concentration at the 200A6 (reductant addition) site was $0.5 \mathrm{mg} / \mathrm{L}$. TRC was higher at the Outfall 150 dechlorination point $(1.5 \mathrm{mg} / \mathrm{L})$, but flow at this outfall is only about $25 \%$ of that at $200 \mathrm{~A} 6$. During the experiment, the automatic in-stream TRC monitor detected the absence of TRC after ascorbic acid 
addition started and dechlorinating system at Outfall 200 stopped the bisulfite feed until the ascorbic acid addition was halted (the system is maintained by Y-12 NSC operation to dechlorinate the discharge with ammonium bisulfite under normal conditions). Stannous chloride was added at $200 \mathrm{~A} 6$ by injecting a solution of $6.7 \mathrm{~g} / \mathrm{L} \mathrm{SnCl}{ }_{2} * 2 \mathrm{H}_{2} \mathrm{O}(0.030 \mathrm{M})$ in $133 \mathrm{~g} / \mathrm{L}$ ascorbic acid $(0.76 \mathrm{M})$ at $1.05 \mathrm{~L} / \mathrm{h}$. Target concentration for Sn in Outfall 200 was the same as in the 2008 experiments, $20 \mu \mathrm{g} / \mathrm{L}(0.17 \mu \mathrm{M})$, which would be diluted to a nominal concentration of about $5 \mu \mathrm{g} / \mathrm{L} \mathrm{Sn}$ at the $\mathrm{C} 11$ monitoring station if the oxidized Sn(IV) remained in solution. Samples for Sn analysis were collected at Outfall 200 and monitoring Station C11.

The $\mathrm{SnCl}_{2}$ solution was prepared the day of the experiment in the laboratory and transported to the field site. The pre-weighed ascorbic acid was mixed with distilled $\mathrm{H}_{2} \mathrm{O}$ at the field site to the required concentration. A dedicated peristaltic pump was used for each solution; flow rates set in the lab were verified again in the field prior to beginning each experiment. Flexible tygon tubing from each pump was fed through fifteen feet of 0.75 -inch PVC well casing which was then inserted through the grate above 200A6 and placed $\sim 2$ feet into the mouth of the pipe leading out of the vault at 200A6 to Outfall 200 (Fig. 14). A similar system was employed at Outfall 150 for delivery of the ascorbic acid.

\subsubsection{Potential $\mathrm{Hg}(0)$ Evasion from Stream Following $\mathrm{SnCl}_{2}$ Addition}

The potential for $\operatorname{Hg}(0)$ evasion from water within and outside the storm drain system exists, although the 2008 study found little evidence that it reduced waterborne total $\mathrm{Hg}$ concentrations in the creek (Southworth et al. 2009). However, the high volatility of $\operatorname{Hg}(0)$ and shallow, turbulent flow of upper EFPC indicate that loss of $\operatorname{Hg}(0)$ should be significant. The mass transfer coefficient for evasion estimated in the 2008 study $(15 \mathrm{~cm} / \mathrm{h})$ predicts a volatilization rate coefficient of $0.9 \mathrm{~h}^{-1}$, or a half-life of 0.8 hours. Under such a scenario, more than $50 \%$ of the $\operatorname{Hg}(0)$ generated at Outfall 200 would be lost to natural volatilization before reaching Station 17. To evaluate the persistence of $\mathrm{Hg}$ in the water column, samples were collected at sites downstream from Outfall 200 before and after reduction of $\mathrm{Hg}$ (II) to $\mathrm{Hg}(0)$. Samples were analyzed for total mercury (HgT) and dissolved gaseous mercury (DGM).

\subsubsection{Chemical Analyses}

Samples for Sn analysis were filtered using $0.45 \mu \mathrm{m}$ filter in the field, preserved with $\mathrm{HNO}_{3} / \mathrm{HCl}$, and refrigerated until analysis by inductively coupled plasma-mass spectrometry (ICP-MS). Preliminary analyses of standards indicated that monitoring two stable $\mathrm{Sn}$ isotopes, ${ }^{118} \mathrm{Sn}$ and ${ }^{120} \mathrm{Sn}$, was useful as these provided slightly different sensitivities and consequently, detection limits. Dissolved gaseous mercury was determined by directly sparging $10 \mathrm{ml}$ water samples and immediate analysis with a Lumex 915+ Zeeman effect Atomic Absorption spectrometer. After sparging had removed all $\mathrm{Hg}(0)$, the samples were preserved with $\mathrm{BrCl} / \mathrm{HCl}$ and subsequently analyzed in the laboratory using the Lumex system following $\mathrm{SnCl}_{2}$ reduction (EPA 245.7). Total $\mathrm{Hg}$ samples were analyzed in the same way, with out purging of the samples.

\subsubsection{Re-oxidation of Reduced Hg(0) During Air Stripping}

Removal of $\operatorname{Hg}(0)$ from water by air stripping requires that the $\mathrm{Hg}(0)$ be purged much faster than it is reoxidized back to $\mathrm{Hg}(\mathrm{II})$ by dissolved oxygen in the purge water. In order to evaluate whether reoxidation was significant, a sample of water from Outfall 200 collected after most $\mathrm{HgT}$ had been converted to $\mathrm{Hg}(0)$ was purged with air at a relatively slow rate $(100 \mathrm{ml} / \mathrm{min}$ air purging $3.2 \mathrm{~L}$ of water). Dissolved gaseous $\mathrm{Hg}$ was measured in the water sample periodically over the course of the purge, and $\mathrm{HgT}$ was measured at the initial and final times. A substantial increase in the difference between $\mathrm{HgT}$ 


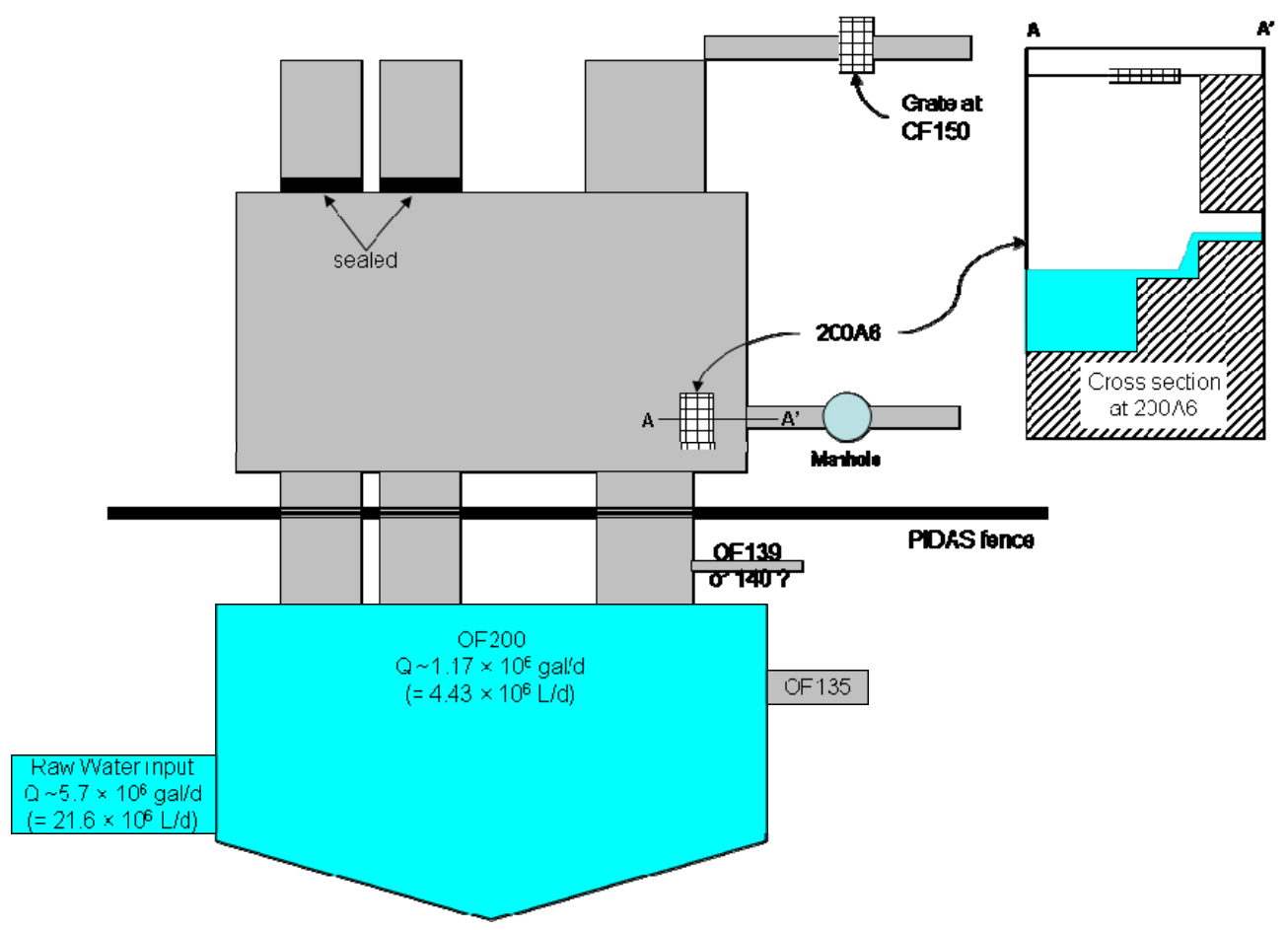

Fig. 14. Schematic plan view of the upper East Fork Poplar Creek (UEFPC) showing the storm drain system (in gray) at its juncture with the open creek (in blue). Ascorbic acid dechlorinating agent was added at Outfall 150 and the stannous chloride delivery system into the storm drain was located at 200A6.

and DGM concentrations over time during purging with air would be evidence that re-oxidation was important.

\subsubsection{Engineering Design Options}

A conceptual operation design has been developed based on the work reported here, as well as work completed in $1997^{1}$. The primary operation units include:

- removal of residual chlorine $\left(\mathrm{Cl}_{2}\right)$ from the water;

- reduction of ionic $\mathrm{Hg}(\mathrm{II})$ to elemental $\mathrm{Hg}(0)$ with stannous tin [Sn (II)]; and

- volatilization of elemental $\mathrm{Hg}(0)$ from the creek water using air stripping.

A fourth process operation adsorbs the $\operatorname{Hg}(0)$ in the air from the strippers on sulfur-impregnated activated carbon. The parameters listed in Table 5 serve as the basis for the conceptual design.

Three alternatives have been considered in the conceptual design. They are: 1) emplacing an engineered stripper in the stream and feeding it $773 \mathrm{gpm}$ of water by gravity flow from a dam downstream of Outfall 200 (Alternative One, In-Stream); 2) placing a stripper across the road south of the creek bank (Alternative Two, On-Shore) and pumping $773 \mathrm{gpm}$ of water from behind the dam downstream of Outfall 200; and 3) the installation of diffuser pipes in the N/S pipe upstream of Outfall 200 allowing the stripping of mercury in the N/S pipe, and collection of the mercury contaminated air in the N/S pipe for treatment. The descriptions of these alternatives are provided in Appendix B.

${ }^{1}$ Y-12 Central Engineering Services, Outfall 51 Air Stripping Feasibility Study for the Reduction of Mercury in Plant Effluent (RMPE) Project, AR-CM-920109-A002, January, 1997. 
Table 5. Conceptual design parameters

\begin{tabular}{ll}
\hline Water design flow rate & \\
\hline Outfall 200 & $700 \mathrm{gpm}^{*}$ \\
Outfall 135 & $73 \mathrm{gpm}$ \\
Sodium bisulfite dose rate & $10 \mathrm{mg} / \mathrm{mg}$ total residual chloride \\
$\mathrm{SnCl}_{2}$ dose rate & $33.7 \mathrm{~mole} \mathrm{Sn} / \mathrm{mole} \mathrm{Hg}$ \\
Ascorbic acid dose rate & $20 \mathrm{~mole} \mathrm{acid} / \mathrm{mole} \mathrm{Sn}$ \\
Stripper air-to-water ratio & 42.5 to $64 \mathrm{scf}$ air/ft ${ }^{3}$ water \\
\hline *gpm = gallons per minute. &
\end{tabular}

\subsection{RESULTS}

\subsubsection{Laboratory Studies}

\subsubsection{Alternate reducing agents for total residual chlorine}

The relative effectiveness of various potential dechlorination agents, as $0.01 \mathrm{~N}$ solutions, in titrating a standard addition of TRC ( 0.0088 milliequivalents of $\left.\mathrm{Cl}_{2}\right)$ of commercial Chlorox ${ }^{\circledR}$ bleach) to distilled water, is presented in Table 6 . The common and frequently used industrial dechlorinating agents, sodium thiosulfate and sodium sulfite, were tested for dechlorination only as benchmarks to compare less commonly used dechlorination agents in Table 6 . As expected both ascorbic acid and stannous chloride were equally efficient as dechlorinating agents. Both hydrogen peroxide and hydroxylamine were found to be ineffective as dechlorinating agents and were eliminated from further consideration in this study. As discussed in the introduction, $\mathrm{SnCl}_{2}$, both by itself and in combination with ascorbic acid, was as effective as thiosulfate and sulfite as a dechlorinating agent. In theory, this one reagent could effect both dechlorination and $\mathrm{Hg}(\mathrm{II})$ reduction in Outfall 200 drainage water in a single addition; however, the levels of Sn required to reduce TRC could potentially elevate total $\mathrm{Sn}$ concentrations in-stream water above the discharge limit for Sn of $5 \mu \mathrm{g} / \mathrm{L}$ at monitoring Station C11. The water-soluble reducing agent, sodium borohydride, was effective as a dechlorinating agent although it also directly reacts with water, decomposing to borate and hydrogen gas:

$$
\mathrm{NaBH}_{4}+2 \mathrm{H}_{2} \mathrm{O} \rightarrow \mathrm{NaBO}_{2}+4 \mathrm{H}_{2}
$$

Although a detailed kinetic study of the $\mathrm{NaBH}_{4}$ decomposition reaction [Eq. 9] was not performed, after four days of storage, $0.01 \mathrm{~N}$ sodium borohydride lost its effectiveness as a dechlorinating agent (Table 6). However, as reported in its chemical properties, sodium borohydride appeared to be stable in dilute base $(0.1 \mathrm{M} \mathrm{NaOH})$ as this solution retained its capacity for TRC reduction after four days (Table 6) whereas the same sodium borohydride in water alone did not.

This instability of $\mathrm{NaBH}_{4}$ in water is not necessarily a disadvantage for application as an in-situ dechlorinating agent; rapid decomposition to nonreactive and non-hazardous borate and hydrogen instream water would not impact discharge limits at any monitoring station in UEFPC. Borate (as the element boron) has no national primary or secondary drinking water standards (USEPA 2008) and only a few states (not Tennessee) have formulated boron drinking water standards which range from 0.6 to 1 $\mathrm{mg} / \mathrm{L}$. Imposing a maximum boron compliance limit of $0.6 \mathrm{mg} / \mathrm{L}$ for discharge at $\mathrm{C} 11$ allows 
Table 6. Iodometric titration of water containing a standard addition of total residual chlorine (TRC) with standard solutions of various potential reducing agents

\begin{tabular}{llc}
\hline \multicolumn{1}{c}{ Chemical formula } & \multicolumn{1}{c}{ Chemical name } & $\begin{array}{c}\mathbf{0 . 0 1 N} \text { solution required } \\
(\mathbf{m L})\end{array}$ \\
\hline $\mathrm{Na}_{2} \mathrm{~S}_{2} \mathrm{O}_{3}$ & Sodium thiosulfate & 1.06 \\
$\mathrm{Na}_{2} \mathrm{SO}_{3}$ & Sodium sulfite & 1.12 \\
$\mathrm{NH}_{2} \mathrm{OH} \cdot \mathrm{HCl}$ & $\begin{array}{l}\text { Hydroxylamine } \\
\text { hydrochloride }\end{array}$ & $>1$ very slow \\
$\mathrm{H}_{2} \mathrm{O}_{2}$ & Hydrogen peroxide & $>10$ no reaction \\
$\mathrm{C}_{6} \mathrm{H}_{8} \mathrm{O}_{6}$ & Ascorbic acid & 1.00 \\
$\mathrm{NaBH}_{4}-($ fresh $)$ & Sodium borohydride & 1.67 \\
$\mathrm{NaBH}_{4}-(4$ day old $)$ & Sodium borohydride & $>10$ \\
$\mathrm{NaBH}_{4} / 0.1 M \mathrm{NaOH}$ & Sodium borohydride & 1.83 \\
$\left(4-\mathrm{day}_{\text {old }}\right)$ & & \\
$\mathrm{SnCl}_{2}$ & Stannous chloride & 1.15 \\
$\mathrm{SnCl}_{2} \& \mathrm{C}_{6} \mathrm{H}_{8} \mathrm{O}_{6}$ & Stannous chloride \& & 1.02 \\
$(\mathrm{Each} 0.005 N)$ & ascorbic acid & \\
\hline
\end{tabular}

considerable flexibility for design of in-situ treatments compared to designs based on Sn(II) because of its negotiated discharge limit of $5 \mathrm{ng} \mathrm{Sn} / \mathrm{L}$ at monitoring station $\mathrm{C} 11$.

In the presence of equimolar or greater concentrations of ascorbic acid, the $\mathrm{Sn}$ (II) solutions remained clear and no visible precipitate $\left(\mathrm{Sn}(\mathrm{OH})_{4}\right.$ and/or $\left.\mathrm{Sn}(\mathrm{OH})_{2}\right)$ formed over several weeks of storage at ambient temperature in the laboratory. This suggests that ascorbic acid may prevent $\mathrm{Sn}$ (II) from oxidation and subsequent precipitation as $\mathrm{Sn}(\mathrm{OH})_{4}$. This is consistent with the general role of ascorbic acid as a water-soluble antioxidant. Notably, the $1 \%(\mathrm{w} / \mathrm{v})$ solution of $\mathrm{SnCl}_{2} \cdot 2 \mathrm{H}_{2} \mathrm{O}$, employed for this year's in-situ treatment of drainage water, was stabilized in ascorbic acid $(20 \% \mathrm{w} / \mathrm{v})$ rather than dilute hydrochloric acid as was used in 2008; the solution remained visibly clear of precipitation during its entire interval (about 4 hours) of use in the field.

\subsubsection{Effects of reducing agents on dissolved oxygen and $\mathrm{pH}$ of stream water}

The response of $\mathrm{O}_{2}$ in NWT stream water to the various additions of $\mathrm{SnCl}_{2} \cdot 2 \mathrm{H}_{2} \mathrm{O}$ is depicted in Fig. 15 . Only at amended concentrations above $100 \mathrm{mg} / \mathrm{L}$ was dissolved oxygen depleted in the stream water. Higher levels of amended Sn did significantly deplete dissolved oxygen in stream water (Appendix C). Although the stock solution of $\mathrm{SnCl}_{2} \cdot 2 \mathrm{H}_{2} \mathrm{O}$, used for addition to drainage water at 200A6 in both 2008 and 2009 studies, was $10,000 \mathrm{mg} / \mathrm{L}$ (or $5,260 \mathrm{mg} \mathrm{Sn} / \mathrm{L}$ ), drainage water mixing and additional water augmentation at Outfall 200 would dilute this Sn concentration to about $0.02 \mathrm{mg} / \mathrm{L}$ well below even the nominal $0.5 \mathrm{mg} \mathrm{Sn} / \mathrm{L}$ for the lowest amendment levels in Fig. 15. Thus, Sn additions to drainage water would not affect dissolved oxygen to levels restrictive to aquatic life. The effects of these same $\mathrm{SnCl}_{2} \cdot 2 \mathrm{H}_{2} \mathrm{O}$ amendment levels to stream water $\mathrm{pH}$ are depicted in Fig. 16. Again stream water $\mathrm{pH}$ was not affected by $\mathrm{SnCl}_{2} \cdot 2 \mathrm{H}_{2} \mathrm{O}$ amendment levels less than $100 \mathrm{mg} / \mathrm{L}$ although higher concentrations resulted in significant acidification of the stream water (Appendix C); the natural alkalinity of this stream water $(>1 \mathrm{mM})$ would be expected to buffer such $\mathrm{pH}$ changes at low $\mathrm{Sn}$ (II) concentrations although additions of $>1,000 \mathrm{mg} \mathrm{Sn} / \mathrm{L}$ represent titratable acidities $>4 \mathrm{mM}$ and, thus, lowered $\mathrm{pH}$ values. Again, the diluted concentrations of Sn used during in-situ stream water amendment would be insufficient to perturb $\mathrm{pH}$ at Outfall 200. 


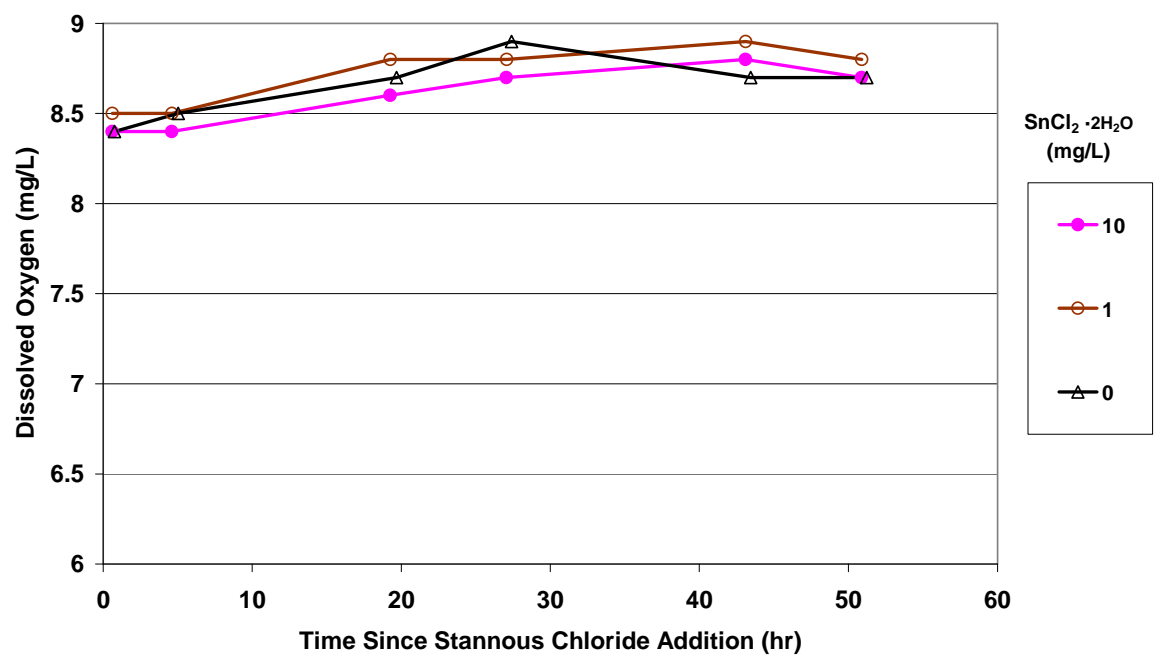

Fig. 15. Dissolved oxygen in Northwest Tributary stream water following additions of increasing concentrations of stannous chloride (see Appendix $\mathrm{C}$ for responses at greater amendment concentrations).

pH Versus Stannous Chloride Concentration In Stream Water

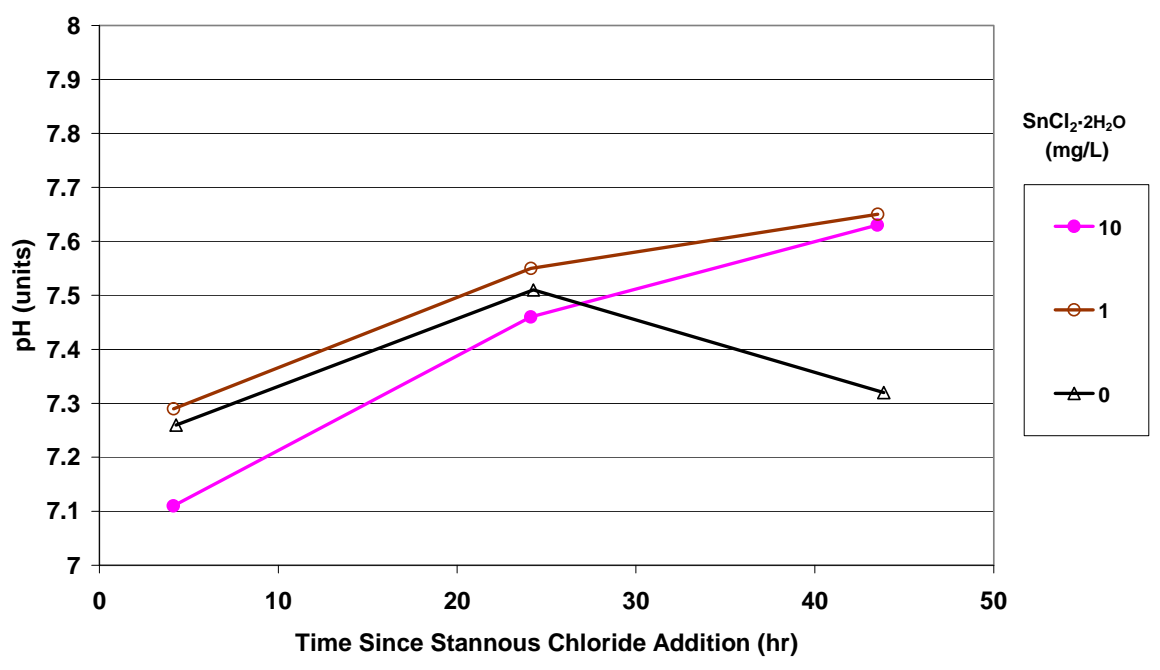

Fig. 16. Northwest Tributary stream water $\mathrm{pH}$ following additions of increasing concentrations of stannous chloride (see Appendix C for responses at greater amendment concentrations).

Ascorbic acid was also tested over the same wide range of concentrations for its effect on stream water dissolved oxygen (Fig. 17) and $\mathrm{pH}$ (Fig. 18). At $<10 \mathrm{mg} / \mathrm{L}$, ascorbic acid exhibited little effect on dissolved oxygen, while sustained depletion of $\mathrm{O}_{2}$ was observed only with concentration $>1,000 \mathrm{mg} / \mathrm{L}$ (Appendix C). Amendment with $100 \mathrm{mg} / \mathrm{L}$ initially depleted $\mathrm{O}_{2}$ by about $50 \%$ but $\mathrm{O}_{2}$ recovered after a day (Appendix C); the test beakers were left open to laboratory air to simulate gas exchange in an open channel streambed but without turbulence. Because the use of ascorbic acid in UEFPC is planned 


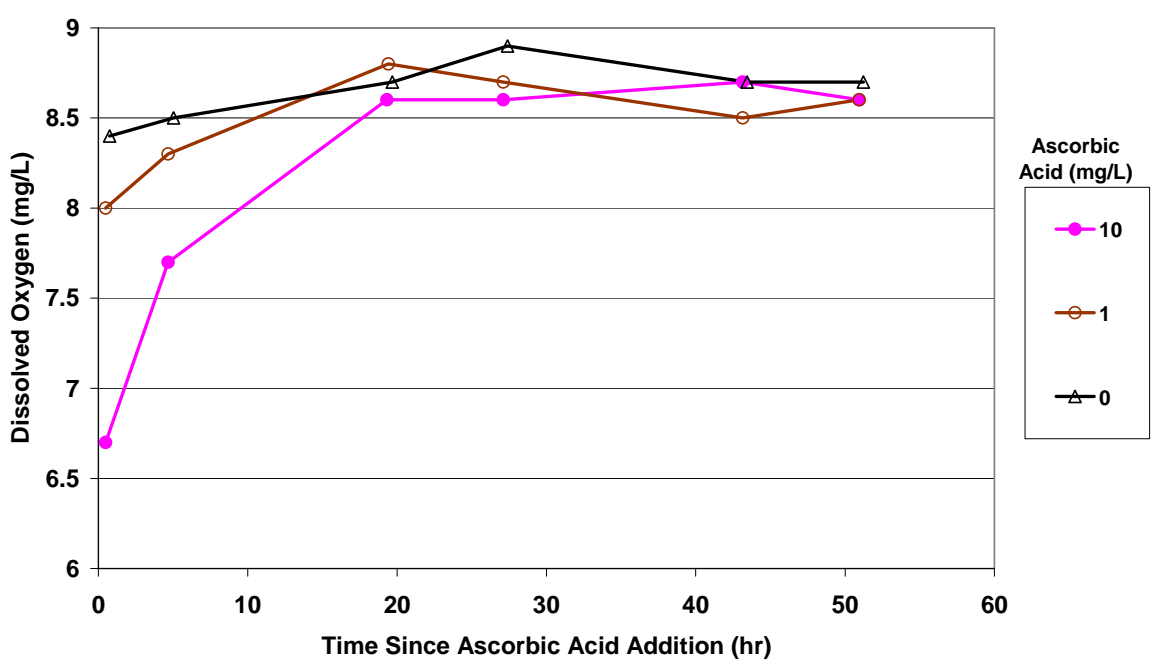

Fig. 17. Dissolved oxygen in Northwest Tributary stream water with increasing concentrations of ascorbic acid (see Appendix $\mathbf{C}$ for responses at greater amendment concentrations).

pH Versus Ascorbic Acid Concentration In Stream Water

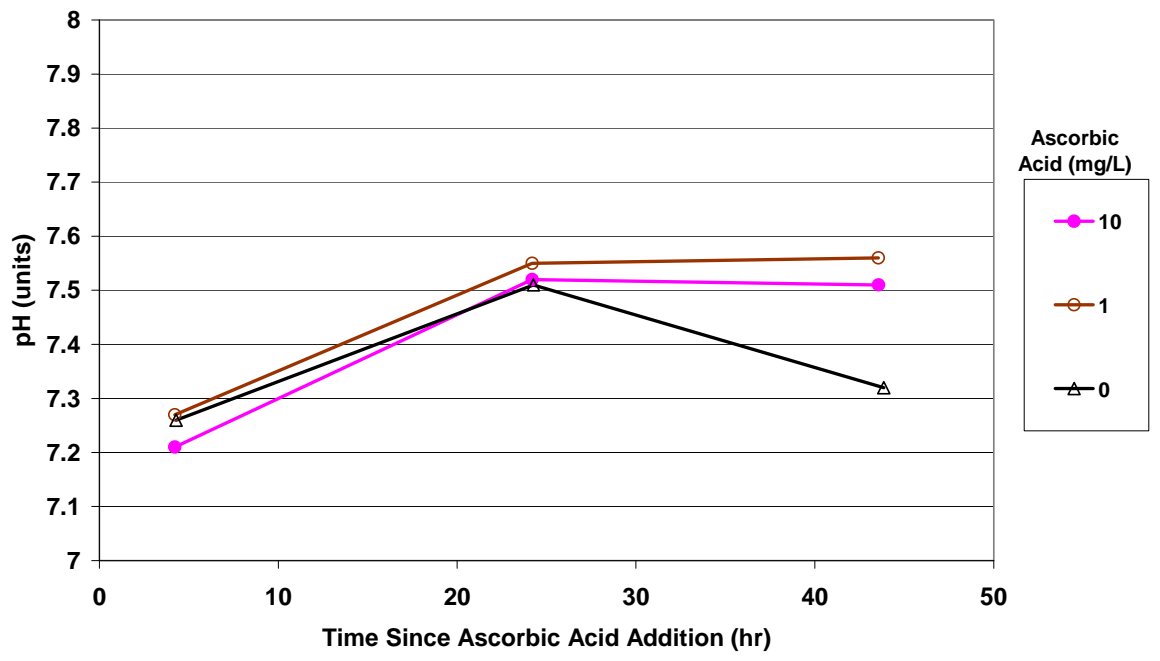

Fig. 18. Northwest Tributary stream water $\mathrm{pH}$ following additions of increasing concentrations of ascorbic acid (see Appendix $\mathrm{C}$ for responses at greater amendment concentrations).

primarily as a dechlorinating agent, concentrations in the range of $28 \mu \mathrm{M}$ would be required to reduce the concentration of TRC; $28 \mu \mathrm{M}$ ascorbic acid calculates to approximately $5 \mathrm{mg} / \mathrm{L}$ required in drainage water upstream of Outfall 200 for its full dechlorination. Because the $10 \mathrm{mg} / \mathrm{L}$ depicted in Fig. 17 exhibited only a slight initial depression of $\mathrm{O}_{2}$ (from 8.5 to $6.7 \mathrm{mg} \mathrm{O} / \mathrm{L}$ ), ascorbic acid concentrations of slightly less magnitude would not be anticipated to deplete $\mathrm{O}_{2}$ to levels deleterious to aquatic life. Ascorbic acid is a weak organic acid and, thus, at concentrations $<100 \mathrm{mg} / \mathrm{L}$ and (less than the anticipated 
applied concentrations at Outfall 200) did not significantly depress stream water pH. Ascorbic acid concentrations of $1,000 \mathrm{mg} / \mathrm{L}$ or greater exerted a significant depression in $\mathrm{pH}$ which could well be harmful to aquatic life in UEFPC (Appendix C).

Sodium borohydride is another potential drainage water amendment which, like stannous chloride, can both reduce $\mathrm{Hg}(\mathrm{II})$ and TRC. Because its decomposition products (borate and hydrogen) are not hazardous at low concentration, $\mathrm{NaBH}_{4}$ has the potential to be a simpler one-reagent treatment approach for in-situ $\mathrm{Hg}(\mathrm{II})$ reduction in the presence of TRC. Thus, $\mathrm{NaBH}_{4}$ was also tested for its potential effects on stream water $\mathrm{O}_{2}$ and $\mathrm{pH}$.

Concentrations of $\mathrm{NaBH}_{4}$ greater than $10 \mathrm{mg} / \mathrm{L}$ significantly and rapidly depleted $\mathrm{O}_{2}$ in the stream water (Fig. 19). Sodium borohydride is a reducing agent powerful enough to reduce $\mathrm{O}_{2}$; at an amended concentration of $10 \mathrm{mg} / \mathrm{L}, \mathrm{NaBH}_{4}$ calculates to $260 \mu \mathrm{M}$ compared to the stream water's dissolved $\mathrm{O}_{2}$ at $230 \mu \mathrm{M}$. However, $\mathrm{NaBH}_{4}$ is also depleted by production of $\mathrm{H}_{2}$ by reaction with stream water [Eq. 9]. Following initial depletion of $\mathrm{O}_{2}$ by $10 \mathrm{mg} \mathrm{NaBH}_{4} / \mathrm{L}$ addition, $\mathrm{O}_{2}$ recovered within a day (Fig. 19). Higher concentrations of $\mathrm{NaBH}_{4}$, i.e. $>100 \mathrm{mg} / \mathrm{L}$, resulted in near complete depletion of dissolved $\mathrm{O}_{2}$ (Appendix C). However, considering that the requirement for $\mathrm{NaBH}_{4}$ addition is dictated by the maximum TRC, i.e., about $28 \mu \mathrm{M}$, only slightly more than $1 \mathrm{mg} \mathrm{NaBH} / \mathrm{L}(26 \mu \mathrm{M})$ would be required for dechlorination. Thus, reduction of drainage water TRC could be effected by $\mathrm{NaBH}_{4}$ without a significant effect on dissolved $\mathrm{O}_{2}$.

Dissolved Oxygen Versus Sodium Borohydride Concentration In Stream Water

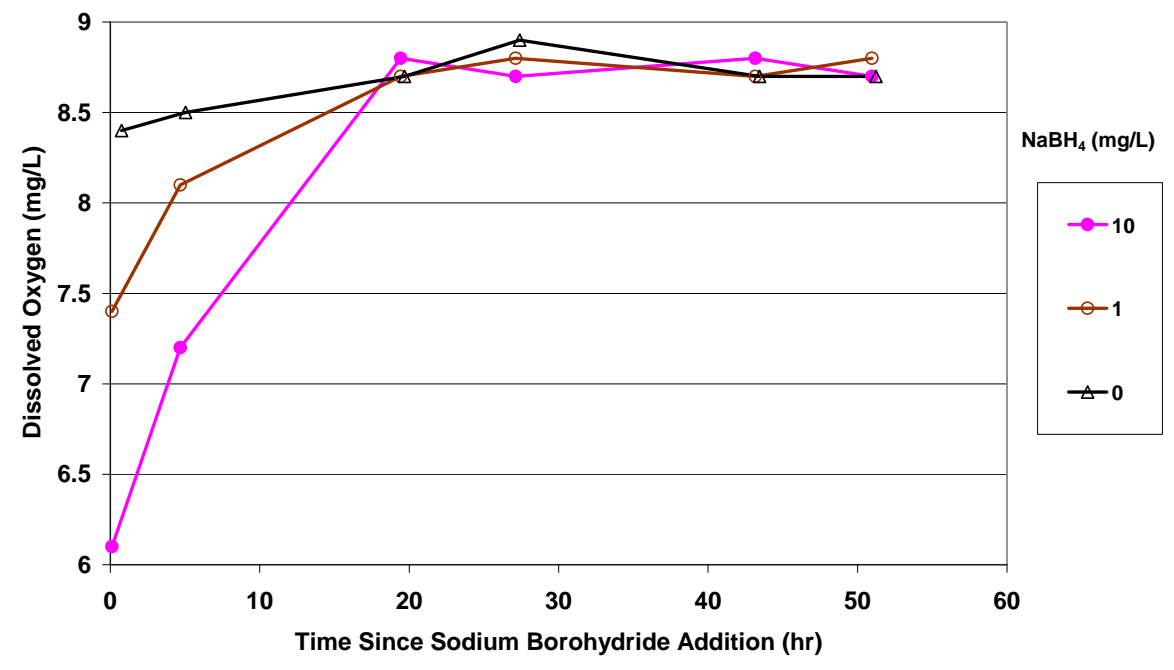

Fig. 19. Effect of sodium borohydride additions to Northwest Tributary stream water on dissolved oxygen (See Appendix $C$ for responses at greater amendment concentrations).

The kinetics of instability of $\mathrm{NaBH}_{4}$ in-stream water [Eq. 9] may be reflected in the recovery of dissolved $\mathrm{O}_{2}$ at the various amended concentrations (Fig. 19). Inspection of the data indicates a recovery "half-life" for $\mathrm{O}_{2}$ was about 1 day (using the $1,000 \mathrm{mg} / \mathrm{L}$ amendment plot - Appendix C). However, the consumption of $\mathrm{NaBH}_{4}$ in-stream water is likely much faster that $\mathrm{O}_{2}$ recovery because the $\mathrm{O}_{2}$ recovery in Fig. 19 was likely limited by $\mathrm{O}_{2}$ diffusion from air into the small beaker employed for these tests. As discussed previously, $\mathrm{NaBH}_{4}$ is stable in aqueous solution under alkaline conditions and stock solution of $\mathrm{NaBH}_{4}$ prepared in $0.1 M \mathrm{NaOH}$ did not loose TRC reducing power over several days unlike solutions in water alone. Thus, stock concentrated solutions of $\mathrm{NaBH}_{4}$ could be prepared in $0.1 \mathrm{M} \mathrm{NaOH}$ for metered 
addition and dilution into drainage water (similar to the approach used for stannous chloride additions at 200A6) relying on flow mixing to effect the dilution from $1,000 \mathrm{mg} \mathrm{NaBH} / \mathrm{L}$ and $0.1 \mathrm{M} \mathrm{NaOH}$ down to 1 $\mathrm{mg} \mathrm{NaBH} / \mathrm{L}$ and $0.1 \mathrm{mM} \mathrm{NaOH}$ in-stream water. Such diluted concentrations of $\mathrm{NaBH}_{4}$ and $\mathrm{NaOH}$ would perturb neither stream water dissolved oxygen nor $\mathrm{pH}$.

The effect of $\mathrm{NaBH}_{4}$ additions on stream water $\mathrm{pH}$ are depicted in Fig. 20. Unlike either ascorbic acid or $\mathrm{SnCl}_{2}$, which resulted in lowering the $\mathrm{pH}$ of stream water at the higher concentrations of amendment, $\mathrm{NaBH}_{4}$ at concentrations $>100 \mathrm{mg} / \mathrm{L}$ resulted in an elevation of stream water $\mathrm{pH}$ from near neutral to greater than 11 at the highest concentration (Appendix C). However, because the required concentration of $\mathrm{NaBH}_{4}$ to effect reduction of both TRC and $\mathrm{Hg}$ (II) is only $28 \mu \mathrm{M}$, only amended concentrations of $<10$ $\mathrm{mg} / \mathrm{L} \mathrm{NaBH}_{4}$ would be necessary; these would have no significant effect on stream water $\mathrm{pH}$ (Fig. 20). Small addition of acids (ascorbic acid or $\left.\mathrm{SnCl}_{2}\right)$ or bases $\left(\mathrm{NaBH}_{4}\right.$ and $\left.\mathrm{NaOH}\right)$ to stream water at $\mu \mathrm{M}$ concentrations are all strongly buffered by the stream water's naturally comparatively large alkalinity (2$3 \mathrm{mM}$ as $\mathrm{CaCO}_{3}$ ).

pH Versus Sodium Borohydride Concentration In Stream Water

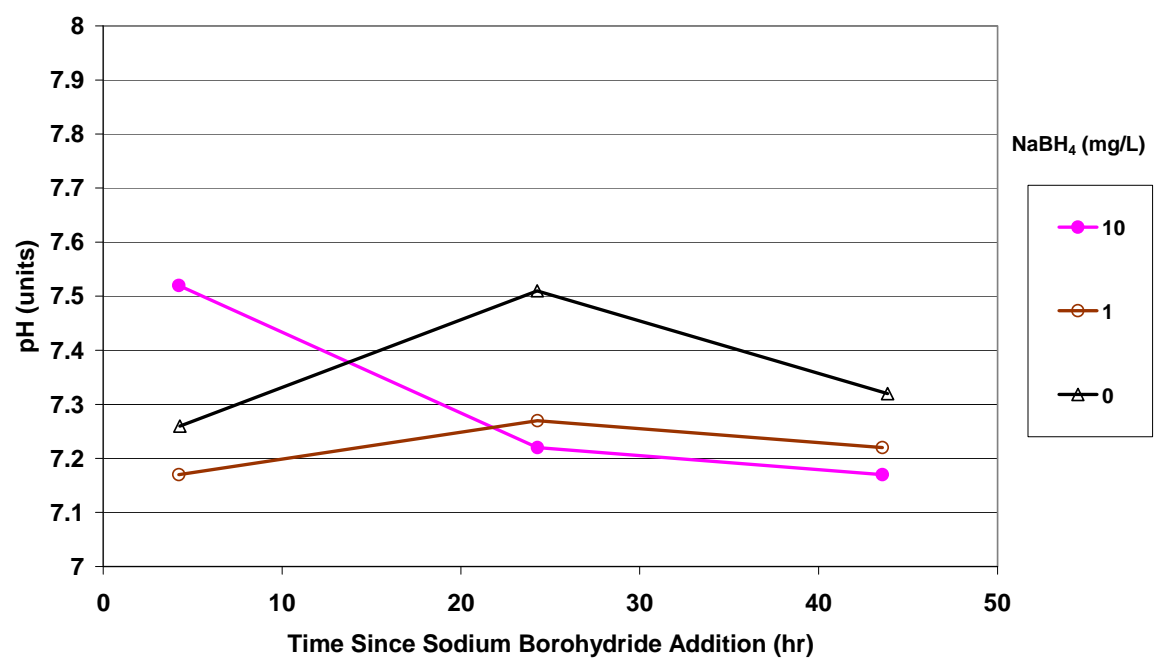

Fig. 20. The effect of sodium borohydride amendments on the pH of Northwest Tributary stream water (see Appendix $\mathrm{C}$ for responses at greater amendment concentrations).

\subsubsection{Reduction of $\mathrm{Hg}(\mathrm{II})$ by sodium borohydride $\left(\mathrm{NABH}_{4}\right)$}

The results of $\mathrm{NaBH}_{4}$ additions on the reductions of $\mathrm{Hg}$ (II) in distilled water, tapwater, and NWT stream water are presented in Fig. 21. However, the interpretation of the effectiveness of $\mathrm{NaBH}_{4}$ in reducing $\mathrm{Hg}(\mathrm{II})$ to $\mathrm{Hg}(0)$ on a relative molar basis requires some elaboration. The distilled water represents a scenario with minimal interference with the $\mathrm{NaBH}_{4}-\mathrm{Hg}(\mathrm{II})$ reaction except for inherent reactivity of $\mathrm{NaBH}_{4}$ with water [Eq. 9] or with dissolved $\mathrm{O}_{2}$. Reduction of the spiked 25 pmoles of $\mathrm{Hg}$ (II) required approximately 300 pmoles of added $\mathrm{NaBH}_{4}$ indicating that a 12-fold molar excess of $\mathrm{NaBH}_{4}$ was required for complete reduction of the spiked $\mathrm{Hg}$ (II); this large molar excess amount of $\mathrm{NaBH}_{4}$ (275 pmoles) would be sufficient to reduce only a trace of the initial dissolved $\mathrm{O}_{2}$ in the $10-\mathrm{mL}$ distilled water sample which amounts to $2.3 \times 10^{6}$ pmoles of $\mathrm{O}_{2}$. [All three waters contained $\mathrm{O}_{2}$ at near air saturation, i.e., $2.3 \times$ $10^{6}$ pmoles of $\mathrm{O}_{2} / 10 \mathrm{~mL}$.] However, the initial dissolved $\mathrm{O}_{2}$ and the continued purging of samples with air during titration could explain the low yield of $\mathrm{Hg}(0)$ per pmole of $\mathrm{NaBH}_{4}$ simply as an alternate but slower reaction for consumption of added $\mathrm{NaBH}_{4}$. When NWT creek water was used for $\mathrm{Hg}$ (II) spiking, 


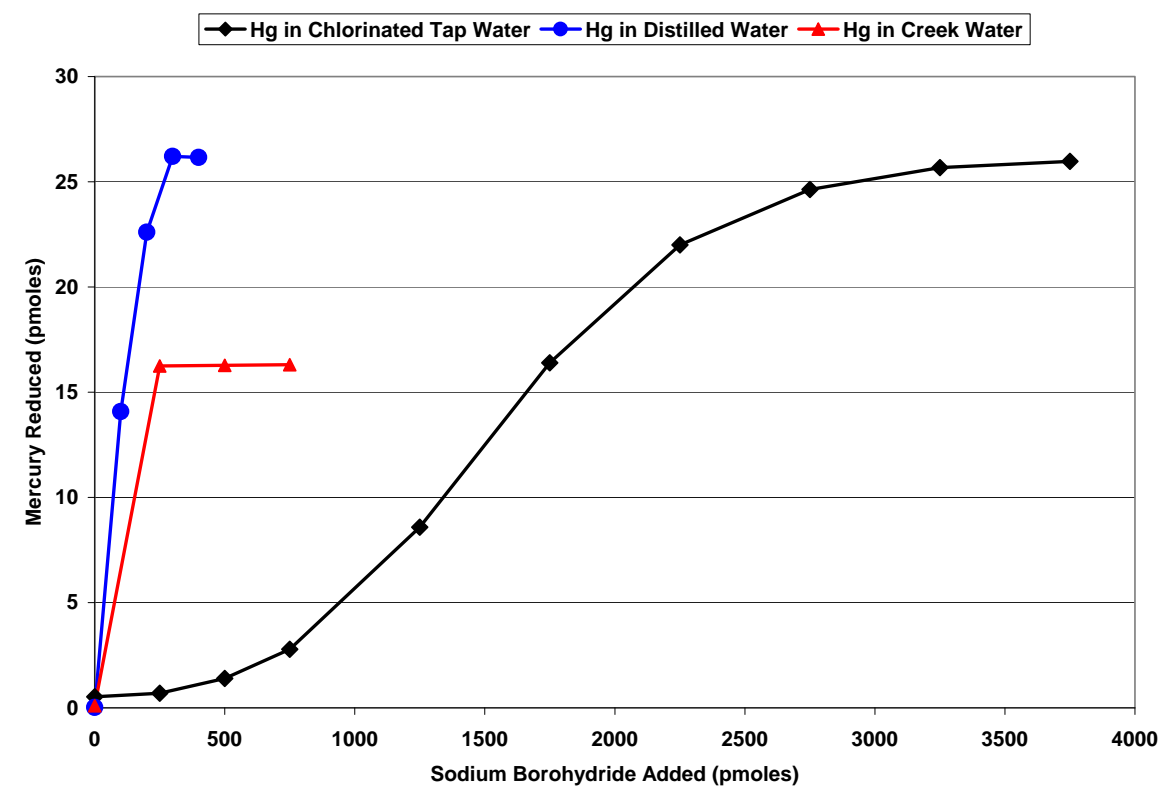

Fig. 21. Reduction of 25 pmoles of $\mathrm{Hg}(\mathrm{II})$ spiked into distilled water, creek (NWT) water, and tap water (containing 318 nmoles $\mathrm{Cl}_{2}$ ) by sodium borohydride.

not only was a similar yield of $\mathrm{Hg}(0)$ per pmole of $\mathrm{NaBH}_{4}$ observed but also an overall lower total yield of $\mathrm{Hg}(0)$ ( 17 out of the 25 pmoles added) even when $\mathrm{NaBH}_{4}$ incremental additions were continued; complexation of the $\mathrm{Hg}(\mathrm{II})$ by natural organic matter (NOM) or other dissolved components in the creek water may have contributed to this lower overall yield similar to the effect hypothesized to shield complexed-Hg(II) from reduction by $\mathrm{Sn}(\mathrm{II})$ within UEFPC creek water.

When tap water with a dissolved TRC of $2.25 \mathrm{mg} \mathrm{Cl} / \mathrm{L}$ was employed for spiking with $\mathrm{Hg}(\mathrm{II})$, much larger amounts of $\mathrm{NaBH}_{4}$ (about 3,800 pmoles) were required to complete the reduction of the added 25 pmoles of $\mathrm{Hg}(\mathrm{II})$. The tap water used for this testing was only slightly more dilute in alkalinity and hardness (hardness $=154 \mathrm{mg} \mathrm{CaCO} / \mathrm{L}$, and alkalinity $=96 \mathrm{mg} \mathrm{CaCO}_{3} / \mathrm{L}$ ) than the NWT creek water (hardness $=223 \mathrm{mg} \mathrm{CaCO}_{3} / \mathrm{L}$, and alkalinity $=134 \mathrm{mg} \mathrm{CaCO}_{3} / \mathrm{L}$ ). Obviously, TRC is the major difference between the tap water and the NWT creek water; TRC is known to interfere with $\mathrm{Hg}$ (II) reduction by $\mathrm{SnCl}_{2}$ as discussed in last year's report. However, the amount of TRC in the 10-mL volume of tap water calculates to 318,000 pmoles or more than 100 times the 3,000 pmoles of $\mathrm{NaBH}_{4}$ required to complete $\mathrm{Hg}$ (II) reduction (Fig. 21). Thus, the total added $\mathrm{NaBH}_{4}(3,800$ pmoles) was about two ordersof-magnitude too small to reduce the TRC in the sample. What appears to be a delay in the onset of $\mathrm{Hg}$ (II) release during the initial additions of $\mathrm{NaBH}_{4}$ could have resulted from the in-situ dechlorination of the sample during its continuing purging with air during the 3-5 minute intervals between each incremental addition of $\mathrm{NaBH}_{4}$ required to accumulate the "peak" of $\mathrm{Hg}(0)$ released after each addition. Aeration is a known water dechlorination treatment method; however, it is quite slow and inefficient and, thus, infrequently used for large-scale treatment systems due to the very high solubility of $\mathrm{Cl}_{2}$ in water compared to purging gases (both $\mathrm{N}_{2}$ and $\mathrm{O}_{2}$ ). As discussed in the $\mathrm{NaBH}_{4}$ dechlorination testing section, treating all the TRC in Outfall 200 drainage water would require $28 \mu \mathrm{M} \mathrm{NaBH}$ amendment (about 1 $\mathrm{mg} / \mathrm{L}$ ) which is well below the threshold for observable effects on $\mathrm{O}_{2}, \mathrm{pH}$, or acute aquatic toxicity. The $28 \mu \mathrm{M}$ concentration of $\mathrm{NaBH}_{4}$ would be about 4,000 times the $7 \mathrm{nM}$ concentration of $\mathrm{Hg}$ (II) in Outfall 200 drainage water and more than sufficient to reduce all of its $\mathrm{Hg}(\mathrm{II})$. Thus, $\mathrm{NaBH}_{4}$ represents an excellent candidate for future in-situ $\mathrm{Hg}$ (II) reduction within UEFPC. 


\subsubsection{Mercury(II) reduction testing of drainage waters at locations upstream of Outfall 200}

The results of the $\mathrm{Hg}(\mathrm{II})$ reduction tests for chlorinated drainage waters upstream of Outfall 200 are summarized in Fig. 22. First, reduction of $\mathrm{Hg}$ (II) by $\mathrm{Sn}$ (II) exhibited initial stoichiometric relationship (the 1:1 line in Fig. 22) in de-ionized water or in an ascorbic acid stabilized solution; however, as $\mathrm{Hg}$ (II) level increased to $>2 \mathrm{nM}$, a 10 -fold of $\mathrm{Sn}$ (II) above the stoichiometric ratio to $\mathrm{Hg}$ (II) were required to complete $\mathrm{Hg}(\mathrm{II})$ reduction. Ultimately, $\mathrm{Sn}$ (II) was able to reduce $\mathrm{Hg}$ (II) in all three drainage water samples at concentrations given in Table 4. The dashed segments of each drainage water reduction series in Fig. 22 represents the final $\mathrm{Hg}(0)$ released from each sample by the particular reductant but at $>>60$ nM. Notably, $\mathrm{NaBH}_{4}$ was able to reduce the same amount of $\mathrm{Hg}$ from the 200A6 drainage water as $\mathrm{SnCl}_{2}$; however, more than a 100-fold stoichiometric excess of $\mathrm{NaBH}_{4}$ was required for equivalent reduction of $\mathrm{Hg}$ compared to ascorbic acid stabilized $\mathrm{SnCl}_{2}$. All drainage water initially required between a 5- and 10-fold stoichiometric excess of $\mathrm{Sn}(\mathrm{II})$ to reduce $\mathrm{Hg}(\mathrm{II})$ in chlorinated drainage water samples from all three locations (200A6, OF 150, and OF 163); when $\mathrm{Hg}$ reduction was complete in these samples, an approximate 10-fold stoichiometric excess of $\mathrm{Sn}(\mathrm{II})$ was required. The observed greater stoichiometric efficiency of $\mathrm{Sn}(\mathrm{II})$ compared to $\mathrm{NaBH}_{4}$ was the primary factor in the selection of $\mathrm{SnCl}_{2}$ as the reductant for use during this year's in-situ Hg-reduction field testing. Although drainage waters were not tested for $\mathrm{Hg}$-reduction efficiency with $\mathrm{SnCl}_{2}$ alone versus $\mathrm{SnCl}_{2}$ stabilized with ascorbic acid for these drainage waters, the equivalencies of $\mathrm{SnCl}_{2}$-induced $\mathrm{Hg}(\mathrm{II})$ reduction with the total $\mathrm{Hg}$ in these samples, was the dominant factor in selecting ascorbic acid as the stabilizing agent for Sn(II) during field testing. Additionally, because ascorbic acid was also selected as the dechlorination agent for upstream amendment (see dechlorination agent testing section) at Outfall 150, its use with $\mathrm{SnCl}_{2}$ at Outfall 200A6 would not add any different chemical amendments to UEFPC.

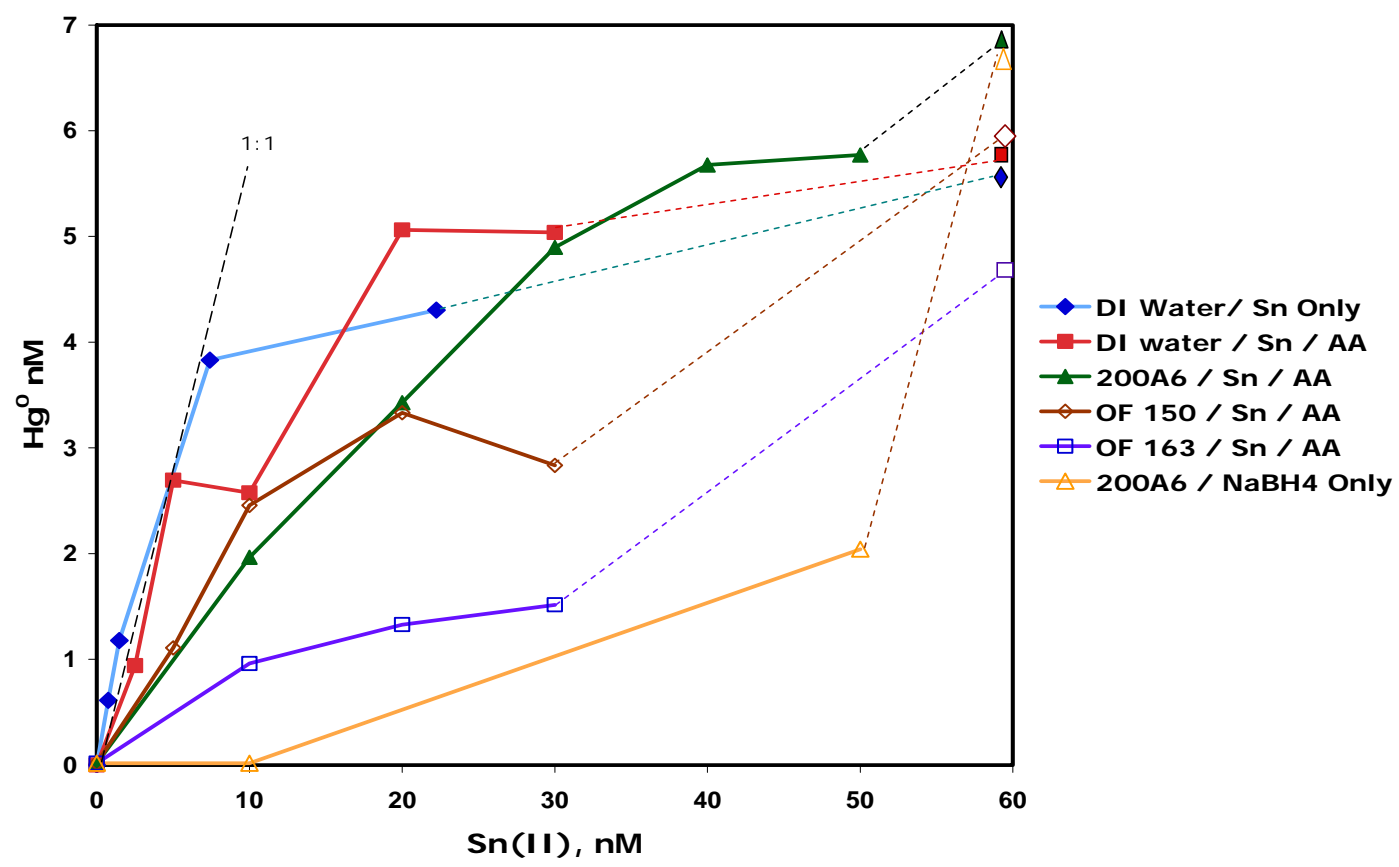

Fig. 22. Incremental additions of $\mathrm{NaBH}_{4}$ or $\mathrm{SnCl}_{2}$ standard solutions, stabilized with ascorbic acid (AA), to de-ionized (DI) water and three drainage waters flowing into UEFPC. 


\subsubsection{Toxicity testing for sodium borohydride and ascorbic acid}

Results for the acute toxicity tests on Ceriodaphnia dubia and fathead minnows are summarized in Table 7. For comparison, $\mathrm{Sn}(\mathrm{II}) \mathrm{Cl}_{2}$ has been found by others to have similar 48 hour- $\mathrm{LC}_{50}$ test values, 19.5-55 mg/L, for Daphnia magna (Howe and Watts 2005).

Table 7. Summary of sodium borohydride and ascorbic acid 48-hour acute toxicity tests conducted June 1619, 2009 (testing by ORNL Environmental Toxicology Laboratory, Mark Greeley, contact)

\begin{tabular}{lllc}
\hline \multicolumn{1}{c}{ Chemical } & \multicolumn{1}{c}{$\begin{array}{c}\text { Test } \\
\text { endpoint }\end{array}$} & \multicolumn{1}{c}{$\begin{array}{c}\text { Test } \\
\text { organism }\end{array}$} & $\begin{array}{c}\text { 48-hr } \mathbf{L C}_{\mathbf{5 0}} \\
\text { (mg/L) }\end{array}$ \\
\hline Sodium borohydride & Mortality & Ceriodaphnia dubia & 95.0 \\
Sodium borohydride & Mortality & Fathead minnow & 118.5 \\
Ascorbic acid & Mortality & Ceriodaphnia dubia & 45.7 \\
Ascorbic acid & Mortality & Fathead minnow & 329.9 \\
\hline
\end{tabular}

Full dechlorination, including reduction of $\mathrm{Hg}(\mathrm{II})$ in the case of $\mathrm{NaBH}_{4}$, of Outfall 200 drainage water would require about $5 \mathrm{mg}$ ascorbic acid/L or about $2 \mathrm{mg} \mathrm{NaBH} / \mathrm{L}$. The toxicity concentrations in Table 7 are at least an order-of-magnitude above these required concentration amendments and, thus, offer considerable safety from resulting acute toxic effects on aquatic life in UEFPC. An additional margin of safety for protection of aquatic life from toxic effects of possible inputs of these chemicals is their consumption within the drainage water upstream of Outfall 200 by the water's TRC and continued dilution of any residuals downstream by natural processes and the limited time of travel within UEFPC relative to this 48-hour exposure for laboratory tests. Of course, ascorbic acid, in addition to its function as a reducing agent, represents an input of biodegradable carbon into UEFPC water; if selected for in-situ dechlorination, the anticipated concentrations of ascorbic acid or its reduced form (dehydroascorbic acid) at Outfall 200 would be approximately $5 \mathrm{mg} / \mathrm{L}$ or $28 \mu \mathrm{M}$ which concentration (even if not consumed) is well below thresholds for acute biological oxygen demand where stream water dissolved $\mathrm{O}_{2}$ would be present at an order-of-magnitude greater concentration (i.e., typically $233 \mu \mathrm{M}$ ).

\subsubsection{Field Studies}

\subsubsection{Conversion of total mercury to dissolved gaseous $\mathrm{Hg}$}

Total mercury (HgT) concentration in the Outfall 200 discharge was relatively constant at $1378 \pm 16 \mathrm{ng} / \mathrm{L}$ (mean $\pm \mathrm{SD}$ ) for the 90 minute baseline period prior to initiation of dechlorination with ascorbic acid at Outfall 150 (Fig. 23). Within 20 minutes of the start of ascorbic acid addition, reduced $\mathrm{Hg}$ (dissolved gaseous $\mathrm{Hg}$ ) was observed in the Outfall 200 discharge, and total $\mathrm{Hg}$ in the discharge decreased (Fig. 23). When the ascorbic acid input was briefly interrupted ( 11:00), DGM in Outfall 200 returned to undetectable levels and total $\mathrm{Hg}$ increased. When ascorbic acid was restarted, DGM and $\mathrm{HgT}$ returned to their previous levels. The complete data sets for this study are included in the appendix of the report (Appendix D). For simplicity, the average values are shown in figures presented in this section unless shown in the figure specifically.

The laboratory analyses of $\mathrm{HgT}$ and post-purge $\mathrm{Hg}$ are likely to be more consistent than field measurements of DGM, hence the reduction efficiency estimates based on ratios of post-purge $\mathrm{Hg}$ to $\mathrm{HgT}$ are deemed more accurate. Mean concentrations of all three mercury measurements for the baseline, dechlorination, and reduction phases of the experiment are shown in Table 8. The fraction of total $\mathrm{Hg}$ in Outfall 200 that was converted to DGM by ascorbic acid alone was $21 \%$. However, if the decrease in $\mathrm{HgT}$ at Outfall 200 observed during the dechlorination phase is assumed to be caused by loss of DGM to the pipe headspace upstream from Outfall 200, the fraction converted to DGM increases to $31 \%$. The 


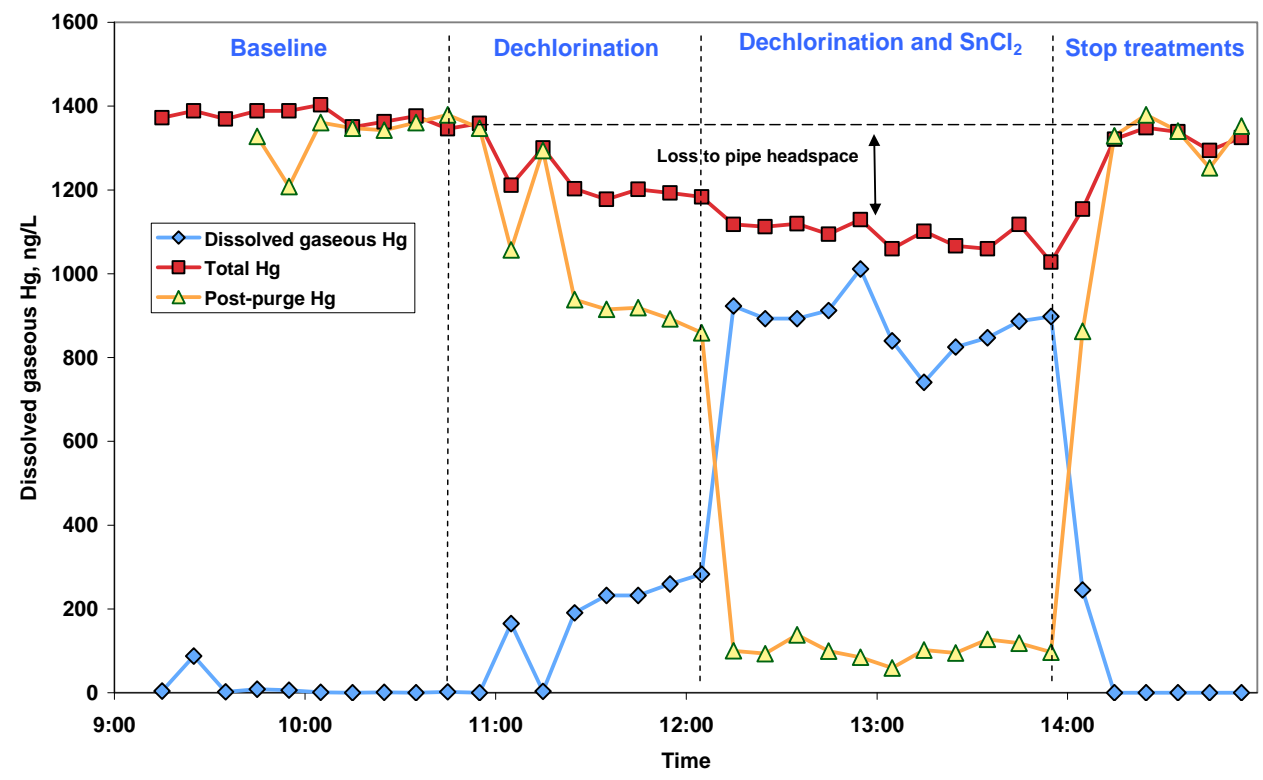

Fig. 23. Concentrations of total $\mathrm{Hg}$, dissolved gaseous $\mathrm{Hg}$ and post-purge $\mathrm{Hg}$ in Outfall 200 water versus time during the September 2009 in-stream Hg reduction experiment in East Fork Poplar Creek.

conversion of $\mathrm{Hg}(\mathrm{II})$ to $\mathrm{Hg}(0)$ by ascorbic acid was an unexpected result. Laboratory tests indicated that ascorbic acid was not effective at reducing $\mathrm{Hg}(\mathrm{II})$ to $\mathrm{Hg}(0)$ in oxygenated water. Results of this experiment suggest that ascorbic acid alone may have reduced most of the $\mathrm{Hg}$ in Outfall 150 to $\mathrm{Hg}(0)$.

Table 8. Results from the September 2009 in-steam Hg reduction experiment in East Fork Poplar Creek. Mean concentrations ( \pm Standard deviation) of total $\mathrm{Hg}$, dissolved gaseous $\mathrm{Hg}$, and post-purge $\mathrm{Hg}$ in Outfall 200 water during baseline, dechlorination, and reduction phases

\begin{tabular}{lccc}
\hline \multicolumn{1}{c}{ Treatment } & $\begin{array}{c}\text { Total Hg } \\
\text { (HgT) ng/L }\end{array}$ & $\begin{array}{c}\text { Dissolved gaseous } \\
\text { Hg ng/L }\end{array}$ & $\begin{array}{c}\text { Post-purge Hg } \\
\text { ng/L }\end{array}$ \\
\hline Baseline & $1359 \pm 31$ & $<5$ & $1327 \pm 51$ \\
Dechlorination & $1198 \pm 13$ & $216 \pm 38$ & $944 \pm 65$ \\
Reduction & $1091 \pm 33$ & $879 \pm 68$ & $101 \pm 21$ \\
\hline
\end{tabular}

When stannous chloride addition was started at site 200A6, dissolved gaseous Hg concentration increased sharply, accompanied by a corresponding decrease in $\mathrm{Hg}$ remaining in purged samples (Fig. 23). Dissolved gaseous $\mathrm{Hg}$ increased to $>900 \mathrm{ng} / \mathrm{L}$, and the $\mathrm{Hg}$ remaining after samples were purged decreased to less than $100 \mathrm{ng} / \mathrm{L}$. Conversion of $\mathrm{Hg}(\mathrm{II})$ to $\mathrm{Hg}(0)$ was high, ranging from $91 \%$ of total $\mathrm{Hg}$ in Outfall 200 samples to $93 \%$ when computed using baseline $\mathrm{HgT}$ concentration as the reference (assumes headspace loss as in the previous comparison). The apparent loss of $\mathrm{Hg}$ to pipe headspace increased only slightly after $\mathrm{SnCl}_{2}$ treatment started (Fig. 23), suggesting that most headspace loss of $\mathrm{Hg}$ was occurring in the upstream section of the storm drain system (between Outfall 150 and 200A6).

The apparent loss of $\mathrm{Hg}$ to headspace within the storm drain system accounted for $20 \%$ of the mean total $\mathrm{Hg}$ concentration observed in baseline monitoring at Outfall 200 prior to dechlorination/reduction (Table 8). An evasion rate of roughly $0.8 \mathrm{~km}^{-1}$ is consistent with the loss of $20 \%$ of $\mathrm{Hg}$ over the $320 \mathrm{~m}$ distance between Outfall 150 and Outfall 200. However, over most of that length, only $20 \%$ of the HgT was reduced to $\mathrm{Hg}(0)$, since the stannous chloride was not added until flow reached 200A6, $260 \mathrm{~m}$ downstream. The headspace loss is thus consistent with: 1) reduction of $>90 \%$ of the $\mathrm{Hg}$ in Outfall 150 and 2) a passive evasion rate well in excess of $0.8 \mathrm{~km}^{-1}$. 
When dechlorination and stannous chloride additions were stopped, DGM decreased within 20 minutes to undetectable levels and total $\mathrm{Hg}$ and post-purge $\mathrm{Hg}$ returned to levels typical of the pre-treatment baseline (1326 ng/L after versus 1378 before, Fig. 23). The mean of all baseline HgT concentrations, $1359 \pm 31$ $\mathrm{ng} / \mathrm{L}$ was used in calculations of $\mathrm{Hg}$ conversion efficiency.

The measured concentration of total tin in water samples at monitoring Station C11 confirmed that the intended target concentration of $5 \mu \mathrm{g} / \mathrm{L}$ Sn was attained (Fig. 24). The difference in tin concentrations between Outfall 200 and $\mathrm{C} 11$ was consistent with dilution by water introduced immediately downstream of Outfall 200 from the flow management system.

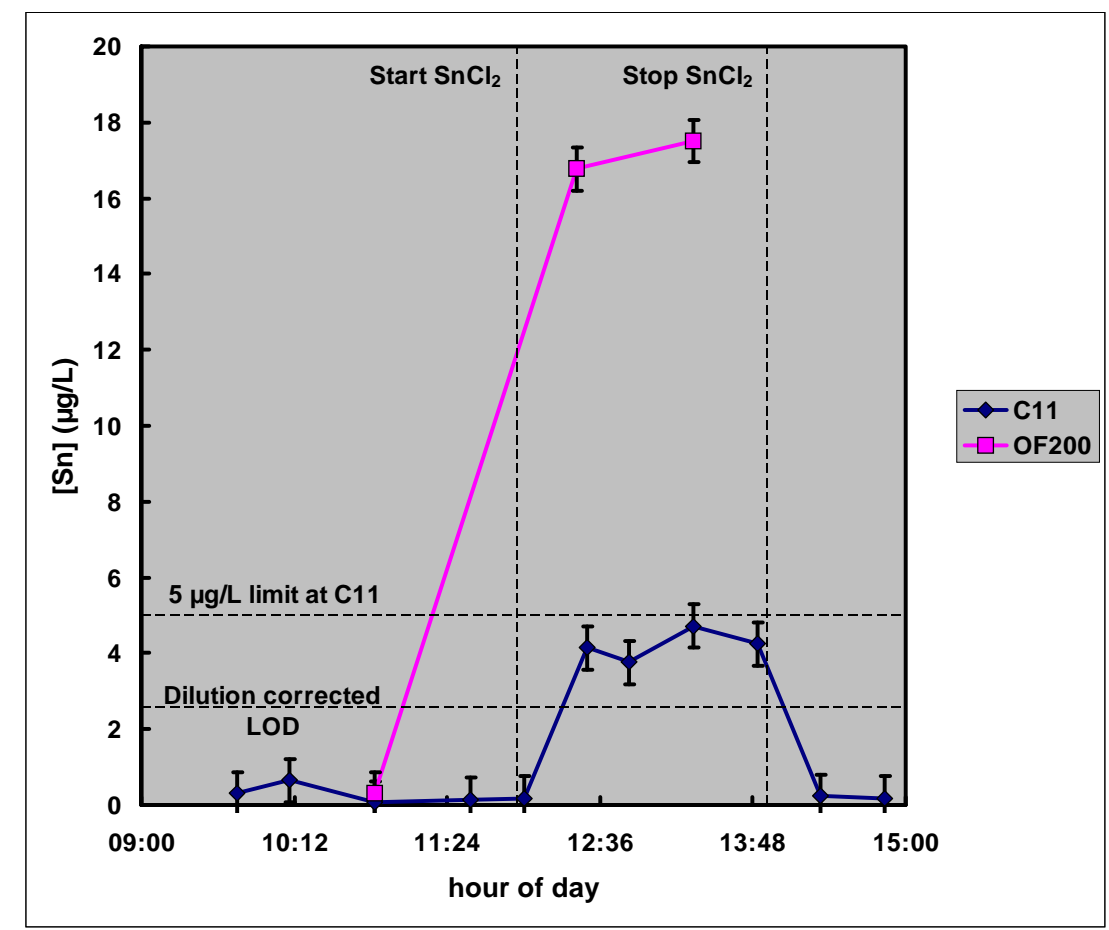

Fig. 24. Concentrations of tin in East Fork Poplar Creek at Outfall 200 and monitoring Station C11 during the in-stream $\mathrm{Hg}$ reduction experiment.

\subsubsection{Downstream profile of dissolved gaseous $\mathrm{Hg}$ and potential loss of $\mathrm{Hg}$ by natural evasion}

A large fraction of the total $\mathrm{Hg}$ in Outfall 200 as dissolved gaseous $\mathrm{Hg}$ during $\mathrm{SnCl}_{2}$ reduction period (Figs. 23 and 25) allows tracking the fate of this volatile but photo-reactive species in the open stream system. Downstream profiles of HgT and DGM in upper EFPC in the periods of before, during and after the $\mathrm{Hg}$ reduction experiment are presented in Figs. 25 and 26. Dissolved gaseous Hg exhibited a pronounced decrease in concentration with distance downstream from Outfall 200 during the in-stream reduction experiment (Fig. 25). From Outfall 200 to station C11, the loss of HgT and DGM is primarily due to dilution with the flow augmentation system. The mechanisms of DGM loss are uncertain. Loss via volatilization could play a part. However, total $\mathrm{Hg}$ in EFPC water did not reflect such a loss, even though more than $50 \%$ of the $\mathrm{Hg}$ in the water at the uppermost two sites was DGM. Comparison of downstream profiles of $\mathrm{HgT}$ before and after chemical reduction likewise shows no evidence of volatilization loss in the open creek channel (Fig. 26). Estimation of $\mathrm{Hg}(0)$ volatilization in the upper $800 \mathrm{~m}$ of EFPC 


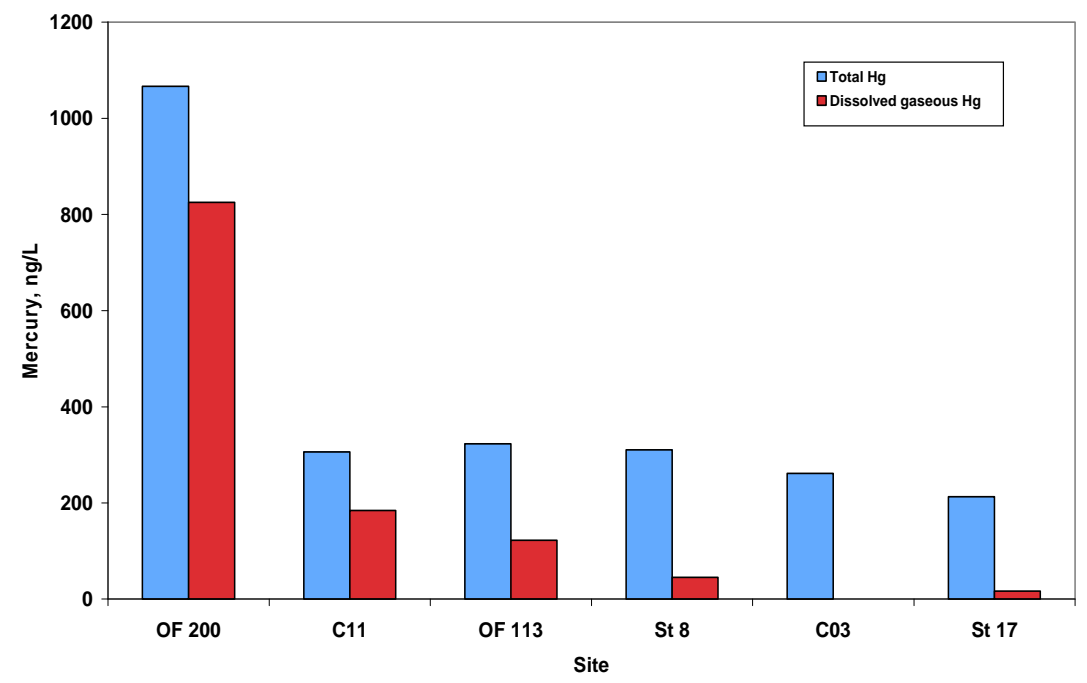

Fig. 25. Concentrations of total $\mathrm{Hg}$ and dissolved gaseous along a downstream profile of sites in upper EFPC during the period when $\mathrm{Hg}$ at Outfall 200 was reduced by $\mathrm{SnCl}_{2}$.

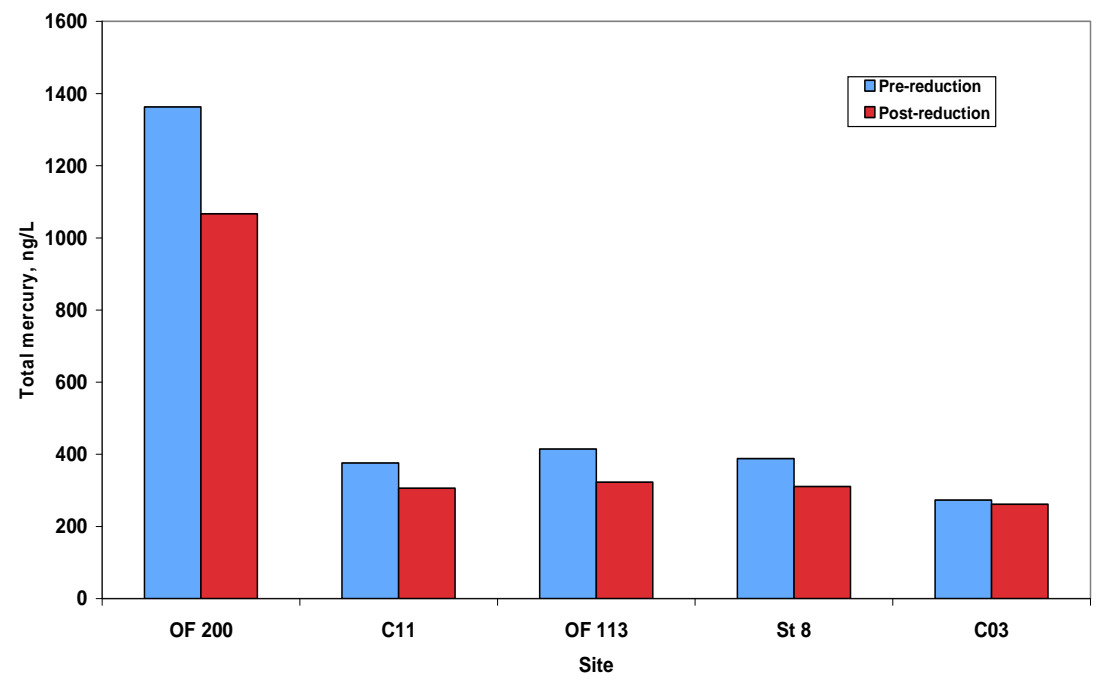

Fig. 26. Concentrations of total $\mathrm{Hg}$ along a downstream profile of sites in upper EFPC before and after reduction of $\mathrm{Hg}(\mathrm{II})$ at Outfall $200 \mathrm{to} \mathrm{Hg}(0)$.

indicates that it is unlikely to account for more than a 50\% decrease in DGM between C11 and C08. Reaction with photochemically produced oxidants probably accounts for much of the loss of DGM, converting $\mathrm{Hg}(0)$ back to $\mathrm{Hg}(\mathrm{II})$. Nevertheless, the persistence of DGM as a significant fraction of the total $\mathrm{Hg}$ in the water column between Outfall 200 and C08 suggests that the kinetics of the re-oxidation by photochemical process is slow, thus not affecting HgT significantly. Additionally, other process may complicate the observed absence of a downstream decrease in $\mathrm{HgT}$ following chemical reduction. For example replacement of lost $\mathrm{Hg}$ by desorption from the surface of the streambed. The ability of $\mathrm{Hg}$ stored in the streambed of EFPC to buffer against change in waterborne $\mathrm{Hg}$ concentrations is discussed in more detail in Section 2 of this report. 


\subsubsection{Re-oxidation of $\mathrm{Hg}(0)$ during air stripping}

A 3.2 L sample of water was collected from Outfall 200 after it appeared that chemical reduction of $\mathrm{Hg}$ (II) had reached its maximum level. The sample was maintained indoors in an amber glass bottle and thus was not exposed to sunlight. The bottle was then purged with ambient air through a ceramic diffuser at the bottom of the container. Dissolved gaseous $\mathrm{Hg}$ in the sample was $786 \mathrm{ng} / \mathrm{L}$ at the start of the purge, and constituted about $90 \%$ of the total $\mathrm{Hg}$ in the sample (Fig. 27). The concentration of DGM decreased steadily at a first order rate, as would be expected if it was being removed by a constant flow of air. After 120 minutes, it was virtually gone (17 ng/l DGM remaining). At the start of the purge, the non-purgable mercury concentration was $84 \mathrm{ng} / \mathrm{L}$. After 120 minute of constant bubbling with air, the non-purgable remnant was $142 \mathrm{ng} / \mathrm{L}$. The difference, $58 \mathrm{ng} / \mathrm{L}$, is assumed to arise from reaction with dissolved oxygen or with photochemically produced oxidants in the water where the sample was collected. (The sample collection point, although at the opening of the storm drain system, is exposed to sunlight and may contain traces of such oxidants). If the oxidation is assumed to be a result of direct reaction with dissolved oxygen, the pseudo-first order rate constant for the reaction is estimated to be $0.002 \mathrm{~min}^{-1}$ $(0.2 \%$ per minute). Such a low rate of re-oxidation is unlikely to be a concern in an efficient air stripping system where DGM removal rate and water retention time are optimized (Section 3.4).

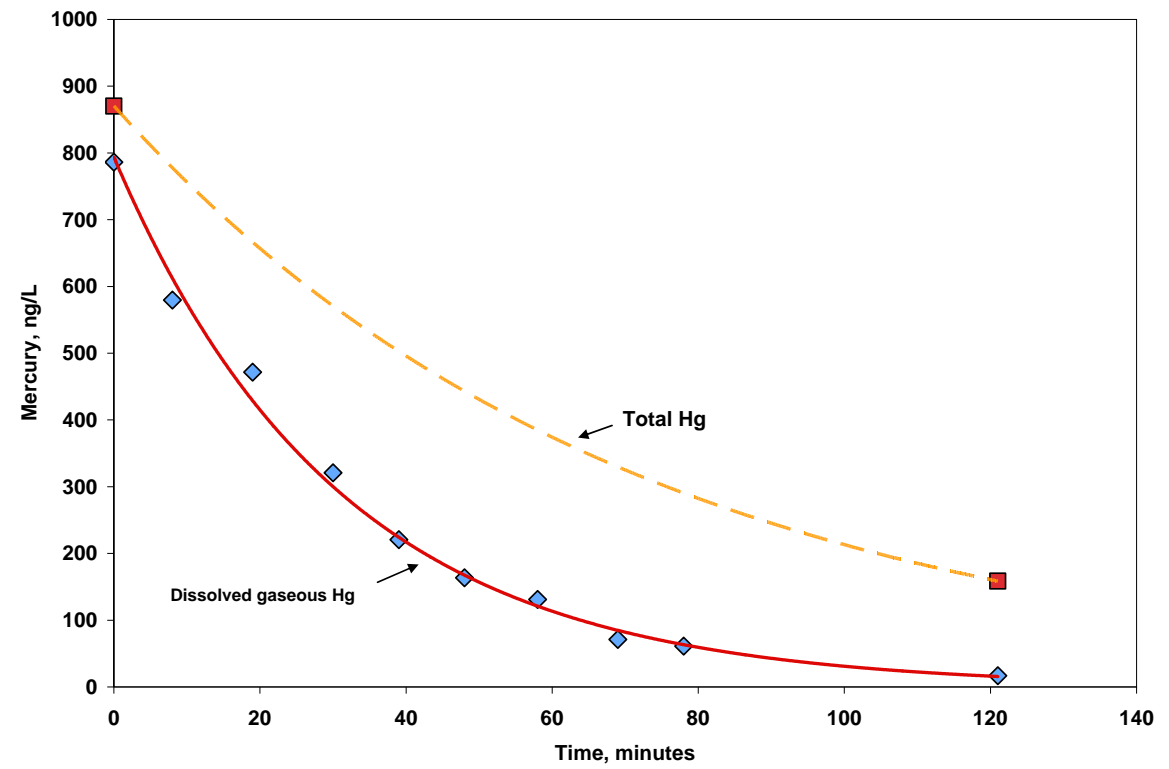

Fig. 27. Concentrations of total $\mathrm{Hg}$ and dissolved gaseous $\mathrm{Hg}$ in a $3.2 \mathrm{~L}$ sample of Outfall 200 water purged with air at $100 \mathrm{ml} / \mathrm{minute}$.

\subsubsection{Engineering Evaluation of Air Stripping at Outfall 200 and within the Storm Drain System Upstream}

Each of the four alternatives described in Appendix B have advantages and disadvantages if implemented. A summary of the strengths and weaknesses of each alternative are summarized in Table 9. Alternatives One and Two should perform similarly in their mercury conversion and removal effectiveness. Both designs are well supported with valid supporting data, the unit operations in the designs are well understood and readily designed using standard engineering methods, and the equipment is readily available. The primary discriminator between these options is the projected ease of maintenance. The equipment in Alternative Two will be more readily maintained than that shown in Alternative One. Further, the projected installed costs of Alternatives One and Two are approximately the same $-\$ 1.5$ 
Table 9. Summary comparison of the three mercury removal options

\begin{tabular}{|c|c|c|c|}
\hline $\begin{array}{c}\text { Alternative One - In-Stream } \\
\text { Option }\end{array}$ & Alternative Two - On-Shore Option & $\begin{array}{c}\text { Alternative Three - North/South (N/S) } \\
\text { Pipe Option }\end{array}$ & Alternative Four - Passive evasion \\
\hline $\begin{array}{l}\text { 1. Since the two stripper units are } \\
\text { anchored in-stream, a 773-gpm } \\
\text { (60-hp) creek water supply pump } \\
\text { to the process equipment is not } \\
\text { required. }\end{array}$ & $\begin{array}{l}\text { 1. Since the process equipment is } \\
\text { installed across the adjacent road } \\
\text { next to the creek, there is no } \\
\text { major streambed disturbance. } \\
\text { 2. Performing maintenance on the } \\
\text { process equipment would not be } \\
\text { costly because the stripper units } \\
\text { are not installed in the streambed. } \\
\text { 3. A total of } 3 \text { (15-hp) stripping air } \\
\text { blowers are required for the } \\
\text { stripper skid. The electrical } \\
\text { power consumption for these } \\
\text { three blowers is less than the two } \\
\text { blowers (75 hp and } 25 \text { hp) for the } \\
\text { In-Stream Option. } \\
\text { 4. Since the stripper skid is located } \\
\text { near the carbon bed, a single } \\
\text { short run of } 16 \text {-inch air } \\
\text { piping/duct is required. } \\
\text { The stripper skid is a proven } \\
\text { mercury removal technology and } \\
\text { has a higher probability of } \\
\text { technical success than the N/S } \\
\text { Pipe Option. }\end{array}$ & $\begin{array}{l}\text { 1. Since the air diffuser stripper piping is } \\
\text { installed inside of the existing N/S pipe, } \\
\text { a } 773 \text {-gpm (60-hp) creek water supply } \\
\text { pump to the process equipment is not } \\
\text { required. }\end{array}$ & $\begin{array}{l}\text { 1. Low capital cost } \\
\text { 2. No in-stream construction } \\
\text { 3. Low risk - Effectiveness would be } \\
\text { demonstrated without large up- } \\
\text { front investment } \\
\text { 4. Lower power consumption }\end{array}$ \\
\hline \multicolumn{4}{|c|}{ Disadvantages } \\
\hline $\begin{array}{l}\text { 1. Major streambed disturbance is } \\
\text { required to anchor the two stripper } \\
\text { units in-stream. } \\
\text { 2. Since the stripper units would be } \\
\text { located in the streambed, the units } \\
\text { would have to be removed and then } \\
\text { reinstalled in order to perform } \\
\text { periodic maintenance. Thus, the } \\
\text { maintenance costs would be higher } \\
\text { than those for the On-Shore }\end{array}$ & $\begin{array}{l}\text { 1. Since the process equipment is } \\
\text { installed across the adjacent road } \\
\text { next to the creek, a large } 773- \\
\text { gpm } \\
\text { (60-hp) creek water supply pump } \\
\text { is required to pump water over } \\
\text { the road to the process } \\
\text { equipment. }\end{array}$ & $\begin{array}{l}\text { 2. Installing air diffuser piping and off-gas } \\
\text { duct inside of the N/S pipe will provide } \\
\text { an } 18 \text {-inch height of creek water above } \\
\text { the air diffuser orifices. It is uncertain } \\
\text { whether this will provide sufficient air- } \\
\text { to-water contact to remove the mercury. } \\
\text { Thus, the mercury removal efficiency } \\
\text { would be less than the In-Stream and } \\
\text { On-Shore Options. } \\
\text { 3. It would be difficult to capture and }\end{array}$ & $\begin{array}{l}\text { a. Low Hg removal efficiency } \\
\text { relative to air stripping } \\
\text { b. Multiple chemical addition and air } \\
\text { removal sites required } \\
\text { c. Likely to need close control of } \\
\text { decholorinating agent (avoid } \\
\text { overdosing) }\end{array}$ \\
\hline
\end{tabular}




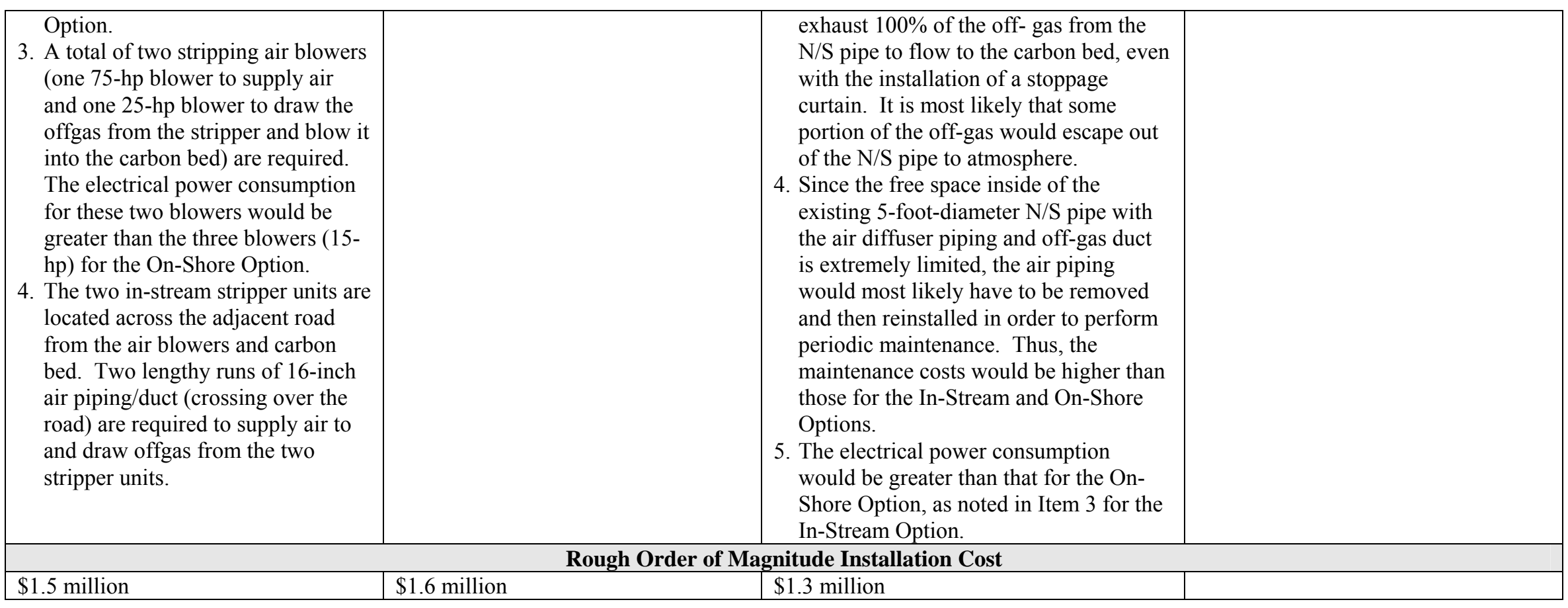


million and \$1.6 million respectively. Also, in the case of either of these alternatives, some lab/pilot data to better determine reaction rate and field performance will lower performance risks associated with the designs.

Alternative Three will present technical challenges to implement. Placing diffuser pipes in the N/S pipe upstream of Outfall 200 is technically feasible. However, this configuration entails that the flow through the N/S pipe be backed up by installation of a dam at Outflow 200 to increase water depth to $0.9 \mathrm{~m}$ for effective air and water contact. Raising the water level within this Hg-contaminated pipe could result in leakage into the highly contaminated subsurface adjacent to it, with subsequent emergence of highly contaminated water downstream and would impair stormflow drainage within the system.

Another challenge with Alternative Three is the collection of the Hg contaminated air in the N/S pipe. As described in Section 3.2.6, an air collection duct is hung on the top of the N/S pipe to gather the stripping air. Even though the mass of air drawn from the N/S pipe will be slightly more that the stripping air added, contaminated air will escape from the N/S pipe that is not treated.

Alternative Three is projected to have an installed cost of approximately $\$ 1.3$ million which is not significantly different from Alternatives One and Two. The operation and maintenance cost is not estimated in this report. Based on the Savannah River Site report, the operation cost using $\mathrm{SnCl}_{2}$ reduction combined with air stripping is $\$ 0.2 / \mathrm{m}^{3}$. This cost can only be higher at $\mathrm{Y}-12$ facility because of the 1-order magnitude higher $\mathrm{Hg}$ concentration and requirement of dechlorination. The flow at Outfall 200 is $\sim 7000 \mathrm{~m}^{3} / \mathrm{d}$. Therefore, the operation cost will be $>\$ 0.5$ million/year without considering the maintenance. This number is consistent to an EPA report that the typical pump-and-treat system operational cost is $\sim \$ 0.5 \mathrm{million} /$ year for a super-fund site (http://www.epa.gov/superfund/cleanup/postconstruction/oigptreport.pdf).

No engineering evaluation was conducted for the passive evasion alternative, but the results of the field test indicate that dechlorination/reduction within Outfall 150 alone has the potential to eliminate $20 \%$ of the baseflow $\mathrm{Hg}$ flux at Outfall 200. If similar results could be obtained by treatment of major $\mathrm{Hg}$ sources farther upstream (Outfalls 169,163, and 160), passive evasion may be capable of removing more than $50 \%$ of the baseflow flux from the system.

Despite major successes in reducing Hg sources to upper EFPC, there has been little or no change in methylmercury accumulation in fish. The degree of source reduction needed to achieve methylmercury concentrations in biota at or below the required EPA level $(0.3 \mathrm{ppm})$ remains unknown, and may present a very difficult technical challenge. It is likely that multiple source reduction efforts, targeting both the west end mercury use area and streambed sources downstream, will be necessary to achieve the low target concentration for $\mathrm{Hg}$ in water that is required. Because models are lacking that accurately link total mercury and methylmercury in water at the contaminated sites, there is no evidence to suggest that any of these four water treatment systems will result in achievement of compliance levels for mercury in fish tissue. In addition, the costs of such systems must be weighed against the regulatory and ecological significance of what is actually achieved.

\subsection{CONCLUSIONS}

Findings of 2009 studies indicate that chemical reduction combined with an engineered air-stripping system has the potential to remove a significant fraction of the waterborne $\mathrm{Hg}$ in the storm drain system at Y-12 NSC. Trace concentrations of a low toxicity reagents (stannous chloride and ascorbic acid) converted more than $90 \%$ of the $\mathrm{Hg}$ in the Outfall 200 discharge to volatile dissolved gaseous $\mathrm{Hg}(0)$. $\mathrm{An}$ engineering evaluation of the feasibility of purging dissolved gaseous $\mathrm{Hg}$ from a flow equivalent to that 
of the Outfall 200 baseflow $\left(7,000 \mathrm{~m}^{3} / \mathrm{d}\right)$ found that off-the-shelf units exist to remove volatile constituents from such flows. The surface area ('footprint') required for a system capable of treating the Outfall 200 discharge was approximately the size of the existing concrete apron underlying EFPC at that discharge point.

The rate of re-oxidation of $\mathrm{Hg}(0)$ back to $\mathrm{Hg}(\mathrm{II})$ under air stripping conditions was estimated to be slow. Natural evasion of $\operatorname{Hg}(0)$ from the turbulent flow of EFPC downstream from Outfall 200 was not effective as we did not see a detectable decrease in waterborne total mercury. However, natural evasion within the storm drain system itself may serve as a relatively simple, inexpensive way to significantly decrease total $\mathrm{Hg}$ concentration at Outfall 200.

Although promising, several key questions need to be answered before chemical reduction combined with air stripping can move forward as a potential remediation option. Although the ascorbic acid and stannous chloride combination proved highly effective in our test, longer term evaluation is needed to ensure that day to day changes in the chemistry of the Outfall 200 discharge do not compromise the effectiveness of chemical reduction. Ascorbic acid has the advantage of not mobilizing $\mathrm{Hg}$ from surfaces within the storm drain system, but it is very expensive to use on a regular basis to dechlorinate the full flow at Outfall 200. It also poses potential concerns with respect to methylmercury production within the system. At the present time, residual chlorine in the storm drain system likely prevents the microbial production of methylmercury (chlorine at potable water levels is toxic to most microbes and biota). Dechlorination with ascorbic acid would remove the residual chlorine and add a carbon source to promote the growth of microbes within the system, possibly resulting in methylmercury production and export to the creek. Such concerns would be relatively insignificant in an engineered air stripping system at Outfall 200 but could be a problem if ascorbic acid was added far upstream in the storm drain system. Therefore, it is likely that deployment of a chemical reduction and air stripping system would need upstream dechlorination by an inorganic reagent $\left(\mathrm{H}_{2} \mathrm{O}_{2}\right.$, thiosulfate, bisulfite) with ascorbic acid possibly used for stabilizing $\mathrm{SnCl}_{2}$ and removal of any excess residual chlorine. The 2008 study found that $\mathrm{Hg}$ mobilization from excess thiosulfate was a short-lived phenomenon. Similarly, interference with the reduction efficiency of $\mathrm{Sn}$ (II) by excess thiosulfate or bisulfite can also be dealt with by careful control over the dosing of these chemicals and possibly by adding Sn(II) in conjunction with an antioxidant such as ascorbic acid. Further study is needed to develop a cost effective chemical mix that can be employed on a continuing basis at Outfall 200.

Tin is subject to microbial methylation in anaerobic sediments (Gilmour et al. 1987), and methyltin compounds have been detected in both fresh and salt water, with high salinity waters generally having higher concentrations of methyltin. Methyltin is capable of reacting with dissolved $\mathrm{Hg}$ (II) to form methylmercury (Bellama, 1988; Hamasaki et al., 1995; Celo et al. 2006), thus raising concerns that the introduction of inorganic Sn(IV) to a Hg-contaminated system could enhance the generation of methylmercury. However, the rate of reaction of methyltin with $\mathrm{Hg}((\mathrm{II})$ at the maximum concentrations likely to occur are very low, and the process is unlikely to produce detectable changes in methylmercury production (Celo et al. 2006). Long-term effects of tin on environmental systems similar to East Fork Poplar Creek are not currently known, and this must be carefully considered before full scale implementation of treatments involving the introduction of potentially hazardous chemicals.

The headspace loss of $\mathrm{Hg}(0)$ after adding ascorbic acid at Outfall 150 presented a substantial removal of $\mathrm{Hg}$ from the Outfall 200 discharge, but the process is not fully understood. Interfacial transfer of $\operatorname{Hg}(0)$ via evation would not be rapid enough to account for this loss. Further investigation of $\mathrm{Hg}$ reduction and fate in the enclosed drain network upstream from Outfall 200 is needed to evaluate how adding dechlorinating agents and reductant to the system at sites close to the primary $\mathrm{Hg}$ sources affect on the total $\mathrm{Hg}$ concentration at Outfall 200. Such a system would require forced draft ventilation and capture of 
the gas phase $\operatorname{Hg}(0)$ on sorbents. Although a system relying on natural evasion of $\mathrm{Hg}(0)$ from water flowing through the storm drain network may not be as efficient as an engineered air stripping system, it could prove to be a relatively inexpensive way to achieve a substantial near-term decrease in baseflow $\mathrm{Hg}$ flux at Outfall 200 before permanent remedial alternatives are completed. 


\section{CONCEPTUAL MODELING EFFORTS AND OTHER PROJECT ACTIVITIES}

In 2009, the research team began the development of conceptual model that defines the mercury issues at Y-12 site. Additionally, technical assistance and programmatic activities that advance overall goals of technology development and remediation of mercury were also conducted in 2009 and summarized here. There are two aspects of the conceptual model development: identifying sources and fluxes of mercury at Y-12 NSC in general, and modeling mercury fluxes change as influenced by flow augmentation systems. The latter has been discussed in Section 2.3.1. Section 4.1 describes use of conceptual and systems-based modeling approaches to identify and characterize mercury sources and mass fluxes. Section 4.2 is chronology of other technical assistance activities that we conducted in 2009. Major activities in 2009 included helping evaluate potential treatment and remediation methods for mercury in soil and sediment (via Mercury Remediation Strategy technology development meetings and WEMA staff collaborations) and active participation in various scientific meetings, including the ICMGP conference (June 2009), the DOE EM-32 Mercury Summit (October 2009), and American Geophysical Union annual meetings (December 2009).

\subsection{CONCEPTUAL MODELING AND DEVELOPMENT OF A SYSTEMS-BASED APPROACH TO MERCURY REMEDIATION}

Conceptual Model - ORNL and Savannah River National Laboratory staff working for DOE's EM-32 program met in June of 2009 to develop a conceptual model of mercury flux at the Y-12 Site. The goal was to create a relatively simple diagram that would help better understand the mercury mass balance situation at Y-12, and assist in effective Environmental Management decision-making. As part of this effort, a conceptual model diagram was generated with some overarching explanatory text, and a historical data table and reference list for the conceptual model. Draft versions of the conceptual model were shared with the technology development team working on the Mercury Remediation Strategy in July 2009. The conceptual model will continue to be modified as new data is obtained in the summer and fall of 2009 as part of the WEMA storm drain work (Section 4.4.). A full report summarizing the mercury conceptual modeling effort will be published in FY2010.

Systems-Based Approach - A systems analysis approach was employed at the Y-12 site in which the bounds of known and suspected transport pathway features (Fig. 28) are documented using geographic information system (GIS) technology (ARCGIS 9.2 ${ }^{\mathrm{TM}}$ ), and assigned a value associated with their risk of migration.

Preferred pathway layers that were determined to have an effect beyond their boundaries (e.g., sumps) were buffered with a multi-part buffer tool and assigned a rating for vulnerability and a weight for the buffer distance. Layers were combined using an overlay tool (union). The union overlay tool computes the geometric intersection of the polygon features. All polygons from the features are split at their intersections and preserved in the output layer (Fig. 29). Each new polygon has all the attributes of all the preferred pathway layers and their buffers that contributed to the new polygon.

For each polygon in the union overlay layer, migration vulnerability was calculated by multiplying the rating for each contributing preferred pathway layer by its distance weight and then summing all the vulnerabilities for each polygon. The result is a map of the facility showing the risk of migration due to the presence of the multiple pathway features (Fig. 30). Existing soil and groundwater contamination information was similarly processed in GIS, overlain and compared with the pathway maps to further refine the assessment of likely contaminant migration pathways (Fig. 31). The pathway analysis results can be used directly to make decisions on additional site investigation and remedial activities or as input to more sophisticated 3-D flow and transport models. 


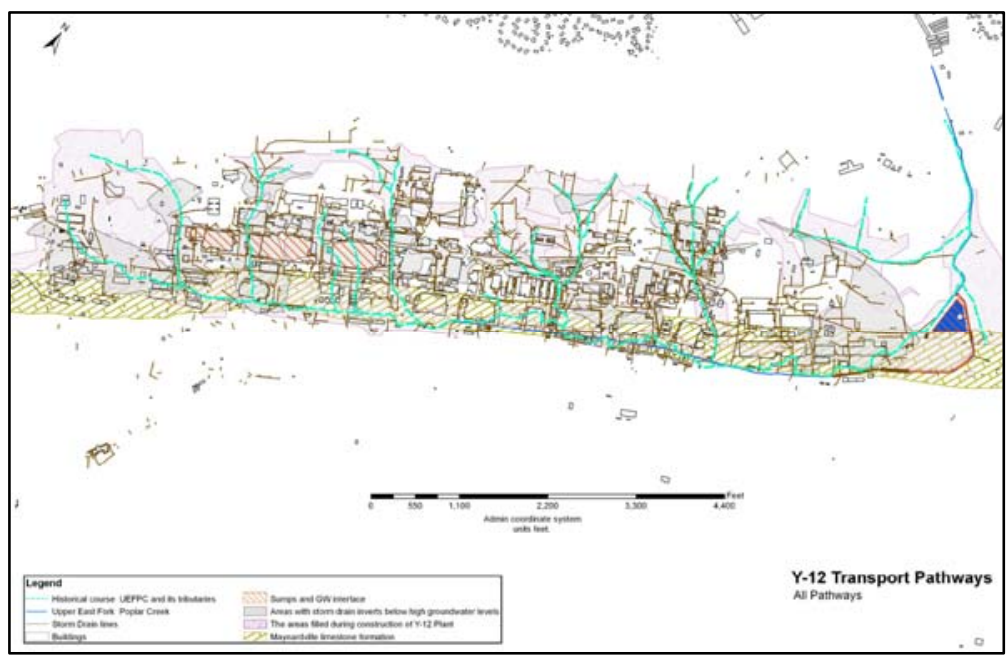

Fig. 28. Overlay of all potential transport pathways considered in evaluation.

Union Overlay - computes geometric intersection of polygon layers

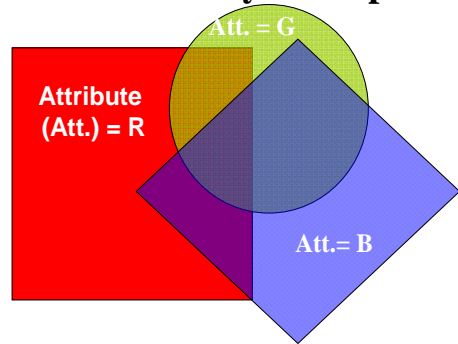

Input has 3 polygons

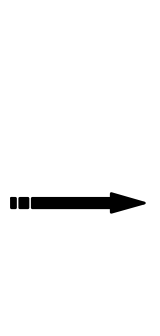

Output has 7 polygons

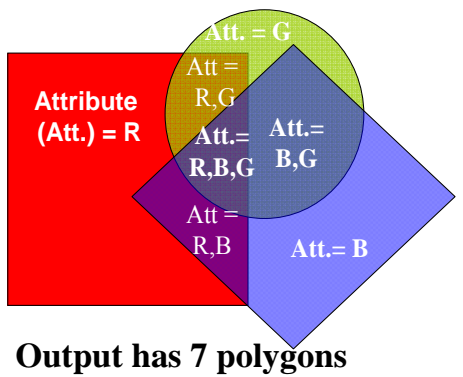

Fig. 29. Combining pathways and buffers in GIS.

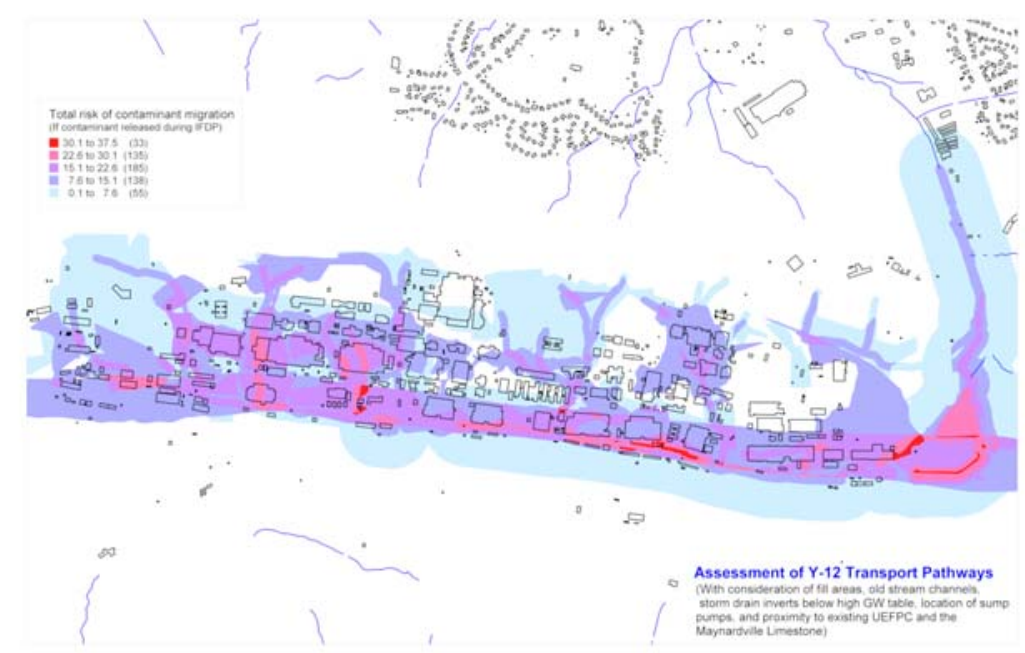

Fig. 30. Result of assigning risk values and joining preferred transport layers. 


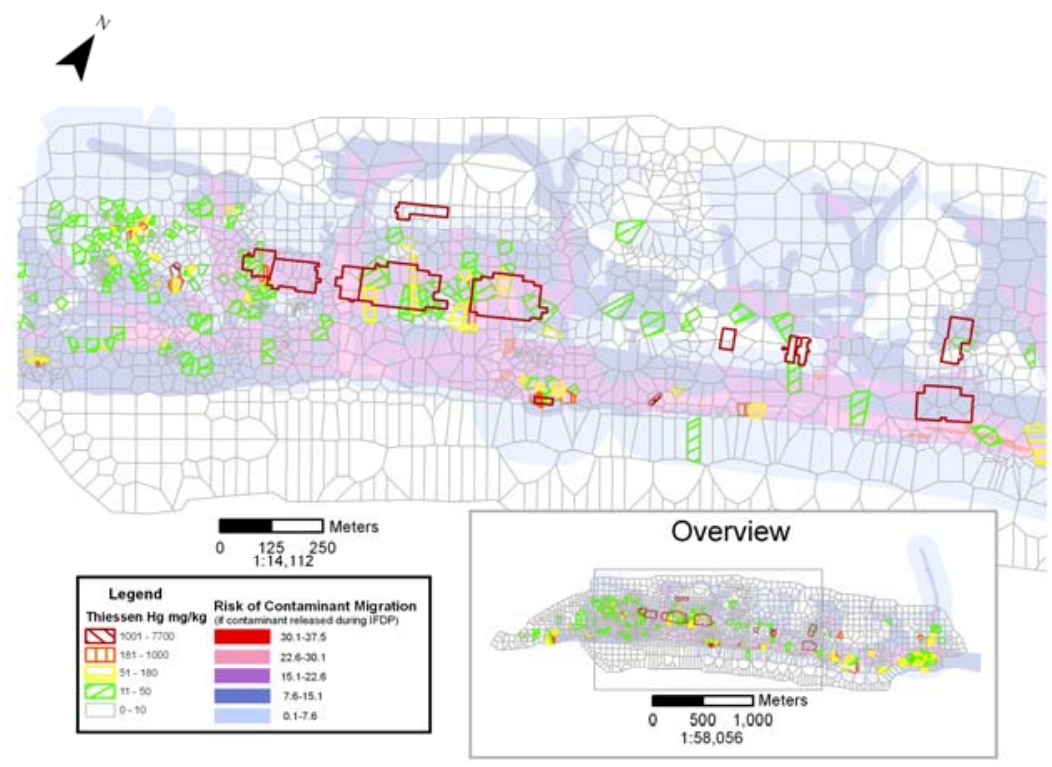

Fig. 31. Overlay of Y-12 Hg soil sampling data converted to Thiessen polygons and $\mathrm{Hg}$ use buildings with high risk transport pathways.

\subsection{TECHNICAL ASSISTANCE}

We provided technical assistance to a number of organizations in 2009 relative to the mercury remediation issues in Oak Ridge. This assistance was important to advancing collaborative and constructive interactions between DOE and facility contractor staff, subcontractors, stakeholders, regulators, and the public. A summary of those major activities is provided in Table 10. Not listed in the following table are the many routine meetings and conference calls throughout the year where technical input was provided, including UEFPC Core Team meetings, the Mercury Remediation Strategy technology development meetings (with local DOE and Pro2Serve offices), various ORNL and Y-12 IFDP and ARRA meetings, and weekly DOE HQ - stakeholder conference calls.

\subsection{STUDIES LEVERAGING WITH THE MERCURY SCIENCE FOCUS AREA}

In addition to the EM funded mercury work at ORNL, the DOE's Office of Science supports a basic research program at ORNL focused on understanding transformation pathways between inorganic mercury and organomercuric species in sediment-water environments. The mercury SFA program uses a systems approach, which integrates chemical and microbiological processes operating at molecular, subcellular, and macroscopic scales. We capitalized on the SFA program by identifying synergistic activities and through active data and information exchange. For example, data on the vertical distribution of mercury species in the sediments of UEFPC (see Section 2) were generated from activities in the SFA. This kind of characterization data falls outside the scope of the EM-32 funded work but provides important information needed to understand the system dynamics that govern mercury release and transport in UEFPC.

Similarly, the EM- 32 funded work may be leveraged by the SFA program by understanding the mercury source terms and varying reactivity. For example, reduction of $\mathrm{Hg}$ (II) by stannous chloride is effective when applied upstream of Outfall 200 but not when applied downstream in another section where the creek passes through a $\sim 250$ meter pipe about $1.7 \mathrm{~km}$ from Outfall 200 . Knowing about the change in reactivity is of practical importance for locating and operating a chemical treatment system for EM while 
Table 10. Summary of ORNL technical assistance activities in calendar year 2010

\begin{tabular}{|c|c|}
\hline Timeframe & Technical Assistance Activities \\
\hline January & $\begin{array}{l}\text { - Provided justification for reducing the flow requirement at Station } 17 \text { which resulted in a } 2 \text { MGD monthly } \\
\text { average decrease in a revision to the NPDES Permit } \\
\text { - Updated TMDL Working Group SharePoint site to include key documents and correspondence relative to the } \\
2008 \text { studies and ensure regulator access } \\
\text { - Drafted summary of } 2008 \mathrm{SnCl} \text { test results for a formal letter from Y-12 to TDEC } \\
\text { - Published ORNL/TM-2009/035 and copies provided to local stakeholders } \\
\text { - Provided input to DOE Groundwater and Soil Strategic Plan and EM Science Plan } \\
\text { - A table highlighting EM and ERSP linkages for mercury remediation was drafted }\end{array}$ \\
\hline February & $\begin{array}{l}\text { - Attended and provided input to the EM Long-term Monitoring (LTM) Workshop in Atlanta, Georgia. Met } \\
\text { with scientists from MSE, FIU, and MSU about collaborative opportunities in Oak Ridge. } \\
\text { - Provided input to Y-12 Utilities and the City of Oak Ridge on engineering options for a change to flow } \\
\text { management at Y-12 } \\
\text { - Participated in an EM Groundwater and Soil Program and IFDP coordination meeting }\end{array}$ \\
\hline March & - ESD hosted a meeting with Vanderbilt/CRESP \\
\hline April & $\begin{array}{l}\text { - TMDL Working Group Meeting held. Presentation given summarizing our } 2008 \text { research efforts. EPA asks } \\
\text { for DOE help in developing an effective TMDL for EFPC } \\
\text { - Hosted a scientist from FIU who provided a seminar in ESD } \\
\text { - Hosted a TDEC visit to the Aquatic Ecology Laboratory to discuss mercury issues } \\
\text { - Conducted a mass balance mercury study in the LEFPC floodplain in support of BJC. Results will be relevant } \\
\text { to defining future mercury remediation strategies. } \\
\text { - The State of the Creek address was given to the public at the Y-12 New Hope Center, that included a } \\
\text { summary of mercury issues and the EM Groundwater and Soil program that were trying to address the } \\
\text { mercury problem } \\
\text { - A presentation was given to the Mercury Remediation TD team summarizing the innovative remote tools } \\
\text { being used for heavy metal and aerosol detection and characterization. }\end{array}$ \\
\hline May & $\begin{array}{l}\text { - A draft Mercury Conceptual Model for Y-12 was presented at a Mercury Remediation Strategy technology } \\
\text { development meeting and later to Y-12 staff }\end{array}$ \\
\hline June & $\begin{array}{l}\text { - Multiple presentations given at the International Conference on Mercury as a Global Pollutant, Guiyang, } \\
\text { China } \\
\text { - Presentation to project Technical Working Group summarizing EM Groundwater and Soil efforts on mercury } \\
\text { and discussion of future plans } \\
\text { - ORNL and SRNL staff met for three days in Oak Ridge to refine development of a conceptual model } \\
\text { for mercury at Y-12 }\end{array}$ \\
\hline July & $\begin{array}{l}\text { - Provided input to Y-12 staff and state regulators and received endorsement for continuing our studies in } \\
\text { summer of } 2009 \\
\text { - Provided initial recommendations for agenda and invited people for the planned DOE EM Mercury } \\
\text { Summit at Vanderbilt } \\
\text { - Worked with WEMA team to develop an effective sampling strategy for storm sewers and conducted mercury } \\
\text { analysis of select sediment samples. } \\
\text { - Provided our EM field work plan to TDEC } \\
\text { - Provided the Mercury Remediation Strategy team with the ORNL-SRNL developed Y-12 mercury conceptual } \\
\text { model diagram, some overarching explanatory text, a data table, and reference list for the model. } \\
\text { - Mercury Remediation research program highlights provided to DOE HQ }\end{array}$ \\
\hline August & $\begin{array}{l}\text { - Toured WEMA storm drains sampled in July studies and tried to determine primary mercury sources } \\
\text { - Participated in UEFPC Core Team meeting and provided a summary of recent sampling results and input into } \\
\text { a strategy and prioritization of WEMA activities. Conducted a field visit to the } 81-10 \text { area. }\end{array}$ \\
\hline September & $\begin{array}{l}\text { - Provided presentation material to DOE ORO for a September presentation to the Site Specific Advisory } \\
\text { Board } \\
\text { - Strategic Action Area brief provided to DOE HQ }\end{array}$ \\
\hline October & - Multiple presentations given at the Mercury Summit at Vanderbilt University in Nashville \\
\hline November & $\begin{array}{l}\text { - Provided data to EPA that they will use in evaluating TMDL options for EFPC } \\
\text { - Presentation given at the EM Groundwater and Soil Program Review meeting }\end{array}$ \\
\hline December & $\begin{array}{l}\text { - Presented and participated in American Geophysical Union meeting in San Francisco } \\
\text { - Met with new DOE ORO management and presented a summary of technology development needs related to } \\
\text { mercury }\end{array}$ \\
\hline
\end{tabular}


understanding the fundamental mechanisms responsible for this change in mercury reactivity is being studied under the SFA and could provide results that benefit a mercury remediation technology.

\subsection{WEST END MERCURY AREA (WEMA) SOURCE INVESTIGATION}

We assisted Y-12 NSC in a 2009 investigation intended to more closely delineate sources of mercury to the storm drain network upstream of Outfall 200. Results of the 2009 sampling effort carried out by Y-12 (DOE 2009) were evaluated in conjunction with a review of source investigation efforts conducted previously by the Y-12 Reduction of Mercury in Plant Effluents Program (RMPE) to produce an assessment of the highest priority site for storm drain restoration/remediation. This study found that most of the baseflow mercury exported from WEMA appears to arise from a small number of relatively short sections of storm drain that contain metallic $\operatorname{Hg}(0)$ mixed with gravel. High priority locations within the network are shown in Fig. 32 and described in the following text.

Outfall 150 - The entire length of relined pipe appears to contain metallic $\operatorname{Hg}(0)$, but the upper, unlined section contains debris and very high mercury concentrations in water that flows at a very low rate. Although sources of new metallic $\mathrm{Hg}(0)$ to the system are unknown, this upper reach north of 9201-4 is likely acting as a source of dissolved mercury to the lined pipe downstream. The segment south of 92014 has not been sampled. The estimated loading at Outfall 150 is $\sim 1 \mathrm{~g} / \mathrm{d}$, up to $80-90 \%$ of which may come from line north of 9201-4.

Outfall 160 - The mercury flux from outfall 160 is estimated at $\sim 0.6 \mathrm{~g} / \mathrm{d}$. RMPE investigations indicated that most mercury comes from the D-3317 catch basin seep. This area contains gravel-covered soil with metallic $\operatorname{Hg}(0)$ present. Remediation of the site may require soil removal. This source may be highly localized and perhaps could be eliminated with a focused effort. The storm drain network upstream from D-3322 to the north contains metallic $\operatorname{Hg}(0)$ in both limbs. Estimated loading at Outfall 160 is $\sim 0.5-1$ $\mathrm{g} / \mathrm{d}$, perhaps more than $50 \%$ from the D-3317 catch basin seep.

Outfall 163 - Most mercury comes from lines east and northeast of D-3232, which were identified in RMPE as responsible for $70 \%$ of loading at Outfall 163. The west line to E-3231 contains metallic $\mathrm{Hg}(0)$, however the loading is relatively small. Estimated loading to EFPC from Outfall 163 is about 2.5 $\mathrm{g} / \mathrm{d}$, up to $70 \%$ from D-3232E and D-3232NE.

Outfall 169 - RMPE identified E-3320N (E-3250N in RMPE) as the major source ( $>70 \%$ ) of mercury to Outfall 169. About $2 \mathrm{~g} / \mathrm{d}$ flux was removed by routing water from E-3250N to CMTS. This site is characterized by low flow, high dissolved mercury, and probably flow under/around old, degraded pipe. The connection to CMTS could be restored with an immediate decrease in mercury flux at Outfalls 169 and 200. The west segment (E-3215W) contributes to the mercury flux and contains metallic $\operatorname{Hg}(0)$ but the flux is smaller than east segment. Estimated loading at Outfall 169 (now inaccessible) is estimated at $2-3 \mathrm{~g} / \mathrm{d}, \sim 70 \%$ from $\mathrm{E}-3320 \mathrm{~N}$.

We recommended the following actions:

1) Carry out simultaneous chemical tracer and mercury sampling/analysis to quantify the significance of potential sources. Use metered dye (fluorescein) and fluorescence spectrometry to measure flows throughout individual drainages.

2) Restore the E3250N (E3320) CMTS link. 


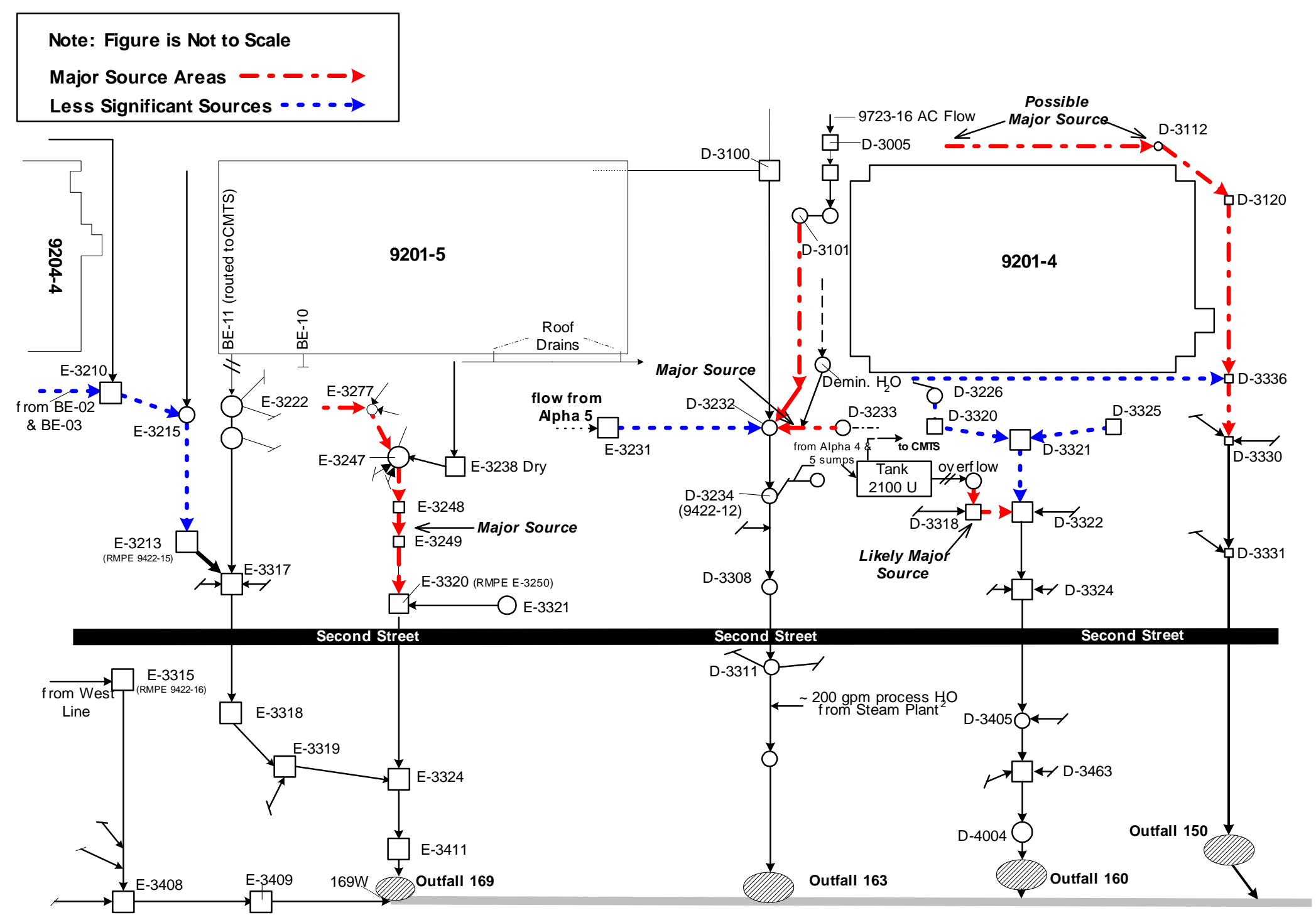

Fig 32. Map of the storm drain network with the West End Mercury Area show highest priority (red) and lower priority (blue) sections of the system that contribute most waterborne mercury to the Outfall 200 discharge. 
3) Clean/reline or excavate and rehabilitate/fill highly contaminated sites. It is imperative that additional gravel and metallic $\mathrm{Hg}(0)$ do not re-enter cleaned/relined conduits.

4) Outfall 150 may be amendable to in-situ reduction: air stripping as an interim action to lessen mercury concentrations at Outfall 200.

5) Major mercury inputs from D-3317 (Outfall 160) and north of 9201-4 (Outfall 150) may be similar to the E-3320N source in that they arise from small flows of highly contaminated ( $>100 \mu \mathrm{g} / \mathrm{L} \mathrm{Hg}$ ) water. If so, an effective temporary measure to reduce much of the baseflow mercury input to EFPC might be to capture these small flows before they get diluted with 'clean' water and route the captured flow to CMTS.

\subsection{RELEVANCE OF EM 32 STUDIES TO MERCURY REMEDIATION AT Y-12 NSC}

Perhaps the greatest uncertainty facing mercury-related remediation efforts at the Y-12 NSC is the lack of understanding of how effectively mercury inputs to EFPC must be constrained in order to achieve the goal of acceptable methylmercury concentrations in aquatic life, particularly fish. Although the relationship between waterborne inorganic mercury concentrations and the accumulation of methylmercury in fish appeared to be roughly commensurate in the 1980's, when $\mathrm{Hg}$ loading to the stream was a factor of ten higher than it is now, the response of $\mathrm{Hg}$ in fish to successful source reduction efforts has been disappointing. It now appears obvious that the relationship between inorganic $\mathrm{Hg}$ concentrations and methylmercury production and bioaccumulation in EFPC is highly non-linear, with a steep, nearly commensurate relationship at very low inorganic mercury concentrations and a flat, asymptotic relationship at high mercury levels (Fig. 33). Such an asymptotic relationship has been observed at Hg-contaminated sites similar to EFPC, such as the South River/Shenandoah R. and North Fork Holston River systems in Virginia. The hope that unique water quality characteristics of the EFPC system systematically altered $\mathrm{Hg}$ biogeochemistry in that system such that inorganic $\mathrm{Hg}$ was less available for methylation does not appear to be borne out as waterborne $\mathrm{Hg}$ concentrations decrease. Nevertheless, the relationship between inorganic mercury concentrations and methylmercury remains a site-specific factor, and thus the shape of the hypothetical curve depicted in Fig. 33 varies from one aquatic ecosystem to another. Inorganic mercury bioavailability may indeed be lower in EFPC than in most other systems. To date, however, there is no site-specific data with which to determine the shape of the curve hypothesized in Fig. 33, other than to say that cleanup efforts to date have failed to move us off the asymptotic part of the curve. Hence, the target waterborne $\mathrm{Hg}$ concentration needed for remedial efforts at Y-12 NSC to be successful remains unknown.

In Fig. 34, the same plot shown in Fig. 33 is depicted with an expanded x-axis to better illustrate how future remedial actions may affect $\mathrm{Hg}$ in fish. The points labeled 1994, 2009, and reference site are concentrations of $\mathrm{Hg}$ in fish at the Y-12 boundary in 1994 and 2009, while reference site is concentration of $\mathrm{Hg}$ in fish at an uncontaminated stream reference site. As can be seen, the decrease in waterborne inorganic Hg between 1994 and 2009 had no effect on Hg bioaccumulation. Observed relationships between waterborne $\mathrm{Hg}$ and $\mathrm{Hg}$ in fish at other $\mathrm{Hg}$-contaminated sites on the Oak Ridge Reservation (White Oak Creek and Mitchell Branch) were used to determine the plot. Thus, while clearly speculative, it is likely that it is a reasonable guess as to what such a relationship would be in EFPC.

The major remedial actions planned for mercury at the Y-12 NSC in the CERCLA Record of Decision involve further rehabilitation/relining and closure of highly contaminated segments of the storm drain network within the WEMA, and the removal of contaminated sediments from the streambed between the source of EFPC (Outfall 200) and Station 17 at the Y-12 boundary. If these actions succeed in eliminating $80 \%$ of the inputs upstream of Outfall 200 and all net $\mathrm{Hg}$ inputs downstream, the resulting 


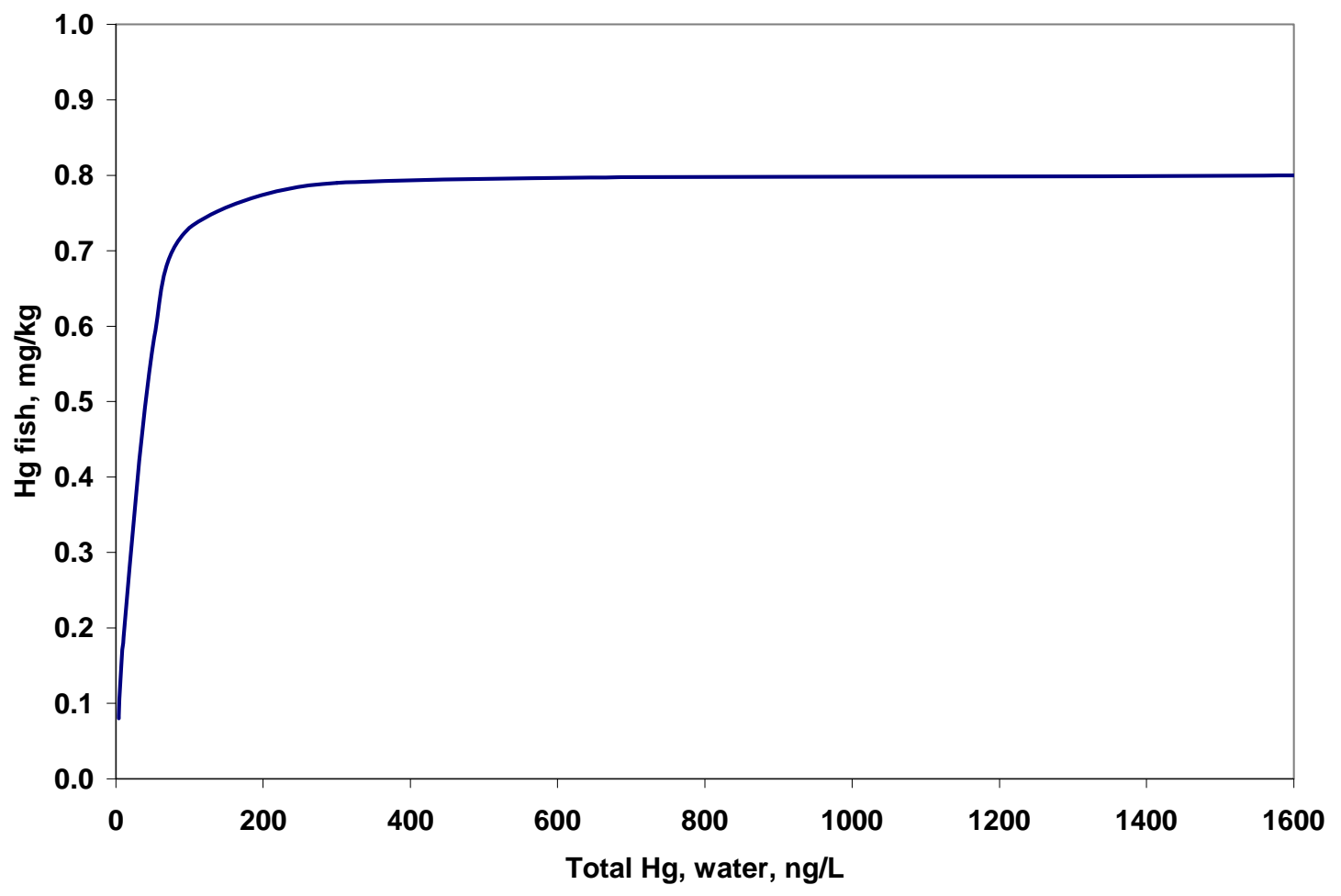

Fig. 33. Hypothetical relationship between total wateraborne HG in upper EFPC and Hg (methylmercury) in fish.

Hypothetical response of fish $\mathrm{Hg}$ to source reduction

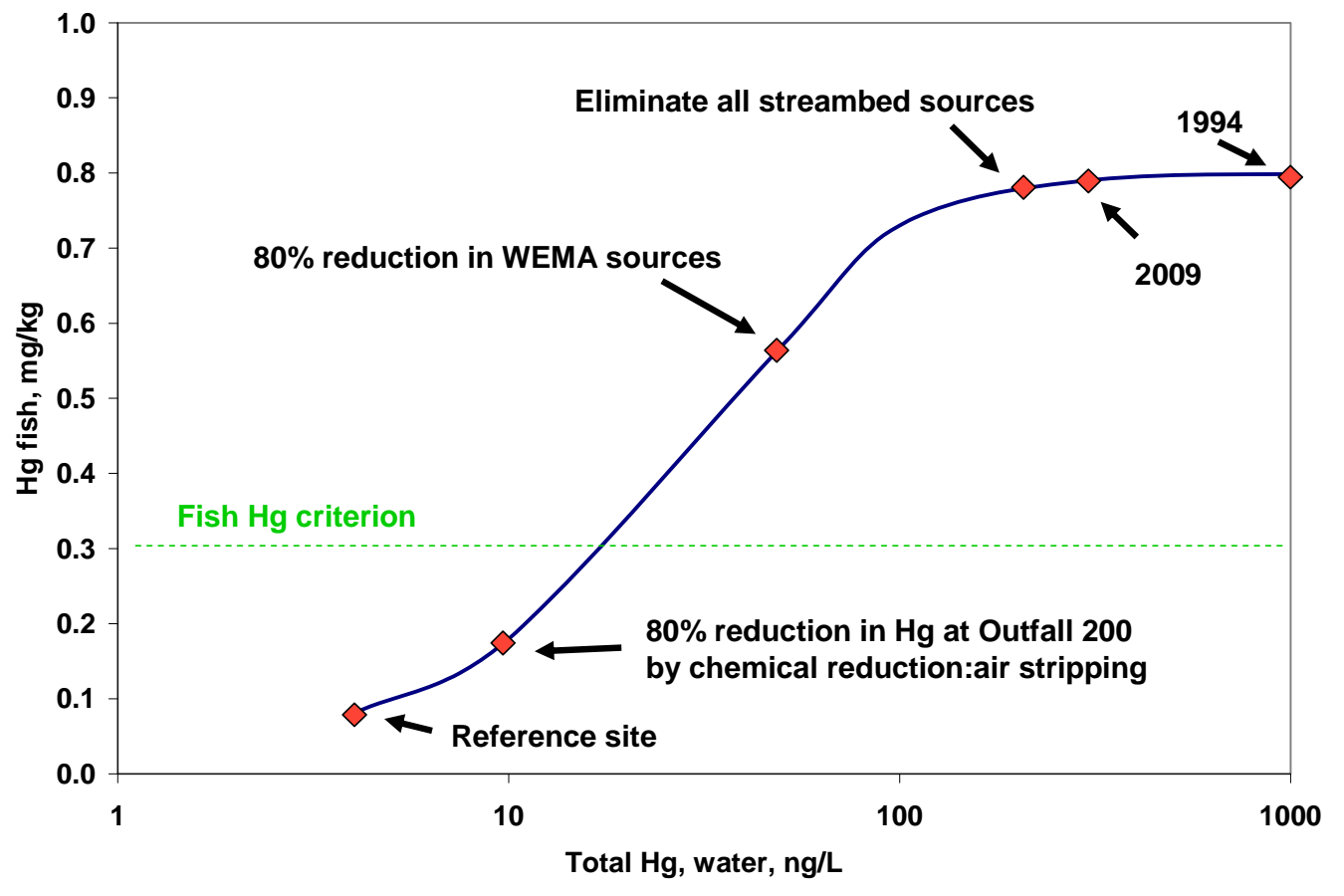

Fig. 34 Hypothetical response of $\mathrm{Hg}$ in fish to decreased total $\mathrm{Hg}$ in water in EFPC. 
waterborne inorganic $\mathrm{Hg}$ concentration in EFPC may still remain too high to allow $\mathrm{Hg}$ in fish to drop below the $0.3 \mathrm{mg} / \mathrm{kg}$ regulatory standard recommended by EPA. If waterborne total $\mathrm{Hg}$ concentrations must be decreased to less than 10-20 ng/L in order to be successful, it is very unlikely that the planned remedial actions, even if highly successful, will be sufficient. If the planned actions are taken and a $\mathrm{Hg}$ removal system is emplaced at Outfall 200 that removes $80 \%$ of the remaining $\mathrm{Hg}$ from the WEMA discharge, $\mathrm{Hg}$ in EFPC could be reduced to levels consistent with acceptable methylmercury concentrations in biota.

Removal of waterborne $\mathrm{Hg}$ from EFPC has been the remedial strategy for over two decades at the Y-12 NSC. If very low waterborne $\mathrm{Hg}$ concentrations are required for success, it is possible (perhaps likely) that that strategy is doomed to failure. While it may be possible to eliminate nearly all $\mathrm{Hg}$ inputs to a confined system such as the WEMA storm drain network, the large inventory of $\mathrm{Hg}$ remaining within streambed deposits and the contaminated floodplain downstream from Y-12 has the potential to act as a long-term low level source. Bank erosion, re-suspension, and desorption of $\mathrm{Hg}$ from the contaminated particulates can act to buffer waterborne $\mathrm{Hg}$ concentrations in the stream. Thus, successful source reduction efforts may reach a point where inputs from downstream contamination determine waterborne $\mathrm{Hg}$ concentrations, and possibly result in steady-state levels too high to attain acceptable concentrations of $\mathrm{Hg}$ in fish.

Short-term interim measures that produce lower baseflow inorganic $\mathrm{Hg}$ concentrations in EFPC can play an important role in determining the appropriate target concentration for $\mathrm{Hg}$ in the stream, even if those measures are not considered too be permanent or long-term solutions. Thus, actions such as flow management manipulation and in-situ $\mathrm{Hg}$ reduction:natural evasion within the storm drain network may be valuable steps in determining the degree of source reduction needed for remediation to succeed.

If source reduction cannot achieve the required levels of mercury in fish, there is a need for alternative strategies for achieving that goal. A number of such alternative strategies were outlined in the 2008 Technical Assistance Team Report (Looney et al. 2008). These strategies focus on altering the ecology of EFPC in order to limit the biological formation of methylmercury. Ideas put forward by the TAT included the addition of trace concentrations of chemical sequestrants at Outfall 200 to bind inorganic $\mathrm{Hg}$ in a non-bioavailable form, the addition of selenite to inhibit formation and food chain biomagnification of methylmercury, and the addition of excess thiosulfate dechlorinator to alter the ecology of the sulfur cycling microorganisms responsible for producing methylmercury. Other strategies considered included shortening the food chain in EFPC by selectively removing high trophic level predators that exhibit the greatest biomagnification of methylmercury and altering the configuration of the Lake Reality detention basin so that it acts as an effective trap for waterborne particle-associated $\mathrm{Hg}$. Alternative strategies for reducing methylmercury bioaccumulation in EFPC have the potential to take advantage of the accomplishments of source reduction efforts to convert what may appear to be a failed remediation into a successful effort. 



\section{PROJECT SUMMARY}

The overarching theme of this project is to control the flux and sources of mercury in soil and water environments for the purpose of protecting groundwater, surface water, and ecological receptors. This is a multi-year effort, with three main technology development themes including: 1. Investigate the means to reduce the fluxes of waterborne mercury to surface streams. 2. Evaluate and develop treatment technologies (in situ and ex situ) for remediating contaminated soil. Mercury immobilization methods are particularly important to sequester the contaminant in situ, if the source has no hydrological connection to the subsurface and surface waters. 3. Source identification and advanced conceptual and numerical modeling, in which measurement tools (including in situ, real time methods) for evaluating the amount and distribution of mercury at contaminated sites are the focus. Tools applicable to long-term monitoring will be developed along with advanced modeling methods to understand the processes that contribute to the mercury flux in surface and subsurface environments at DOE sites.

In the first couple of years, the main research has been on Theme 1, developing treatment technologies that reduce waterborne mercury contamination to surface streams. We also began to address Theme 3 for the development of conceptual models.

We conducted laboratory, field experiments and numerical modeling to evaluate how to reduce mercury fluxes from two source zones that contribute $\sim 6-8 \mathrm{~g} / \mathrm{L}$ mercury at the compliance points at Station 17 on EFPC. The first source zone is the sediment $\mathrm{Hg}$ contamination, 250-m downstream from Outfall 200. The second source zone is the discharge at Outfall 200, which contains $\sim 1 \mu \mathrm{g} / \mathrm{L} \mathrm{of} \mathrm{Hg}$.

For the sediment $\mathrm{Hg}$ source, we found that minimizing flow velocity generally produces less $\mathrm{Hg}$ flux from the source (see Chapter 2). This finding is mainly attributed to a decrease in suspended load that associated with mercury. Better characterization is needed to define the sorption and physical characteristics of the sediments and mercury association.

For the waterborne mercury in Outfall 200 discharge, chemical reduction using $\mathrm{SnCl}_{2}$ following dechlorination with ascorbic acid can convert $>90 \%$ of $\mathrm{Hg}(\mathrm{II})$ to $\mathrm{Hg}(0)$. The elemental $\mathrm{Hg}(0)$ may be volatilized naturally (in dark) or forced air stripping. Additional engineering efforts show that a combination of reduction with air stripping can provide a short-term removal of mercury, particularly it can be used to counter a large release of mercury during D\&D actions. However, we note that long-term effects of tin on ecosystems similar to East Fork Poplar Creek are not currently available, and must be evaluated in detail before any full scale implementation. 



\section{REFERENCES}

BJC (Bechtel Jacobs Co. LLC). 1999. Mercury Abatement Report for the U.S. Department of Energy Oak Ridge Y-12 Plant for Fiscal Year 1999, Oak Ridge, Tennessee. BJC/OR-422. Prepared by Environmental Sciences Division, Oak Ridge National Laboratory, Oak Ridge, TN.

BJC (Bechtel Jacobs Co. LLC). 1998. Mercury Abatement Report for the U.S. Department of Energy Oak Ridge Y-12 Plant for Fiscal Year 1998, Oak Ridge, Tennessee. BJC/OR-183. Prepared by Environmental Sciences Division, Oak Ridge National Laboratory, Oak Ridge, TN.

Celo, V., D.R.S. Lean, and S. L. Scott. 2006. Abiotic methylation of mercury in the aquatic environment. Science of the Total Environment 368:126-137.

Environmental Systems Research Institute (ESRI). 2008. ArcGIS 9.2 Computer Software, Redlands, California: Environmental Systems Research Institute Inc.

Gilmour, C. C., J. H. Tuttle, and J. C. Means. 1987. Anaerobic microbial methylation of inorganic tin in estuarine sediment slurries. Microb Ecol. 14:233-242.

Hach Company. 2006. Digital Titrator Model 16900. Hach Company, Loveland, CO. 196 pp.

Hamasaki, T., H. Nagase, Y. Yoshioka, and T. Sato. 1995. Formation, distribution, and ecotoxicology of methylmetals of tin, mercury, and arsenic in the environment. Critical Reviews in Environmental Science and Technology 25:45-91.

Howe, P. and P. Watts. 2005. Tin and Tin Compounds: Concise International Assessment Document No. 65. World Health Organization (WHO). Geneva, Switzerland. 77 pp. http://www.who.int/ipcs/publications/cicad/cicad 65 web version.pdf

Lanning, J. M. 1993. Aqueous Mercury Treatment Technology Review for NPDES Outfall 49 Y-12 Plant. Y/DZ-1043. Oak Ridge Y-12 Plant, Oak Ridge, Tennessee. 12 pp.

Looney B., C. Eddy-Dilek, R.Turner, G. Southworth, M. Peterson, and A. Palumbo. 2008. Recommendations to Address Technical Uncertainties in the Mitigation and Remediation of Mercury Contamination at the Y-12 Plant, Oak Ridge, Tennessee, WSRC-STI-2008-00212.

Margel, S. and J. Hirsh. 1984. Reduction of organic mercury in water, urine, and blood by sodium borohydride for direct determination of total mercury content. Clinical Chem. 30:243-245.

Moran, B. P. 1996. Modeling of the hydrological transport of Mercury in the Upper East Fork Poplar Creek (UEFPC) Watershed. Knoxville, the University of Tennessee. Master's Thesis.

Southworth, G. R., S. Brooks, M. Peterson, M. A. Bogle, C. Miller, M. Elliot, and L. Liang. 2009. Controlling Mercury Release from Source Zones to Surface Water: Initial Results of Pilot Tests at the Y12 National Security Complex. ORNL/TM-2009/035. Oak Ridge National Laboratory, Oak Ridge, Tennessee.

Southworth, G. 1997. Proposed Experiment for $\mathrm{SnCl}_{2}$ Treatment of Outfall 200 for the Purpose of Mercury Removal from East Fork Poplar Creek, Y-12 Plant, Oak Ridge, Tennessee, Y/TS-1663, Martin Marietta Energy Systems Y-12 Plant, Oak Ridge, TN, 7 pp. 
United States Environmental Protection Agency (U.S. EPA). 2002a. Fathead minnow (Pimephales promelas) acute toxicity test. EPA Test Method 2000.0. In, Methods for Measuring the Acute Toxicity of Effluents and Receiving Waters to Freshwater and Marine Organisms, EPA/821-R-02-012 (October 2002, $5^{\text {th }} \mathrm{Ed}$.).

United States Environmental Protection Agency (U.S. EPA). 2002b. Ceriodaphnia acute toxicity test. EPA Test Method 2002.0. In, Methods for Measuring the Acute Toxicity of Effluents and Receiving Waters to Freshwater and Marine Organisms, EPA/821-R-02-012 (October 2002, $5^{\text {th }}$ Ed.).

United States Environmental Protection Agency (U.S. EPA). 2008. Drinking Water Health Advisory for Boron and Compounds. Prepared by Health and Ecological Criteria Division (HECD), Office of Science and Technology (OST), Office of Water (OW) for Office of Groundwater/Drinking Water (OGWDW), OW, U.S. EPA.

Yeh, G. T., G. B. Huang, H. P. Cheng, F. Zhang, H. C. Lin, E. Edris, and D. Richards. 2005. A First Principle, physics-based watershed model: WASH123D. Watershed Models V. P. Singh and D. K. Frevert. Boca Raton, CRC Press LLC: 211-244.

Zhang, F., G. T. Yeh, J. C. Parker, and P. M. Jardine. 2008. A reaction-based river/stream water quality model: Model development and numerical schemes. Journal of Hydrology 348:496-509. 


\section{APPENDIX A \\ FLOW MANAGEMENT PILOT TEST DATA}

Table A-1. Total mercury concentration (HgT), flow rate, mercury loading and total suspended (TSS) at monitoring locations before the flow diversion period

\begin{tabular}{|c|c|c|c|c|c|c|c|c|c|}
\hline & \multicolumn{9}{|c|}{ Pre- Flow Diversion } \\
\hline & Day 1 & Day 2 & Day 3 & Day 4 & Day 7 & Day 8 & Day 9 & Day 10 & Day 13 \\
\hline Site & \multicolumn{9}{|c|}{ HgT (ng/L) } \\
\hline Raw $\mathrm{H}_{2} 0$ & 9 & 10 & 9 & 2.5 & 1.5 & 4.5 & 5.5 & 6 & 11.5 \\
\hline OF 200 & 1250 & 1750 & 1420 & 1290 & 931 & 924 & 928 & 1340 & 2360 \\
\hline $\mathrm{C} 11$ & 335 & 334 & 326 & 301 & 289 & 244 & 234 & 318 & 565 \\
\hline Above OF 109 & 414 & 376 & 374 & 412 & 415 & 412 & 304 & 405 & 702 \\
\hline $\mathrm{C} 08$ & 325 & 276 & 304 & 300 & 320 & 254 & 254 & 344 & 733 \\
\hline \multirow[t]{2}{*}{ Sta. 17} & 214 & 264 & 164 & 236 & 146 & 136 & 144 & 181 & 160 \\
\hline & \multicolumn{9}{|c|}{ Flow (million gallons per day) } \\
\hline $\mathrm{C} 11$ & 5.6 & 5.2 & 5.3 & 5.5 & 5.7 & 5.9 & 5.7 & 5.5 & 5.5 \\
\hline $\mathrm{C} 08$ & 5.3 & 5.2 & 5.3 & 5.3 & 5.5 & 5.5 & 5.2 & 5.8 & 5.9 \\
\hline \multirow[t]{2}{*}{ Sta. 17} & 9.0 & 8.9 & 9.3 & 8.8 & 9.1 & 9.2 & 9.3 & 9.2 & 9.2 \\
\hline & \multicolumn{9}{|c|}{ Hg Loading (grams per day) } \\
\hline $\mathrm{C} 11$ & 7.2 & 6.7 & 6.7 & 6.4 & 6.3 & 5.6 & 5.1 & 6.8 & 12.0 \\
\hline $\mathrm{C} 08$ & 7.3 & 5.8 & 6.5 & 6.7 & 7.4 & 6.1 & 5.9 & 7.7 & 16.3 \\
\hline \multirow[t]{2}{*}{ Sta. 17} & 7.4 & 9.1 & 5.9 & 8.0 & 5.1 & 4.8 & 5.2 & 6.4 & 5.7 \\
\hline & \multicolumn{9}{|c|}{ TSS (mg/L) } \\
\hline Raw $\mathrm{H}_{2} \mathrm{O}$ & 6.5 & 5 & 4.2 & 4.2 & 4.4 & 5.2 & 5.6 & 4 & 5.9 \\
\hline OF 200 & 0.6 & 2.9 & 0.4 & 0.9 & 0.7 & 1.1 & 0.9 & 0.8 & 0.7 \\
\hline C11 & 4.6 & 7.9 & 3.2 & 2.4 & 3.9 & 4.5 & 2.5 & 1.8 & 3.2 \\
\hline Above OF 109 & 3.6 & 3.9 & 3.1 & 2 & 3.5 & 3.7 & 2.8 & 3.3 & 3.2 \\
\hline $\mathrm{C} 08$ & 4.1 & 4 & 2.2 & 2.8 & 3.2 & 3.7 & 3.4 & 2.4 & 3.3 \\
\hline Sta. 17 & 3.2 & 3.4 & 2.4 & 3.1 & 2.8 & 3.6 & 2.5 & 3.7 & 3.2 \\
\hline
\end{tabular}


Table A-2. Total mercury concentration (HgT), flow rate, mercury loading and total suspended solids (TSS) at UEFPC monitoring locations during the flow diversion

\begin{tabular}{|c|c|c|c|}
\hline & \multicolumn{3}{|c|}{ Flow Diversion } \\
\hline & Day 1 & Day 5 & Day 7 \\
\hline Site & \multicolumn{3}{|c|}{ HgT (ng/L) } \\
\hline Raw $\mathrm{H}_{2} \mathrm{O}$ & 9 & - & - \\
\hline OF 200 & 1160 & 1130 & 948 \\
\hline $\mathrm{C} 11$ & 1060 & 986 & 842 \\
\hline Above OF 109 & 1080 & 1290 & 1220 \\
\hline $\mathrm{C} 08$ & 697 & 788 & 748 \\
\hline \multirow[t]{2}{*}{ Sta. 17} & 190 & 225 & 232 \\
\hline & \multicolumn{3}{|c|}{ Flow (million gallons per day) } \\
\hline $\mathrm{C} 11$ & 1.3 & 2 & 2.2 \\
\hline $\mathrm{C} 08$ & 2.2 & 3 & 3.1 \\
\hline \multirow[t]{2}{*}{ Sta. 17} & 6.0 & 6.3 & 6.4 \\
\hline & \multicolumn{3}{|c|}{ Hg Loading (grams per day) } \\
\hline $\mathrm{C} 11$ & 5.5 & 7.6 & 7.1 \\
\hline $\mathrm{C} 08$ & 5.9 & 9.1 & 9.0 \\
\hline \multirow[t]{2}{*}{ Sta. 17} & 4.4 & 5.5 & 5.7 \\
\hline & \multicolumn{3}{|c|}{ TSS (mg/L) } \\
\hline Raw $\mathrm{H}_{2} \mathrm{O}$ & 4.4 & - & 4.6 \\
\hline OF 200 & 0.9 & 0.5 & 1.4 \\
\hline $\mathrm{C} 11$ & 0.5 & 0.2 & 3.6 \\
\hline Above OF 109 & 0.8 & 1.4 & 4.4 \\
\hline $\mathrm{C} 08$ & 1.4 & 3.9 & 4.7 \\
\hline Sta. 17 & 4.5 & 7 & 7.7 \\
\hline
\end{tabular}




\section{APPENDIX B}

\section{DESIGN ALTERNATIVES FOR AIR STRIPPING NEAR OUTFALL 200}

Conceptual designs for the use of stannous chloride to remove mercury entering EFPC have been developed by MSE staff based on the ORNL field and laboratory work reported here, as well as work completed in $1997^{2}$. The primary elements of any conceptual design involve removal of residual chlorine from the water, reduction of $\mathrm{Hg}(\mathrm{II})$ to elemental $\mathrm{Hg}(0)$ with stannous tin, volatilization of elemental $\mathrm{Hg}$ from the creek water using air stripping, and absorbing the $\mathrm{Hg}(0)$ in the air from the strippers on sulfurimpregnated activated carbon. The parameters listed in Table 5 of Section 3.3.6 serve as the basis for the three engineering design alternatives considered here. They are: 1) emplacing an engineered stripper in the stream and feeding it 773 gpm of water by gravity flow from a dam downstream of Outfall 200 (Alternative One, In-Stream); 2) placing a stripper across the road south of the creek bank (Alternative Two, On-Shore) and pumping $773 \mathrm{gpm}$ of water from behind the dam downstream of Outfall 200; and 3) the installation of diffuser pipes in the N/S pipe upstream of Outfall 200 allowing the stripping of mercury in the N/S pipe, and collection of the mercury contaminated air in the N/S pipe for treatment.

A fourth alternative of using passive evasion has not been evaluated as to the engineering considerations, but may have promise based on field and laboratory results. Some of the potential design considerations for this fourth option are also considered in this appendix.

\section{Alternative One - In-Stream Option}

In this first design alternative (Fig. B-1), sodium bisulfite and $\mathrm{SnCl}_{2}$ are to be injected into the North/South (N/S) pipe several hundred feet upstream of Outfall 200. The injection pumps and ancillary equipment will be placed outside of the limited area with only the injection piping running underground within the N/S pipe.

The injection piping will be hung from the interior, top side of the N/S pipe and will allow the reagents to drip downward into the stream flow. Several feet of cobblestones will be placed laterally on the bottom of the pipe below the point of reagent injection to enhance mixing. The determination of a suitable location to place the reagent injection point in the N/S pipe upstream of Outfall 200 will be a subject for detailed design.

The water from the N/S pipe will flow from Outfall 200 and build up behind a dam that will provide hydraulic head to control the flow of water into the air strippers.

The In-Creek Option uses two, six-stage diffused aeration tanks to provide air stripping of Hg. The tanks are 8 - $\mathrm{ft}$ wide by $24-\mathrm{ft}$ long by 3 - $\mathrm{ft}$ high and include mounting brackets to allow anchoring the tanks in the stream.

The strippers are to be emplaced in the stream with water from the N/S pipe flowing into them by gravity. Since the strippers are 8-ft wide, the two units may have to be placed one after the other in the streambed. Parallel placement of the stripper tanks may require widening the stream and reinforcing the stream banks with concrete shoulders.

${ }^{2}$ Y-12 Central Engineering Services, Outfall 51 Air Stripping Feasibility Study for the Reduction of Mercury in Plant Effluent (RMPE) Project, AR-CM-920109-A002, January, 1997. 


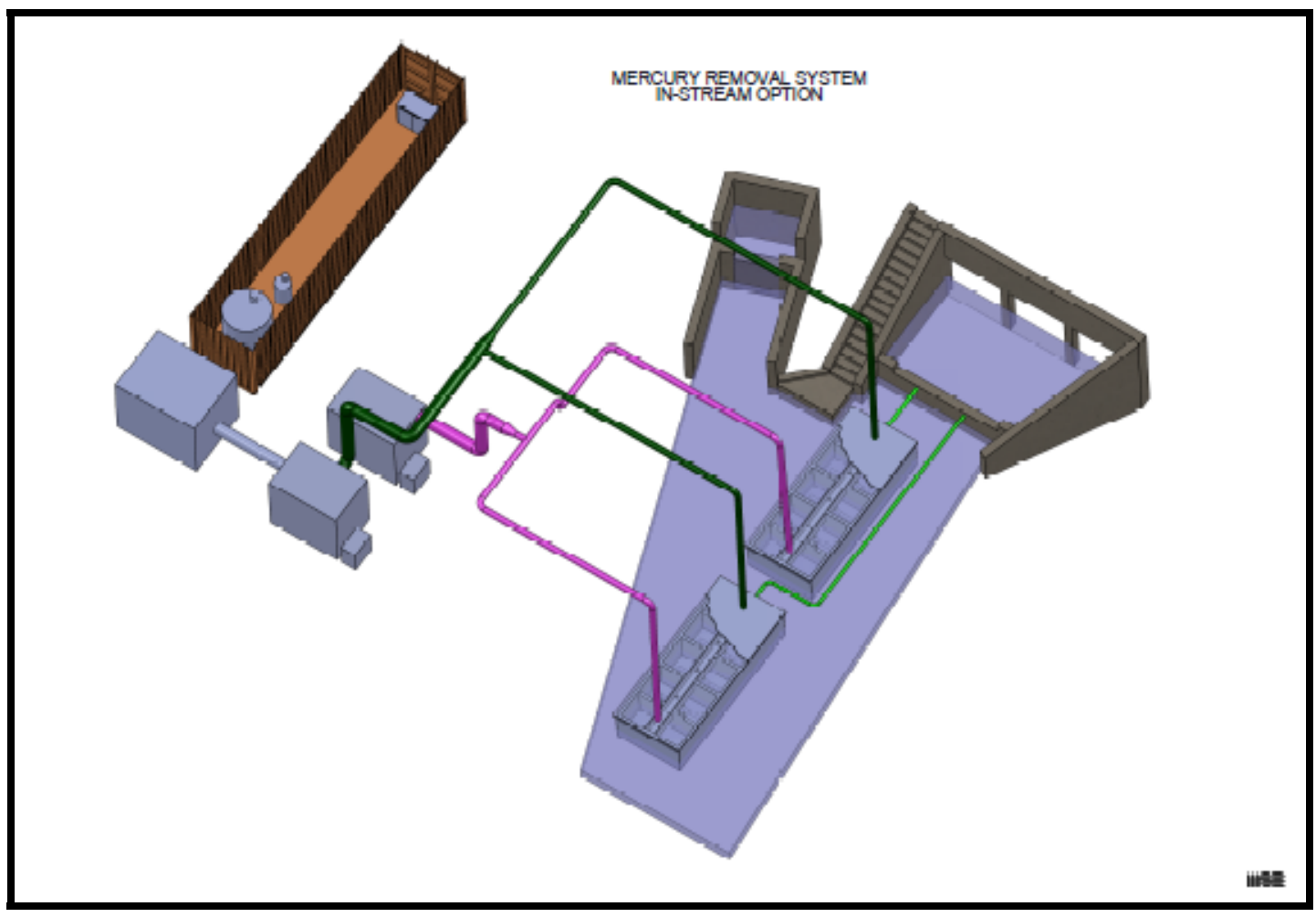

Fig. B-1. Mercury removal system In-Stream Option.

The vessels will be anchored to the bottom of the stream to keep them from floating away during high water. It is anticipated that the vessels will be entirely submerged at various times and will continue operating at the design flow rate.

The vessel is to be fabricated of stainless steel to inhibit corrosion from the creek and from the reagents added to the water.

The vessels will be designed for 773-gpm total water input. The 773 gallons include water from Outflow 200 (the N/S pipe) and from Outflow 135, which flows into the creek from a small sump located at the side of the creek. The flow rate from Outflow 135 is about $73 \mathrm{gpm}$.

Each in-creek stripper was sized at a nominal 387 gpm and a nominal 3,050 standard cubic feet per minute $(\mathrm{scfm})[3,190$ actual cubic feet per minute $(\mathrm{acfm})]$ of stripping air for an air-to-water ratio of 62actual liters of air per liter of water. The strippers are capable of a maximum water rate of $500 \mathrm{gpm}$. Processed water will drain by gravity from the strippers back into the creek.

A shallow dam will be built upstream of the stripper vessels. The dam will raise the creek water sufficiently to allow gravity feed to the stripper vessels at the design flow rate.

The dam will be constructed approximately $8 \mathrm{ft}$ downstream of the Outfall 200 grating. The dam will be upstream of Outfall 135 and will butt against the stairs leading from the roadway to the edge of the creek.

The dam will allow water in excess of the stripper design basis to flow over the dam through one or several "spillways." Designed spillways are necessary to prevent erosive wear on the dam connections between the staircase wall on one side and the creek-side on the other side. 
The present sump of Outfall 135 will be located downstream of the dam. Outfall 135 will be modified slightly to allow placing a sump pump within it; the pump will transfer water at $73 \mathrm{gpm}$ from Outfall 135 to a discharge point on the upstream side of the dam. Any water produced from Outfall 135 in excess of the capacity of the sump pump will overflow as it currently does into the streambed. The pump will automatically shut off if the water flow from Outfall 135 ceases. During a high-water/storm event, the sump pump can be submerged and will continue to operate.

Two pipes will protrude through the face of the dam at a height sufficient to allow gravity flow of water to the in-creek strippers. The pipes will be sized such that the water flow through them will be somewhat greater than the stripper design flow rate when the inlets to the pipes are totally submerged. Eccentric orifices will be placed in the pipes downstream of the dam to allow measurement and control of the water flow rate to each stripper.

Stripping air will be provided by a 75-hp blower providing 6,100 scfm at 35.4 inches of water column (iwc). The blower will be mounted outside either on a concrete base or on a skid located on the flat area across the road on the south side of the creek. The blower discharge air will be ducted over the road on a pipe rack. The airflow then will be split in two to feed the strippers.

The air exiting the strippers will enter a header and then be ducted over the pipe rack to the carbon bed blower. The stripper exhaust line will contain considerable moisture. The exhaust line may need to be electric traced and will need to slope backwards to drain condensate to the stripper.

The 25-hp carbon bed blower develops 10 iwc to draw the air from the stripper exhaust and deliver it to the carbon bed. The carbon bed blower will be mounted outside next to the stripping air blower. The air leaving the carbon bed blower will enter a vapor box containing 13,000 pounds of activated carbon. The activated carbon will be sulfur impregnated for enhanced $\mathrm{Hg}$ capture. The vapor box is an 8 -ft wide by 20 -ft long by 8.5 -ft high modified shipping container with a 3.5 -ft carbon bed depth.

After passing through the carbon bed, the stripping air will exhaust to the atmosphere through a stack at $10 \mathrm{ft}$ above grade.

A shipping container will be modified to serve as the process control room and as a reagent preparation, storage, and injection pump area. Sodium bisulfite will be made up in a 1,000-gallon tank. $\mathrm{SnCl}_{2}$ solution and ascorbic acid will be made up in a 55-gallon tank. Both quantities represent a 7-day supply of the reagent.

The control/process container will be set on a concrete pad next to the stripper and carbon bed blowers.

Except for the dam, the Outfall 135 sump pump, and the strippers, the other equipment will be located in the flat area across the road from the south bank of the creek. Reagents will be pumped from tanks in the process building and piped into the N/S pipe upstream of the dam.

\section{Alternative Two - On-Shore Option}

Alternative Two (Fig. B-2) utilizes tray strippers to transfer elemental Hg from the water into air and then a vapor box unit containing sulfur-impregnated carbon to capture the $\mathrm{Hg}$. The strippers are to be skid mounted and located on a concrete pad; the carbon unit is to be installed and piped to the strippers as determined during the detailed design phase. A modified shipping crate ( 8 - $\mathrm{ft}$ wide by $40-\mathrm{ft}$ long by $8.5-\mathrm{ft}$ high) will be used to house the process controls, the power equipment and motor controls, the reagent 
tanks and pumps, and one or both of the reactors. The shipping crate will be called the reactor/control building.

A shallow dam will be constructed approximately $8 \mathrm{ft}$ downstream of the Outfall 200 grating. The dam will be upstream of Outfall 135 and will butt against the stairs leading from the roadway to the edge of the creek. For Alternative Two, the dam will serve as a sump to allow pumping of the creek water to the strippers.

The dam will be designed to allow stream water flow in excess of the stripper design basis to flow over the dam through one or several "spillways." It is not desirable to allow water to flow over the entirety of the top of the dam to prevent erosive wear on the joints between the stair case wall on one side, and the creek-side on the other side.

The present sump of Outfall 135 is located below the dam. Outfall 135 will be modified slightly to allow placing a sump pump within it; the pump will transfer water at $73 \mathrm{gpm}$ from Outfall 135 to a discharge point on the upstream side of the dam. Any water produced from Outfall 135 in excess of the capacity of the sump pump will overflow as it currently does into the streambed. The pump will automatically shut off if the water flow from Outfall 135 ceases. During a high water/storm event, the sump pump can be submerged and will continue to operate.

A 60-hp sump pump will be used to feed the reactors and air strippers. The feed pump will be anchored behind the dam on a short pedestal. The Outfall 200 sump pump will discharge through a flexible coupling to a 60 -inch pipe to feed the strippers.

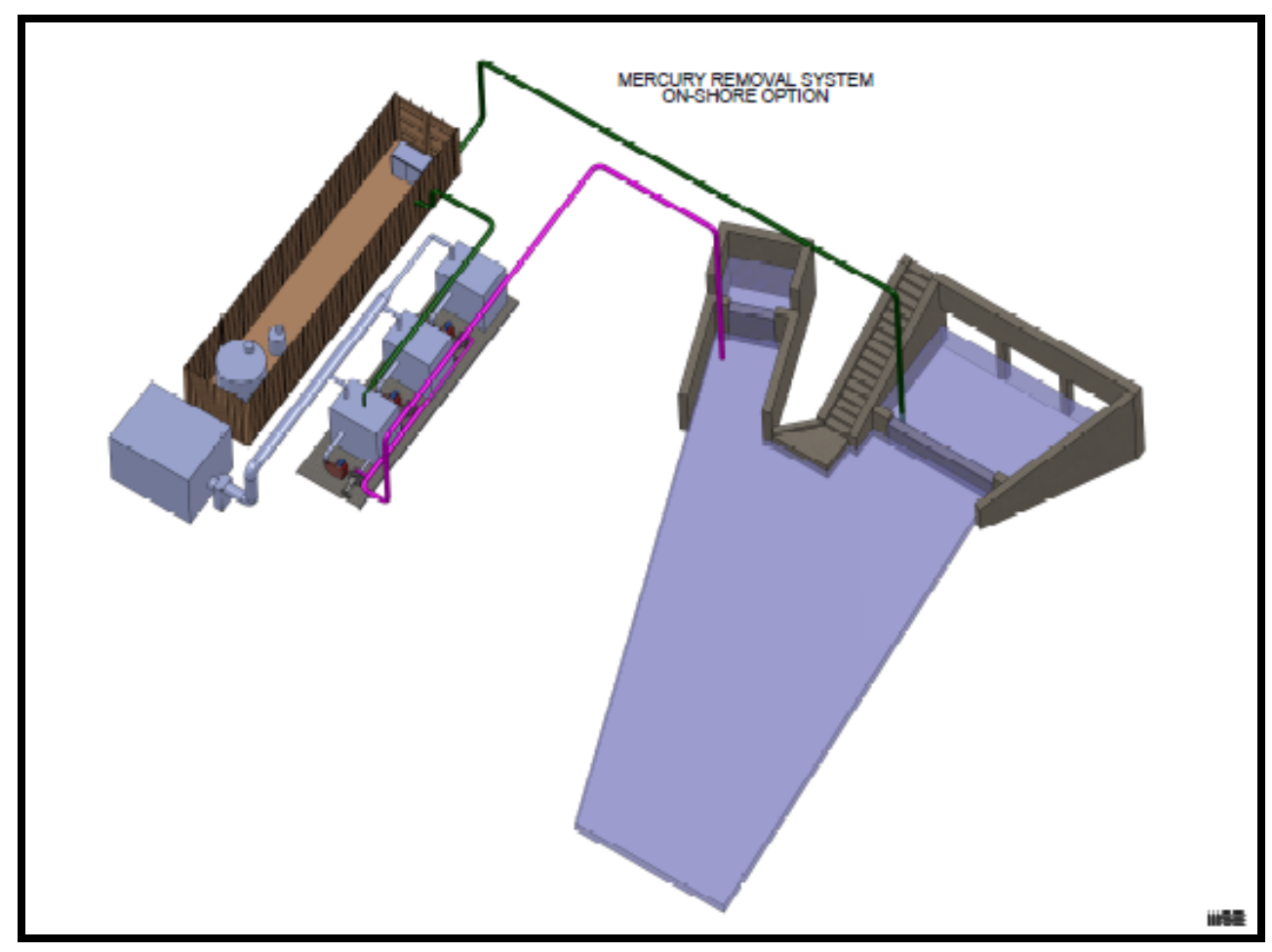

Fig. B-2. Mercury removal system On-Shore Option. 
A pipe rack will be installed that will support the feed and discharge water piping, as well as the power and control wiring. The pipe rack will extend vertically upward to a height sufficient to allow vehicles to pass underneath. The rack will then extend horizontally south over the creek bank and the creek-side road to a flat location near the existing lot where gravel is currently being stored. The horizontal length of the rack is estimated to be approximately $150 \mathrm{ft}$. The pipe rack will then extend downward to the edge of the reactor/control building (modified shipping container).

Dechlorination will occur after the water is pumped from the creek. Sodium bisulfite solution will be injected into the water upstream of a four-stage static mixer. The mixer will be 8 inches in diameter and will contain four mixing elements. Mixing is to be complete within three pipe diameters downstream of the mixer.

There are two places that the dechlorination reactor can be placed in the piping. One location is in the vertical section of piping just downstream of the Outfall 200 sump pump. The advantage of this location is that there is a long piping run to allow reaction to occur during the water's transit over the pipe rack. In this situation, the sodium bisulfite will be piped over the rack and injected just downstream of the sump pump.

The second location to place the dechlorination reactor is in the reactor/control building. However, it will be required to place piping in the room to allow the dechlorination reaction to occur. Currently, there is no data regarding the amount of time that is required for the dechlorination reaction to be completed; consequently, one or several 10- or 15-ft-long sections of piping connected by hair-pin elbows are envisioned to be fixed to the building sidewall to allow residence time for the reaction. It is advantageous to place the pipe loops in the building to minimize heat tracing of the main piping and the reagent piping.

The reduction reaction will be treated in the same manner as the dechlorination reaction. An 8-inch static mixer will be used to mix the $\mathrm{SnCl}_{2} /$ ascorbic acid solution into the dechlorinated water. Hair-pin piping will be used to give the reaction time to occur. Again, no data is available for reaction time versus conversion for the $\mathrm{Hg}$ reduction reaction.

After reacting, the stream water will exit the reactor/control building and be piped to the inlet of the airstripper skid.

The air-stripper skid will consist of three stripper packages piped in parallel. The strippers are a lowprofile, four-stage design that facilitates cleanout and maintenance. Each stripper package includes a separate 15-hp blower and a 7.5-hp pump to transport the treated water back to the creek. Each stripper was sized at a nominal $235 \mathrm{gpm}$ and a nominal 1,344 acfm of stripping air for an air-to-water ratio of 42.5 actual liters of air per liter of water.

The air strippers, blowers, and pumps will be mounted on an 8 -ft wide by 30 -ft long skid. The skid will be prepiped and will include its own control panel and motor control center. Creek water will enter the skid in one location and be distributed to the tops of the strippers; stripped water will be pumped from each stripper sump to a common header, which will return the water to the creek through a 6-inch pipe.

The air leaving the top of each stripper will enter a common header that leads to the bottom of a mist eliminator. The mist eliminator will remove aerosol water that is entrained in the airstreams as they exit the strippers, preventing the buildup of liquid water in the activated carbon in the next unit.

The vapor box is an 8 - $\mathrm{ft}$ wide by 10 -ft long by 8.5 - $\mathrm{ft}$ high shipping container that has been modified to hold 9,000 pounds of sulfur-impregnated activated carbon. The activated carbon will form a layer about 
$3 \mathrm{ft}$ deep in the container. The quantity of activated carbon in the vapor box is sufficient to capture the design basis quantity of $\mathrm{Hg}$ for about 1 year.

The stripper blowers provide sufficient head to force the air through the mist eliminator and the vapor box. The air will discharge from the vapor box through a 12-inch duct to a height about $10 \mathrm{ft}$ above grade.

\section{Alternative Three - N/S Pipe Option}

Alternative Three, North/South (N/S) Pipe Option, (Fig. B-3) is similar to Alternative One; it replaces the diffuse-air strippers with piping and ductwork inside the N/S pipe. All other process units such as the blowers, activated carbon vessel, and the dam are retained.

In this alternative, two 10-inch stainless steel pipes (75-ft long) are anchored on the bottom of the N/S pipe to provide stripping air. Each pipe has coarse bubble diffusers installed in it. A blower supplies stripping air to the 10-inch pipes at the same rate as the Alternative One (slightly over $6000 \mathrm{scfm}$ ).

To ensure that the stripper pipes are submerged, the dam at Outlet 200 is retained in this option. The dam will ensure that the N/S pipe is approximately one-half full of water at all times (approximately 18 inches of water will be above the tops of the pipes).

A 16-inch duct is hung on the top of the N/S pipe to gather the stripping air from the N/S pipe. Air is drawn through the duct by an induced draft fan. The induced draft fan feeds the air to the carbon bed. The duct will be designed similar to an HVAC return air duct with grilled openings set to draw return air equally along the 75-ft length of the stripping section. The mass of air drawn from the N/S pipe will be slightly more than the stripping air added to it to ensure that the mercury laden air be fed to the activated carbon. A variable speed drive will be procured for the stripping air blower to allow balancing stripping and return air.

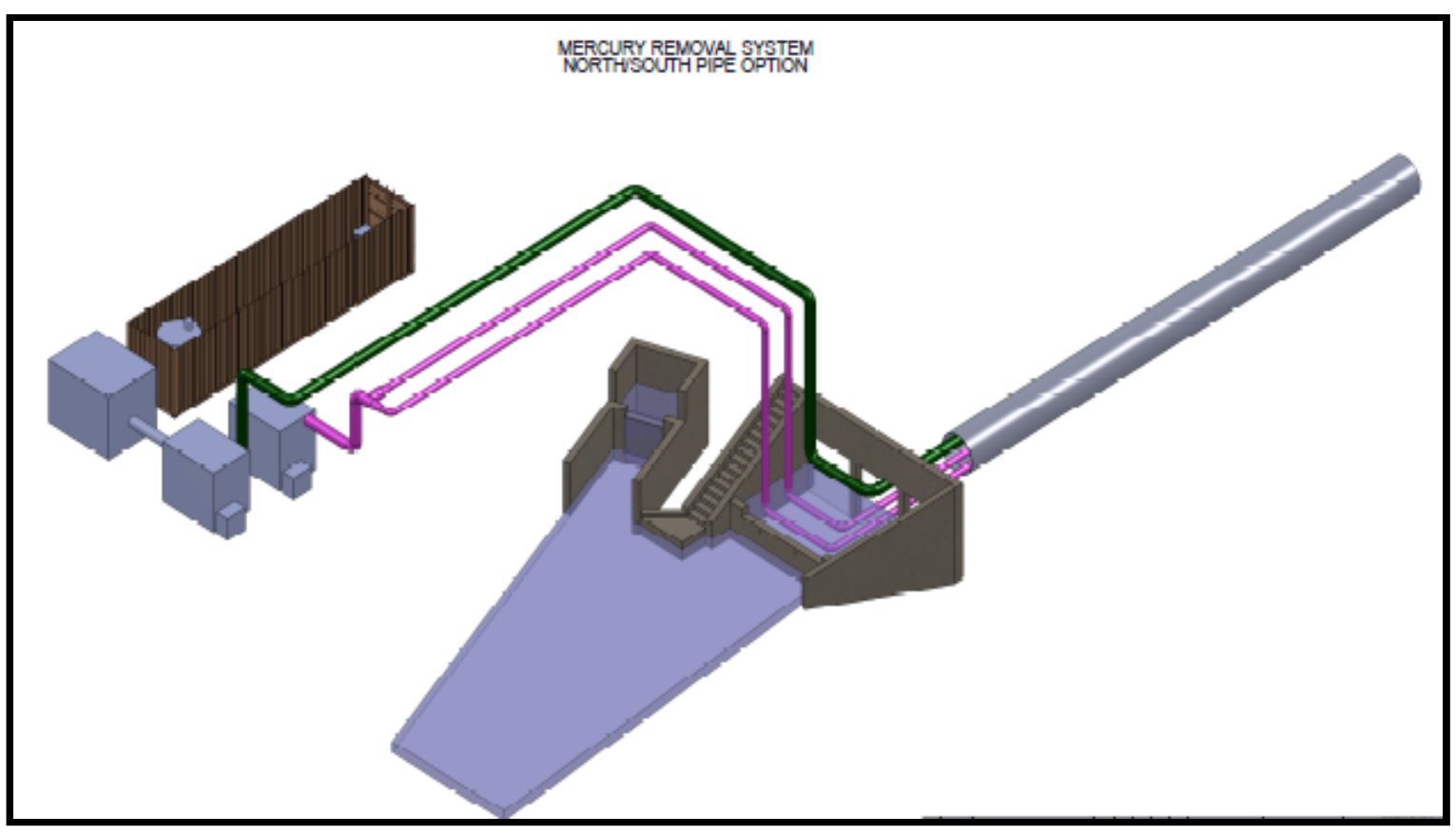

Fig. B-3. Mercury removal system North/South Pipe Option. 
The end of the N/S pipe that empties into Outfall 200 will be partially closed off with a flexible curtain (air stoppage) that will inhibit drawing external air into the N/S pipe but will allow water to flow outwards during high water events. A crossbar screen installed over the top half of the N/S pipe will reinforce the stoppage curtain. The curtain will be drawn against the screen during normal operation as the induced draft fan returns the stripper air to the carbon bed.

A major uncertainty of attempting to strip mercury from the water in the N/S pipes is whether the 18 inches of water over the tops of the diffusers will allow sufficient contact to remove the mercury. The air-to-water ratio will be the same as the In-Stream Option; however, the contact path of the air and its areal distribution will be less.

In this alternative, the reagents to convert ionic mercury to its elemental form will be injected several hundred feet upstream (of the stripping pipes) in the same manner as in the other two alternatives. The reagent injection tubing will be installed within the N/S pipe, supported in-part by the return air duct.

\section{Alternative Four - Passive evasion of $\mathrm{Hg}(0)$ within the storm drain network}

This alternative converts $\mathrm{Hg}(\mathrm{II})$ to $\mathrm{Hg}(0)$ at sites as close to the primary sources areas within the storm drain network upstream from Outfall 200 and allows the $\mathrm{Hg}(0)$ to escape from the water into the pipe headspace without additional enhancement from a forced air diffuser system. Air exchange within the system would need to be accomplished by forced air ventilation at multiple sites within the system, with $\mathrm{Hg}(0)$ in air withdrawn from the system being trapped on sulfur impregnated charcoal. The length of pipe with Hg-contaminated water at concentrations high enough to treat was roughly estimated at roughly $1300 \mathrm{~m}$. The theoretical rate of evasion of $\mathrm{Hg}(0)$ from the surface of EFPC downstream from Outfall 200 was estimated at $0.56 \mathrm{~km}^{-1}$ in Southworth et al. 2009. Depths of velocity of flowing water are key determinants of volatilization rate as a function of distance. If the flow velocities within the storm drain system are similar to that of the open portion of the creek but mean water depth is half that of the open stream (because of lower volumetric flow), the theoretical evasion rate could be double that estimated for the open stream, around $1.1 \mathrm{~km}^{-1}$. Applying this rate to $1300 \mathrm{~m}$ of subsurface drainage suggests that more than $50 \%$ of the baseflow $\mathrm{Hg}$ transported by the system could be removed by passive evasion if airflow was high enough to prevent $\mathrm{Hg}$-saturation of the headspace air. No engineering evaluation of the passive evasion process was conducted, but empirical results of the 2009 field study suggest that this option may have significant promise. 



\section{APPENDIX C \\ DISSOLVED OXYGEN AND PH RESPONSES TO STANNOUS CHLORIDE, ASCORBIC ACID, AND SODIUM BOROHYDRIDE}

The responses of dissolved oxygen and $\mathrm{pH}$ of Northwest Tributary stream water to amendments of stannous chloride, ascorbic acid, and sodium borohydride at concentrations between 1 and 10,000 $\mathrm{mg} / \mathrm{L}$ are reported in Figures C-1 to C-6.

Dissolved Oxygen Versus Stannous Chloride Concentration In Stream Water

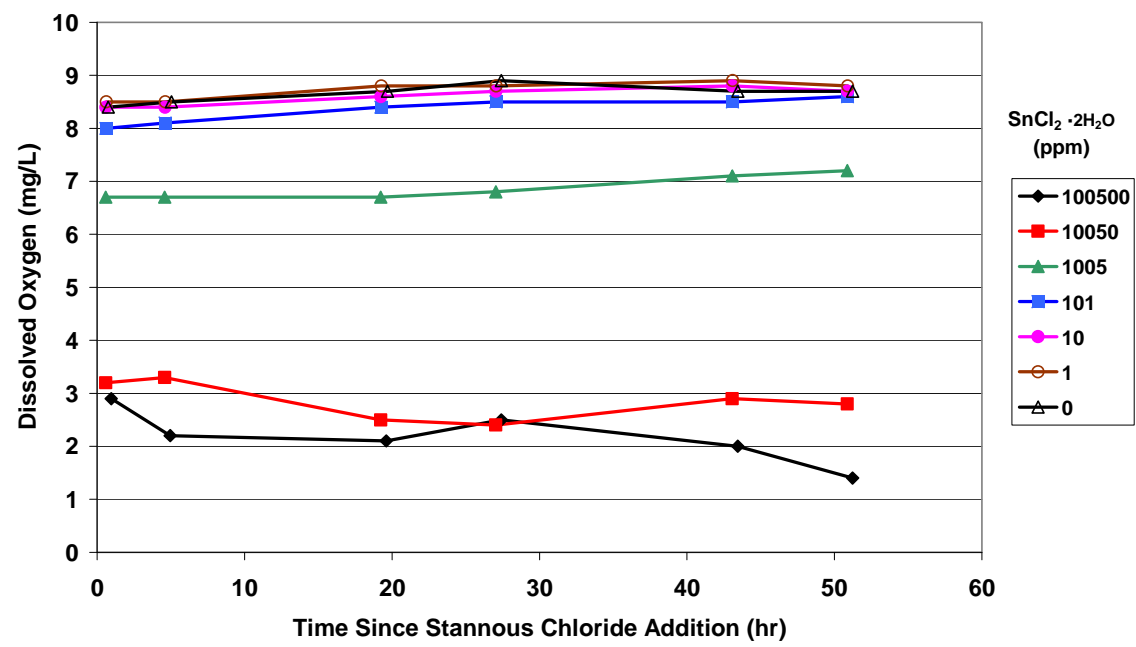

Fig. C-1. Dissolved oxygen in Northwest Tributary stream water following additions of increasing concentrations of stannous chloride.

pH Versus Stannous Chloride Concentration In Stream Water

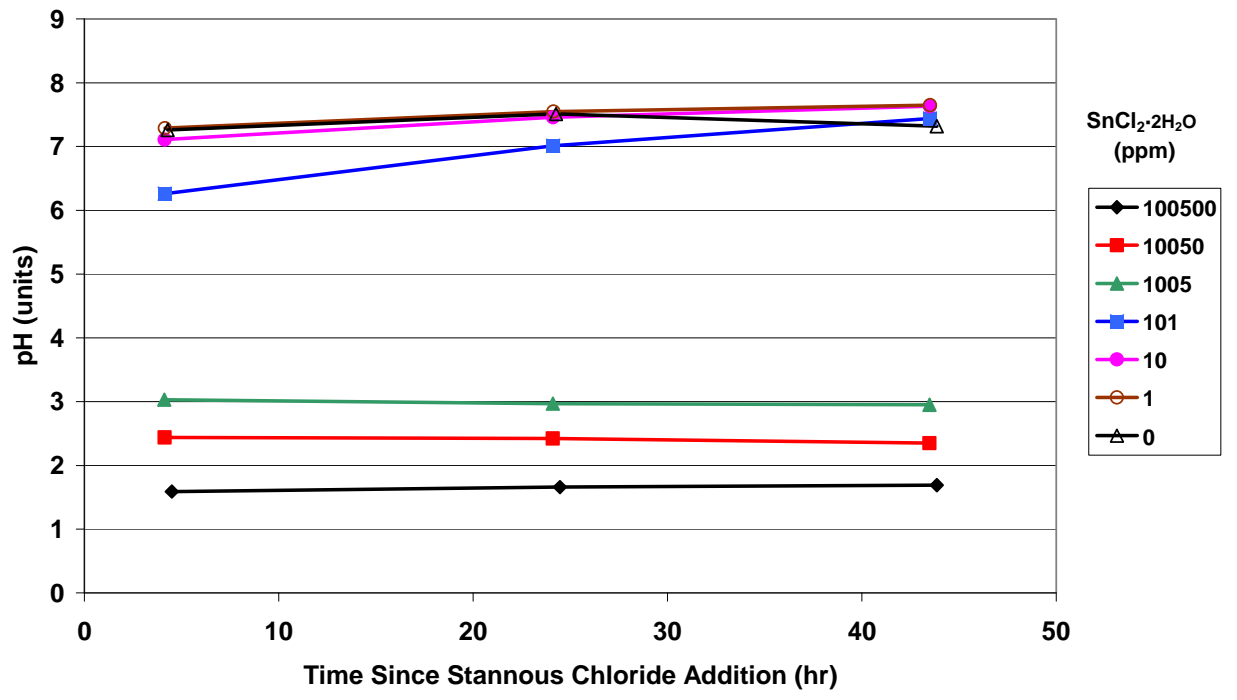

Fig. C-2. Northwest Tributary stream water $\mathrm{pH}$ following of increasing concentrations of stannous chloride. 
Dissolved Oxygen Versus Ascorbic Acid Concentration In Stream Water

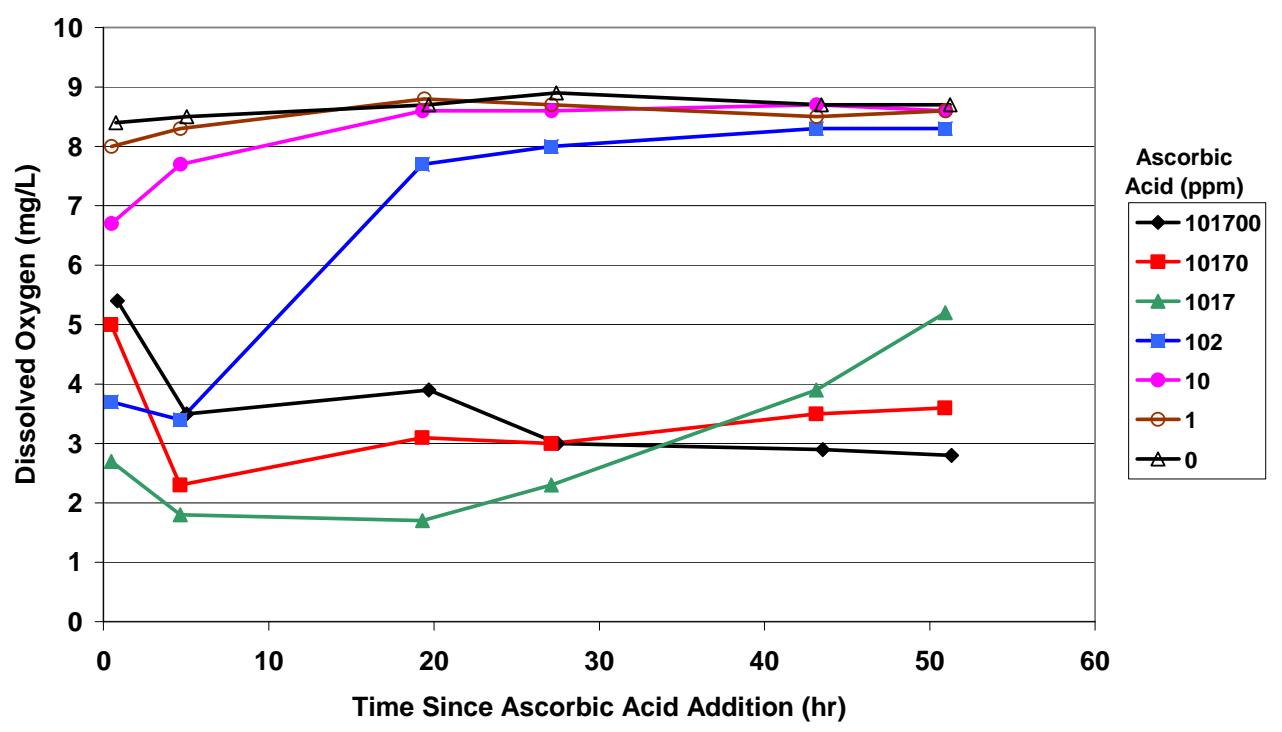

Fig. C-3. Dissolved oxygen in Northwest Tributary stream water following additions of increasing concentrations of ascorbic acid.

pH Versus Ascorbic Acid Concentration In Stream Water

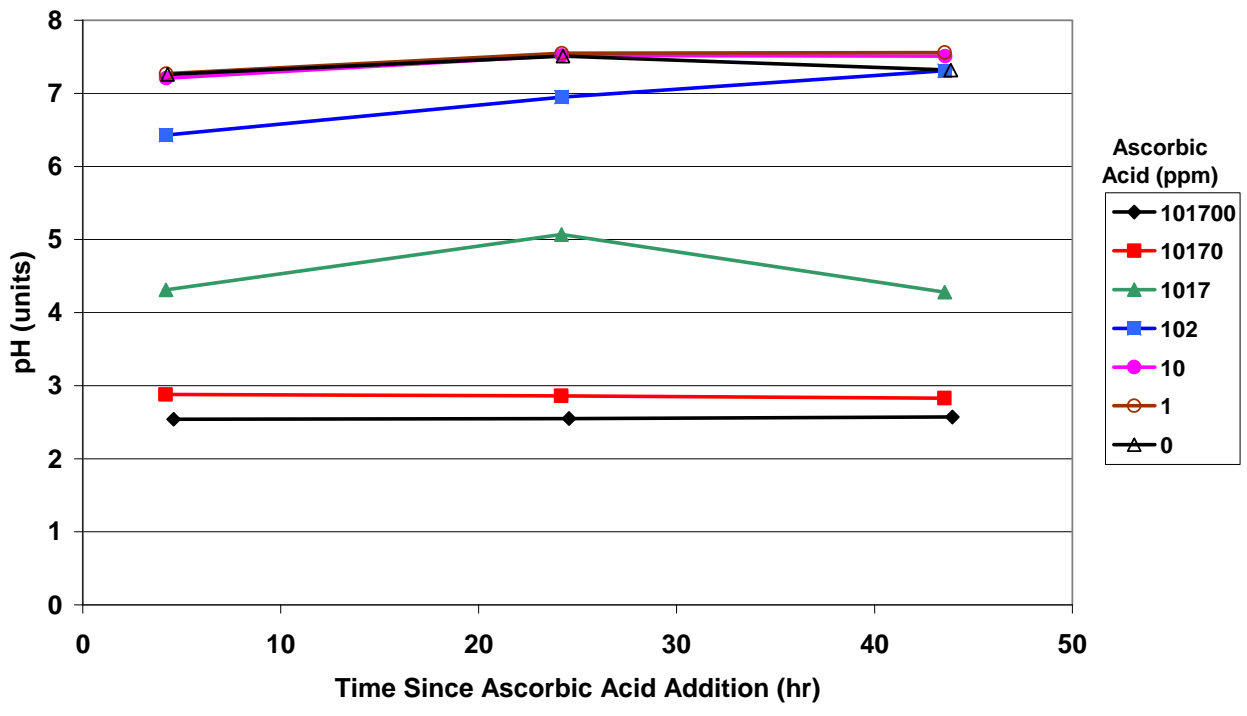

Fig. C-4. Northwest Tributary stream water $\mathrm{pH}$ following additions of increasing concentrations of ascorbic acid. 
Dissolved Oxygen Versus Sodium Borohydride Concentration In Stream Water

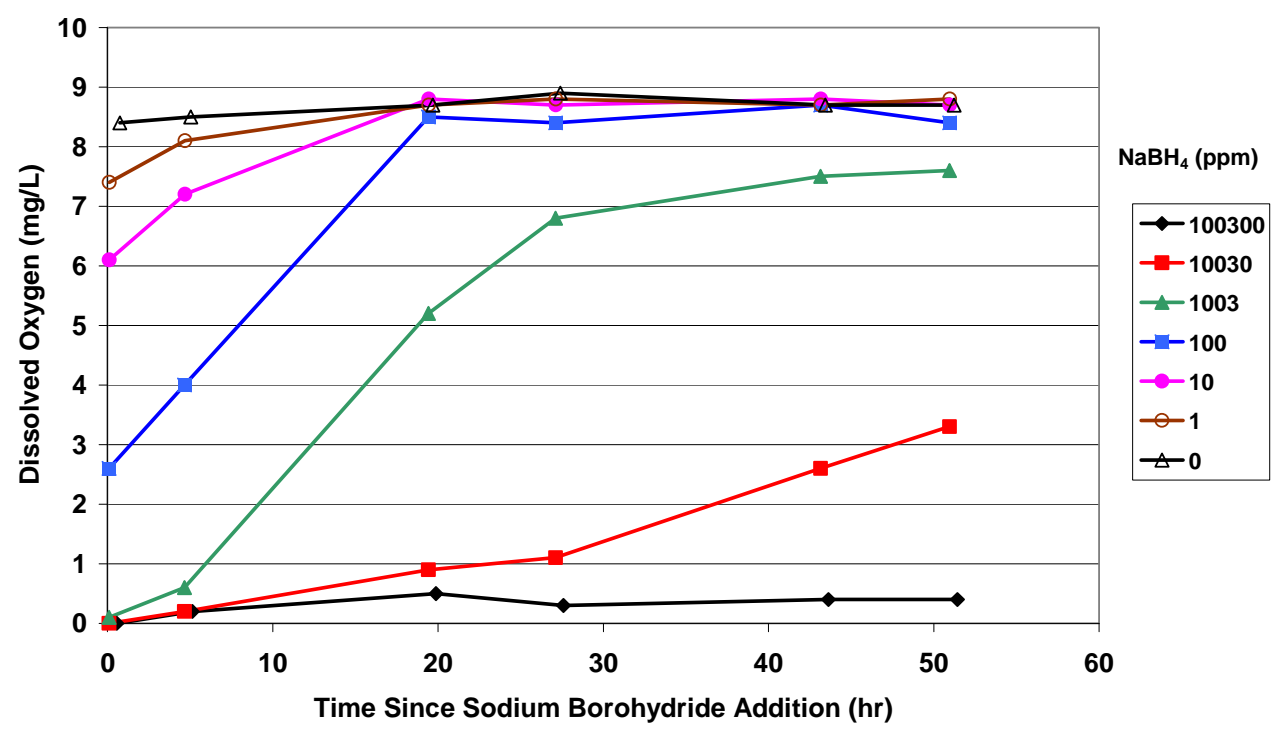

Fig. C-5. Dissolved oxygen in Northwest Tributary stream water following additions of increasing concentrations of sodium borohydride.

pH Versus Sodium Borohydride Concentration In Stream Water

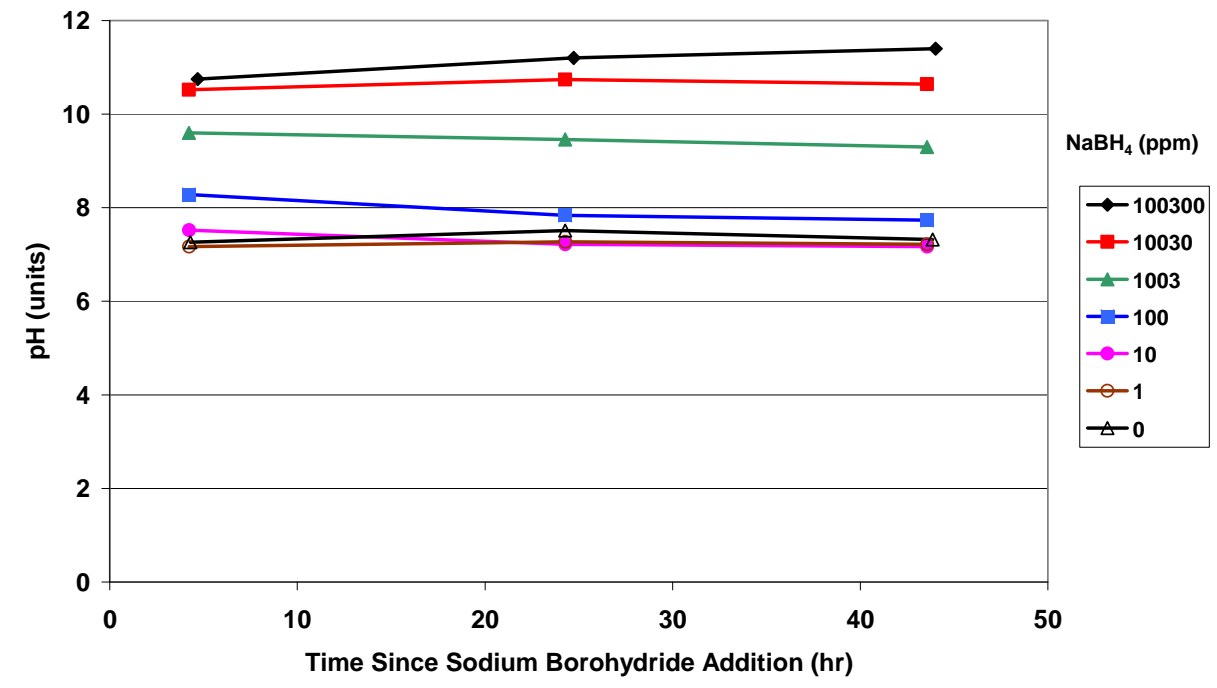

Fig. C-6. Northwest Tributary stream water $\mathrm{pH}$ following additions of increasing concentrations of sodium borohydride. 



\section{APPENDIX D}

\section{STANNOUS CHLORIDE PILOT TEST DATA}

Table D-1. Results of tin (Sn) analysis by ICP-MS for samples collected during the September $2009 \mathbf{S n C l}_{2}$ addition test. Results are given for two stable isotopes of tin. Values indicated by "<" (less than) are below the dilution corrected detection limit for the instrumental run.

\begin{tabular}{|c|c|c|c|c|c|c|c|c|c|}
\hline \multirow[b]{3}{*}{ Sample Name } & \multirow[b]{3}{*}{ Location } & \multirow[b]{3}{*}{ Collection Date } & \multirow[b]{3}{*}{$\begin{array}{c}\text { Collection } \\
\text { Time } \\
\end{array}$} & \multirow[b]{3}{*}{$\begin{array}{c}\text { Analysis } \\
\text { Date }\end{array}$} & \multirow[b]{3}{*}{$\begin{array}{c}\text { Dilution } \\
\text { Factor }\end{array}$} & \multicolumn{4}{|c|}{ Dilution corrected final result } \\
\hline & & & & & & \multicolumn{2}{|c|}{ Sn-118 } & \multicolumn{2}{|c|}{ Sn-120 } \\
\hline & & & & & & $\mu g / L$ & $\pm 1 \mathrm{~s}$ & $\mu g / L$ & $\pm 1 \mathrm{~s}$ \\
\hline Sn-C11-9-45am & $\mathrm{C} 11$ & 09/01/09 & $09: 45$ & $11 / 08 / 09$ & 2 & $<2.6$ & & $<4.0$ & \\
\hline Sn-C11-10-10am & $\mathrm{C} 11$ & 09/01/09 & $10: 10$ & $11 / 08 / 09$ & 2 & $<2.6$ & & $<4.0$ & \\
\hline Sn-C11-10-50am & $\mathrm{C} 11$ & 09/01/09 & $10: 50$ & $11 / 08 / 09$ & 2 & $<2.6$ & & $<4.0$ & \\
\hline Sn-C11-11-35am & $\mathrm{C} 11$ & 09/01/09 & $11: 35$ & $11 / 08 / 09$ & 2 & $<2.6$ & & $<4.0$ & \\
\hline Sn-C11-12-00pm & $\mathrm{C} 11$ & 09/01/09 & $12: 00$ & $11 / 08 / 09$ & 2 & $<2.6$ & & $<4.0$ & \\
\hline Sn-C11-12-30pm & $\mathrm{C} 11$ & 09/01/09 & $12: 30$ & $11 / 08 / 09$ & 2 & 4.14 & 0.57 & 4.24 & 0.88 \\
\hline Sn-C11-12-50pm & $\mathrm{C} 11$ & 09/01/09 & $12: 50$ & $11 / 08 / 09$ & 2 & 3.76 & 0.57 & $<4.0$ & \\
\hline Sn-C11-13-20pm & $\mathrm{C} 11$ & 09/01/09 & $13: 20$ & $11 / 08 / 09$ & 2 & 4.72 & 0.57 & 4.85 & 0.88 \\
\hline Sn-C11-13-50pm & $\mathrm{C} 11$ & 09/01/09 & $13: 50$ & $11 / 08 / 09$ & 2 & 4.25 & 0.57 & 4.34 & 0.88 \\
\hline Sn-C11-14-20pm & $\mathrm{C} 11$ & 09/01/09 & $14: 20$ & $11 / 08 / 09$ & 2 & $<2.6$ & & $<4.0$ & \\
\hline Sn-C11-14-50pm & $\mathrm{C} 11$ & 09/01/09 & $14: 50$ & $11 / 08 / 09$ & 2 & $<2.6$ & & $<4.0$ & \\
\hline Sn-OF200-10-50am & OF200 & 09/01/09 & $10: 50$ & $11 / 08 / 09$ & 2 & $<2.6$ & & $<4.0$ & \\
\hline Sn-OF200-12-25pm & OF200 & 09/01/09 & $12: 25$ & $11 / 08 / 09$ & 2 & 16.77 & 0.56 & 16.76 & 0.87 \\
\hline Sn-OF200-13-20pm & OF200 & 09/01/09 & $13: 20$ & $11 / 08 / 09$ & 2 & 17.51 & 0.56 & 17.53 & 0.87 \\
\hline
\end{tabular}


Table D-2. Dissolved gaseous mercury (DGM), total mercury (HgT) and non-purgable Hg measured during the September $2009 \mathrm{SnCl}_{2}$ addition test

\begin{tabular}{|c|c|c|c|c|}
\hline Time & Action & $\begin{array}{l}\text { DGM } \\
\text { (ng/L) }\end{array}$ & $\begin{array}{c}\mathrm{HgT} \\
\text { (ng/L) }\end{array}$ & $\begin{array}{c}\text { Non-purgable Hg } \\
\text { (ng/L) }\end{array}$ \\
\hline \multicolumn{5}{|c|}{ No Treatment } \\
\hline $9: 15$ & baseline & 4 & 1372 & - \\
\hline $9: 25$ & baseline & 88 & 1389 & - \\
\hline $9: 35$ & baseline & 2 & 1369 & - \\
\hline $9: 45$ & baseline & 9 & 1389 & 1328 \\
\hline $9: 55$ & baseline & 6 & 1389 & 1208 \\
\hline 10:05 & baseline & 1 & 1403 & 1361 \\
\hline 10:15 & baseline & 0 & 1350 & 1347 \\
\hline $10: 25$ & baseline & 1 & 1362 & 1343 \\
\hline $10: 35$ & baseline & 0 & 1376 & 1361 \\
\hline \multicolumn{5}{|c|}{ Start of Ascorbic Acid Addition at OF 150} \\
\hline 10:45 & $\mathrm{w} /$ ascorbic acid & 2 & 1346 & 1379 \\
\hline 10:55 & $\mathrm{w} /$ ascorbic acid & 0 & 1358 & 1347 \\
\hline 11:05 & $\mathrm{w} /$ ascorbic acid & 165 & 1211 & 1057 \\
\hline $11: 15$ & ascorbic acid off & 4 & 1300 & 1294 \\
\hline $11: 25$ & $\mathrm{w} /$ ascorbic acid & 191 & 1203 & 938 \\
\hline $11: 35$ & w/ ascorbic acid & 233 & 1178 & 915 \\
\hline 11:45 & $\mathrm{w} /$ ascorbic acid & 233 & 1201 & 919 \\
\hline \multicolumn{5}{|c|}{ Start of $\mathrm{SnCl}_{2}$ Addition at 200A6 } \\
\hline $11: 55$ & $\mathrm{w} /$ ascorbic $+\mathrm{SnCl}_{2}$ & 260 & 1193 & 893 \\
\hline 12:05 & $\mathrm{w} /$ ascorbic $+\mathrm{SnCl}_{2}$ & 283 & 1183 & 859 \\
\hline $12: 15$ & $\mathrm{w} /$ ascorbic $+\mathrm{SnCl}_{2}$ & 923 & 1118 & 100 \\
\hline $12: 25$ & $\mathrm{w} /$ ascorbic $+\mathrm{SnCl}_{2}$ & 893 & 1112 & 93 \\
\hline $12: 35$ & $\mathrm{w} /$ ascorbic $+\mathrm{SnCl}_{2}$ & 893 & 1119 & 138 \\
\hline $12: 45$ & $\mathrm{w} /$ ascorbic $+\mathrm{SnCl}_{2}$ & 912 & 1094 & 100 \\
\hline $12: 55$ & $\mathrm{w} /$ ascorbic $+\mathrm{SnCl}_{2}$ & 1011 & 1129 & 85 \\
\hline 13:05 & $\mathrm{w} /$ ascorbic $+\mathrm{SnCl}_{2}$ & 840 & 1059 & 59 \\
\hline $13: 15$ & $\mathrm{w} /$ ascorbic $+\mathrm{SnCl}_{2}$ & 741 & 1101 & 102 \\
\hline $13: 25$ & $\mathrm{w} /$ ascorbic $+\mathrm{SnCl}_{2}$ & 825 & 1066 & 95 \\
\hline $13: 35$ & $\mathrm{w} /$ ascorbic $+\mathrm{SnCl}_{2}$ & 847 & 1059 & 127 \\
\hline 13:45 & $\mathrm{w} /$ ascorbic $+\mathrm{SnCl}_{2}$ & 886 & 1118 & 118 \\
\hline \multicolumn{5}{|c|}{ End Ascorbic Acid and $\mathrm{SnCl}_{2}$ Additions } \\
\hline $13: 55$ & return to baseline & 898 & 1028 & 97 \\
\hline 14:05 & return to baseline & 246 & 1154 & 862 \\
\hline 14:15 & return to baseline & 0 & 1321 & 1329 \\
\hline $14: 25$ & return to baseline & 0 & 1349 & 1379 \\
\hline $14: 35$ & return to baseline & 0 & 1339 & 1340 \\
\hline 14:45 & return to baseline & 0 & 1294 & 1253 \\
\hline $14: 55$ & return to baseline & 0 & 1325 & 1353 \\
\hline
\end{tabular}


Table D-3. Downstream profile of total mercury (HgT) and dissolved gaseous mercury (DGM) before and during treatment with ascorbic acid and $\mathrm{SnCl}_{2}$ (September 2009 test)

\begin{tabular}{llccc}
\hline Site & \multicolumn{1}{c}{ Action } & $\begin{array}{c}\text { Distance } \\
(\mathbf{k m})\end{array}$ & $\begin{array}{c}\text { HgT } \\
(\mathbf{n g} / \mathbf{L})\end{array}$ & $\begin{array}{c}\text { DGM } \\
(\mathbf{n g} / \mathbf{L})\end{array}$ \\
\hline OF 200 & pre-treatment phase & 0 & 1362 & 1 \\
C11 & pre-treatment phase & 0.2 & 376 & 12 \\
OF 113 & pre-treatment phase & 0.35 & 415 & 54 \\
Sta. 8 & pre-treatment phase & 0.6 & 388 & 0 \\
C03 & pre-treatment phase & 1.6 & 273 & 0 \\
& & & & \\
OF 200 & treatment phase & 0 & 1066 & 825 \\
C11 & treatment phase & 0.2 & 306 & 184 \\
OF 113 & treatment phase & 0.35 & 323 & 122 \\
Sta. 8 & treatment phase & 0.6 & 310 & 45 \\
C03 & treatment phase & 1.6 & 262 & 0 \\
Sta. 17 & treatment phase & 2.6 & 213 & 17 \\
\hline
\end{tabular}


Table D-4. Concentrations of total mercury (HgT) and dissolved gaseous mercury (DGM) in a $3.2 \mathrm{~L}$ sample of ascorbic acid/SnCl 2 treated Outfall 200 water purged for 2 hours with air at $100 \mathrm{ml} / \mathrm{minute}$. This experiment was conducted in the field in conjunction with the September $2009 \mathrm{SnCl}_{2}$ test.

\begin{tabular}{cccc}
\hline Time & $\begin{array}{c}\text { Elasped Purge Time } \\
\text { (minutes) }\end{array}$ & $\begin{array}{c}\text { DGM } \\
\text { (ng/L) }\end{array}$ & $\begin{array}{c}\text { HgT } \\
\text { (ng/L) }\end{array}$ \\
\hline $12: 42$ & 0 & 786 & 870 \\
$12: 50$ & 8 & 580 & - \\
$13: 01$ & 19 & 472 & - \\
$13: 12$ & 30 & 321 & - \\
$13: 21$ & 39 & 221 & - \\
$13: 30$ & 48 & 164 & - \\
$13: 40$ & 58 & 131 & - \\
$13: 51$ & 69 & 71 & - \\
$14: 00$ & 78 & 61 & 159 \\
$14: 43$ & 121 & 17 & \\
\hline
\end{tabular}

